Cahiers $d u$ MONDE RUSSE

\section{Cahiers du monde russe}

Russie - Empire russe - Union soviétique et États indépendants

$53 / 1 \mid 2012$

Pratiques du droit et de la justice en Russie (XVIII ${ }^{-} X X^{e}$ siècles)

\title{
ПОЧЕМУ ГЕНЕРАЛ-ГУБЕРНАТОРЫ 1-Й ТРЕТИ ХІХ В. УТВЕРЖДАЛИ ПРИГОВОРЫ ПО УГОЛОВНЫМ \\ ПРЕСТУПЛЕНИЯМ
}

ОТ ИДЕИ К ЗАКОНУ, ОТ ЗАКОНА К ПРАКТИКЕ

Why did governors general of the first third of the nineteenth century confirm general criminal sentences?. From idea to law, from law to practiceDe l'idée à la loi, de la loi à la pratique

Pourquoi les gouverneurs généraux du premier tiers du XIXe siècle confirmaientils les sentences dans les affaires criminelles de droit commun. De l'idée à la loi, de la loi à la pratique

\section{Виктория Ефимова}

\section{(2) OpenEdition}

\section{Journals}

Édition électronique

URL : http://journals.openedition.org/monderusse/9366

DOI : $10.4000 /$ monderusse.9366

ISSN : $1777-5388$

Éditeur

Éditions de l'EHESS

Édition imprimée

Date de publication : 15 mars 2012

Pagination : 65-93

ISBN : 978-2-7132-2390-7

ISSN : 1252-6576

Référence électronique

Виктория Ефимова, « Почему генерал-губернаторы 1-й трети XIX в. утверждали приговоры по уголовным преступлениям », Cahiers du monde russe [Онлайн], 53/1 | 2012, Выложить онлайн 02 avril 2015, Наводить справки в 21 décembre 2020. URL : http://journals.openedition.org/ monderusse/9366; DOI : https://doi.org/10.4000/monderusse.9366

Ce document a été généré automatiquement le 21 décembre 2020.

(c) École des hautes études en sciences sociales 


\section{ПОЧЕМУ ГЕНЕРАЛ-ГУБЕРНАТОРЫ 1-Й ТРЕТИ ХІХ В. УТВЕРЖДАЛИ ПРИГОВОРЫ ПО УГОЛОВНЫМ ПРЕСТУПЛЕНИЯМ}

ОТ ИДЕИ К ЗАКОНУ, ОТ ЗАКОНА К ПРАКТИКЕ

Why did governors general of the first third of the nineteenth century confirm general criminal sentences?. From idea to law, from law to practiceDe l'idée à la loi, de la loi à la pratique

Pourquoi les gouverneurs généraux du premier tiers du XIXe siècle confirmaientils les sentences dans les affaires criminelles de droit commun. De l'idée à la loi, de la loi à la pratique

\section{Виктория Ефимова}

1 ДО СИХ ПОР НИКТО ИЗ ИССЛЕДОВАТЕЛЕЙ ИСТОРИИ ОТЕЧЕСТВЕННОГО ГОСУДАРСТВА И ПРАВА НЕ ОСПАРИВАЕТ МНЕНИЯ О ТОМ, ЧТО ИМЕВШЕЕСЯ У ГЕНЕРАЛ-ГУБЕРНАТОРОВ И ГУБЕРНАТОРОВ В 1-Й ПОЛОВИНЕ ХІХ В. ПРАВО УТВЕРЖДАТЬ УГОЛОВНЫЕ ПРИГОВОРЫ ЯВЛЯЕТСЯ ОДНИМ ИЗ САМЫХ ЯРКИХ ПРИМЕРОВ ОТСУТСТВИЯ НЕЗАВИСИМОСТИ СУДА ОТ АДМИНИСТРАЦИИ В ДОРЕФОРМЕННЫЙ ПЕРИОД СУЩЕСТВОВАНИЯ РОССИЙСКОЙ ИМПЕРИИ, НЕ СМОТРЯ НА ЕГО БОЛЕЕ ПОСЛЕДОВАТЕЛЬНОЕ ОРГАНИЗАЦИОННОЕ ОТДЕЛЕНИЕ, ПРОИЗВЕДЕННОЕ В «БЛАГОЧЕСТИВЕЙШИЯ САМОДЕРЖАВНЕЙШИЯ ВЕЛИКИЯ ГОСУДАРЫНИ ИМПЕРАТРИЦЫ ЕКАТЕРИНЫ ВТОРЫЯ УЧРЕЖДЕНИЯ ДЛЯ УПРАВЛЕНИЯ ГУБЕРНИЙ ВСЕРОССИЙСКИЯ ИМПЕРИЯ» 1775 Г. (ДАЛЕЕ - «УЧРЕЖДЕНИЯ ДЛЯ ГУБЕРНИЙ»). БОЛЕЕ ТОГО, СЧИТАЕТСЯ, ЧТО ЭТО ПРАВО ЕЩЁ БОЛЕЕ УСУГУБЛЯЛО ТАКИЕ НЕГАТИВНЫЕ ЧЕРТЫ ОКОНЧАТЕЛЬНО ОФОРМИВШЕГОСЯ К НАЧАЛУ 1830-ХГГ. В РОССИЙСКОЙ ИМПЕРИИ СЛЕДСТВЕННОГО ПРОЦЕССА, КАК МЕДЛИТЕЛЬНОСТЬ, ВОЛОКИТА, КАНЦЕЛЯРСКАЯ ТАЙНА, НЕГЛАСНОСТЬ РАССМОТРЕНИЯ ДЕЛ, НО, САМОЕ ГЛАВНОЕ, ГОСПОДСТВО ФОРМАЛЬНОЙ СИСТЕМЫ ДОКАЗАТЕЛЬСТВ, КОТОРАЯ НЕИЗБЕЖНО ПРИВОДИЛА «К ОСУЖДЕНИЮ 
НЕКОТОРОГО ЧИСЛА НЕВИНОВНЫХ», ТАК КАК ДАЖЕ «САМЫЙ ДОБРОСОВЕСТНЫЙ СУДЬЯ ИНОГДА ВЫНУЖДЕН БЫЛ ПРИНИМАТЬ РЕШЕНИЕ ВОПРЕКИ ЗДРАВОМУ СМЫСЛУ И СВОЕЙ СОВЕСТИ» ${ }^{2}$.

ОДНАКО НЕ БЫЛО ЛИ В СУЩЕСТВОВАВШЕМ В ДОРЕФОРМЕННЫЙ ПЕРИОД ПРАВЕ УТВЕРЖДЕНИЯ ГЕНЕРАЛ-ГУБЕРНАТОРАМИ УГОЛОВНЫХ ПРИГОВОРОВ РАЦИОНАЛЬНОГО ЗЕРНА? ЧТОБЫ ОТВЕТИТЬ НА ЭТОТ ВОПРОС, ПРЕДСТАВЛЯЕТСЯ, ЧТО УЖЕ НЕДОСТАТОЧНО ОГРАНИЧИТСЯ АНАЛИЗОМ ЗАКОНОДАТЕЛЬСТВА, А НЕОБХОДИМО ОБРАТИТЬСЯ К ИДЕЕ, ПОРОДИВШИМ ЭТУ ПРАВОВУЮ НОРМУ, И САМОЙ ПРАКТИКЕ 3 В С СЯЗИ С ЭТИМ РАЗОБЬЕМ НАШУ СТАТЬЮ НА НЕСКОЛЬКО ЧАСТЕЙ, А ИМЕННО В 1-Й ЧАСТИ ПРЕДСТАВИМ ИСТОРИОГРАФИЮ ВОПРОСА, ВО 2-Й - ВЫЯСНИМ РОЛЬ ГЕНЕРАЛ-ГУБЕРНАТОРОВ В СУДЕБНОЙ СИСТЕМЕ В ПОСЛЕДНЕЙ ТРЕТИ ХVIII - 1-Й ТРЕТИ ХІХ В., ВЗЯВ ВО ВНИМАНИЕ НЕ ТОЛЬКО ЗАКОНОДАТЕЛЬНЫЕ НОРМЫ, НО И ИДЕИ, ИХ ПОРОДИВШИЕ, В 3-Й - НА ПРИМЕРЕ АРХАНГЕЛЬСКОГО, ВОЛОГОДСКОГО И ОЛОНЕЦКОГО (ДАЛЕЕ - АРХАНГЕЛЬСКОГО) ГЕНЕРАЛГУБЕРНАТОРА А.Ф.КЛОКАЧЕВА И С.И. МИНИЦКОГО ПРОАНАЛИЗИРУЕМ СТЕПЕНЬ ИХ РЕАЛЬНОГО ВМЕШАТЕЛЬСТВА В СУДЕБНУЮ ДЕЯТЕЛЬНОСТЬ. В ЗАКЛЮЧЕНИИ ПОСТАРАЕМСЯ ВЫСКАЗАТЬ СВОЕ ИТОГОВОЕ МНЕНИЕ ПО ПОВОДУ ВЫНЕСЕННОГО В ЗАГОЛОВОК СТАТЬИ ВОПРОСА.

\section{Историография вопроса}

СЛОЖНОСТЬ ИСТОРИОГРАФИЧЕСКОГО АНАЛИЗА ПРОБЛЕМЫ СОСТОИТ В ТОМ, ЧТО ЕЕ РАЗРАБОТКА ВЕДЕТСЯ В РАМКАХ СРАЗУ НЕСКОЛЬКИХ НАПРАВЛЕНИЙ: ТЕМИ, КТО ИЗУЧАЛ И ИЗУЧАЕТ ИСТОРИЮ ОТДЕЛЬНЫХ ПЕРИОДОВ РУССКОЙ ИСТОРИИ И РЕФОРМ ${ }^{4}$, ИСТОРИЮ РАЗВИТИЯ ДОРЕВОЛЮЦИОННОЙ СУДЕБНОЙ СИСТЕМЫ И СУДОПРОИЗВОДСТВА СОБСТВЕННО ИНСТИТУТА «НАЧАЛЬНИКОВ ГУБЕРНИЙ» ${ }^{6}$. НО В ЛЮБОМ СЛУЧАЕ, НАУЧНАЯ ПРОРАБОТКА ЭТОГО ВОПРОСА СТАЛА ВОЗМОЖНОЙ ТОЛЬКО В ЭПОХУ ПОДГОТОВКИ И ПРОВЕДЕНИЯ «ВЕЛИКИХ РЕФОРМ», КОГДА «ВРЕМЕННЫМИ ПРАВИЛАМИ ДЛЯ ПЕЧАТИ» 1865 Г. БЫЛО ПОЗВОЛЕНО ВООБЩЕ ЧТО-ЛИБО ОБСУЖДАТЬ В ПЕЧАТИ. ЦЕЛЬЮ ЩОТЦОВ И ДЕТЕЙ» СУДЕБНОЙ РЕФОРМЫ 1864 Г. БЫЛО, КАК МОЖНО УБЕДИТЕЛЬНЕЕ ПОКАЗАТЬ НЕДОСТАТКИ СУЩЕСТВОВАВШЕЙ ДО ЭТОГО СУДЕБНОЙ СИСТЕМЫ. СЕЙЧАС ДОСТАТОЧНО ТРУДНО ОТВЕТИТЬ НА ВОПРОС, КТО ПЕРВЫМ ИЗ ДОРЕВОЛЮЦИОННЫХ УЧЕНЫХ 2-Й ПОЛОВИНЫ ХІХВ. ЗАЯВИЛ, А ГЛАВНОЕ ОСУДИЛ, ОТСУТСТВИЕ НЕЗАВИСИМОСТИ ДОРЕФОРМЕННЫХ СУДОВ ОТ АДМИНИСТРАЦИИ, НАИБОЛЕЕ ЯРКИМ ПРОЯВЛЕНИЕМ КОТОРОГО БЫЛО ПРАВО ГУБЕРНАТОРОВ И ГЕНЕРАЛ-ГУБЕРНАТОРОВ УТВЕРЖДАТЬ УГОЛОВНЫЕ ПРИГОВОРЫ. ЭТО ВИТАЛО В ВОЗДУХЕ. ОТРИЦАТЬ ТО, ЧТО БЫЛО ЧЕТКО ПРОПИСАНО В ЗАКОНЕ, БЕССМЫСЛЕННО, ПОЭТОМУ ОБ ЭТОМ, КАК ИСКЛЮЧИТЕЛЬНО НЕГАТИВНОМ ЯВЛЕНИИ, СТАЛИ ПИСАТЬ ПРАКТИЧЕСКИ ВСЕ ИССЛЕДОВАТЕЛИ, КАКУЮ БЫ НАУЧНУЮ ТЕМУ ОНИ НЕ РАЗРАБАТЫВАЛИ, К КАКИМ БЫ ИСТОРИЧЕСКИМ ЭПОХАМ И НАУЧНЫМ НАПРАВЛЕНИЯМ НЕ ПРИНАДЛЕЖАЛИ ${ }^{7}$. ОДНАКО ТОЛЬКО СОВСЕМ НЕДАВНО И ТО, КАК КАЖЕТСЯ, ПОД ВЛИЯНИЕМ ИССЛЕДОВАНИЙ НАШИХ ЗАРУБЕЖНЫХ КОЛЛЕГ СТАЛИ ДЕЛАТЬСЯ ПОПЫТКИ БОЛЕЕ ОБЪЕКТИВНО ОЦЕНИТЬ ДОРЕФОРМЕННОЕ СУДОПРОИЗВОДСТВО И, В ТОМ ЧИСЛЕ, ПРЕДОСТАВЛЕННОЕ ГЛАВАМ РЕГИОНОВ ПРАВО УТВЕРЖДЕНИЯ ПРИГОВОРОВ. ТАК, НАПРИМЕР, АМЕРИКАНСКИЙ ИССЛЕДОВАТЕЛЬ ДЖ. ЛЕДОНН, ХАРАКТЕРИЗУЯ СУДЕБНЫЕ ФУНКЦИИ ГЕНЕРАЛ-ГУБЕРНАТОРОВ, ОБРАТИЛ ВНИМАНИЕ НА ТО, ЧТО ИХ ВМЕШАТЕЛЬСТВО В УГОЛОВНЫЙ ПРОЦЕСС «БЫЛО ВАЖНО, ПОСКОЛЬКУ, ПО ОБЩЕМУ ПРИЗНАНИЮ, УГОЛОВНОЕ ПРАВО БЫЛО СЛИШКОМ СУРОВЫМ», 
НО «ВМЕСТО ТОГО, ЧТОБЫ ВНОСИТЬ ПОПРАВКИ К ЗАКОНАМ, РАДИ СМЯГЧЕНИЯ ИХ УСЛОВИЙ, БЫЛО РЕШЕНО, ЧТО ВЫГОДНЕЕ ПОЗВОЛИТЬ ГЕНЕРАЛ-ГУБЕРНАТОРУ ОБЛЕГЧАТЬ ЗАКОН ВО ИМЯ БОЛЕЕ ЧЕЛОВЕЧНОГО СУДА, ССЫЛАЯСЬ НА МИЛОСЕРДНОЕ РАСПОЛОЖЕНИЕ САМОЙ ЕКАТЕРИНЫ. В РОССИИ БЫЛИ СТРОГИЕ ЗАКОНЫ, НО ПРАВИТЕЛЬНИЦА (И ЕЕ ПРЕДСТАВИТЕЛИ НА МЕСТАХ) БЫЛИ МИЛОСТИВЫ: ЭТО ЯВЛЯЛОСЬ ОДНОЙ ИЗ ОСНОВ АБСОЛЮТИЗМА». ДАЛЕЕ АВТОР ЗАКЛЮЧАЕТ, ЧТО ГЛАВНОЙ ОБЯЗАННОСТЬЮ ГЕНЕРАЛГУБЕРНАТОРА В СУДЕБНОЙ СФЕРЕ БЫЛО ОБЕСПЕЧЕНИЕ ВЕРХОВЕНСТВА ЗАКОНА (СПРАВЕДЛИВОСТИ), НО ТУТ ЖЕ ОГОВАРИВАЕТСЯ:

ПОКА ОДИН ГЕНЕРАЛ-ГУБЕРНАТОР МОГ ДЕЛАТЬ УСПЕХИ В СМЯГЧЕНИИ УГОЛОВНОГО СУДОПРОИЗВОДСТВА, ДРУГОЙ МОГ ВРЕДИТЬ ЭТОМУ ПРОЦЕССУ, УСТАНАВЛИВАЯ СВОЕ СОБСТВЕННОЕ ПОНИМАНИЕ СПРАВЕДЛИВОСТИ. ЗЛОУПОТРЕБЛЕНИЕ ЛИЧНЫМИ ПОЛНОМОЧИЯМИ ОСТАВАЛОСЬ ПРАКТИЧЕСКИ ГЛАВНОЙ ОСОБЕННОСТЬЮ В СИСТЕМЕ СУДЕБНЫХ ОРГАНОВ 9

ОСНОВАНИЕМ ДЛЯ ТАКОГО ВЫВОДА АВТОРУ, ПО-ВИДИМОМУ, ПОСЛУЖИЛИ МАТЕРИАЛЫ СЕНАТОРСКИХ РЕВИЗИЙ. ОТЕЧЕСТВЕННЫЕ ЖЕ ИСТОРИКИ ТРАДИЦИОННО ССЫЛАЮТСЯ НА МНЕНИЕ М.М.СПЕРАНСКОГО ИЗ «ВВЕДЕНИЯ К НАМЕСТНИЧЕСКОМУ ОБЛАСТНОМУ УПРАВЛЕНИЮ», НЕГАТИВНО ОЦЕНИВШЕГО ОПЫТ ГЕНЕРАЛ-ГУБЕРНАТОРСКОГО УПРАВЛЕНИЯ, А В КАЧЕСТВЕ ПРИМЕРА УКАЗЫВАЮТ НА СИБИРСКОГО ГЕНЕРАЛГУБЕРНАТОРА И.Б. ПЕСТЕЛЯ, КОТОРЫЙ «ОТРЕЗАЛ СИБИРЬ ОТ ВСЯКОГО ПРАВОСУДИЯ» ${ }^{10}$. ПОЛОЖИТЕЛЬНЫЕ ЖЕ ПРИМЕРЫ СУДЕБНОЙ ДЕЯТЕЛЬНОСТИ «ГЛАВНЫХ НАЧАЛЬНИКОВ ГУБЕРНИИ» В НАУЧНОЙ ЛИТЕРАТУРЕ ПРАКТИЧЕСКИ НЕ ВСТРЕЧАЮТСЯ. СЛЕДУЕТ ЛИШЬ ОТМЕТИТЬ НЕКОТОРЫЕ ПОДВИЖКИ В ОТНОШЕНИИ ГЕНЕРАЛ-ГУБЕРНАТОРА А.Д. БАЛАШОВА 11. В.А. ВОРОПАНОВ В СВОЕЙ МОНОГРАФИИ ТАКЖЕ ПОЛАГАЕТ, ЧТО В 1-Й ПОЛОВИНЕ ХІХ В. «ОБЯЗАННОСТИ КОНТРОЛЬНОГО ПРОСМОТРА ПРИГОВОРОВ БЫЛИ ОПТИМАЛЬНО РАСПРЕДЕЛЕНЫ» МЕЖДУ ГЕНЕРАЛ-ГУБЕРНАТОРАМИ И ГУБЕРНАТОРАМИ, А РЕАЛЬНОЕ ВМЕШАТЕЛЬСТВО ВЫСШИХ ЧИНОВНИКОВ В ПОРЯДОК ВСТУПЛЕНИЯ ТЫСЯЧ СУДЕБНЫХ РЕШЕНИЙ БЫЛО НЕВЕЛИКО॥ ${ }^{12}$. СВОИ ВЫВОДЫ АВТОР ПОДКРЕПЛЯЕТ СТАТИСТИКОЙ УТВЕРЖДЕННЫХ ИМИ ПРИГОВОРОВ. ОДНАКО И НА СЕГОДНЯШНИЙ ДЕНЬ ЕЩЕ НЕ СОЗДАНО РАБОТЫ, КОТОРАЯ БЫЛА БЫ СПЕЦИАЛЬНО ПОСВЯЩЕНА ИЗУЧЕНИЮ СУДЕБНОЙ ДЕЯТЕЛЬНОСТИ ГЕНЕРАЛ-ГУБЕРНАТОРОВ В ДОРЕФОРМЕННЫЙ ПЕРИОД. СВОЮ СТАТЬЮ МЫ РАССМАТРИВАЕМ ЛИШЬ В КАЧЕСТВЕ ОДНОГО ИЗ ПЕРВЫХ ШАГОВ В ЭТОМ НАПРАВЛЕНИИ.

\section{Роль генерал-губернаторов в судебной системе Российской империи в 1-й трети XIX века}

\section{Судебные полномочия генерал-губернаторов по «Учреждениям для губерний» 1775 г.}

НАЧНЕМ ОТСЧЕТ С «УЧРЕЖДЕНИЙ ДЛЯ ГУБЕРНИЙ» 1775 Г., ТАК КАК ИМЕННО В НИХ ВПЕРВЫЕ БЫЛО ОПРЕДЕЛЕНО, ЧТО: 1) ГУБЕРНИЮ (НАМЕСТНИЧЕСТВО) ДОЛЖЕН ВОЗГЛАВЛЯТЬ ГОСУДАРЕВ НАМЕСТНИК ИЛИ ГЕНЕРАЛ-ГУБЕРНАТОР, А ГУБЕРНАТОР СТАНОВИТСЯ ЛИШЬ ПРАВИТЕЛЕМ ГУБЕРНСКОГО ПРАВЛЕНИЯ; 2) ГЕНЕРАЛ-ГУБЕРНАТОР И ГУБЕРНАТОР НЕ ВОЗГЛАВЛЯЮТ НИ ОДИН ИЗ СУДОВ ${ }^{13}$. ПОСЛЕДНЯЯ НОВЕЛЛА НЕИЗБЕЖНО ПОВЛЕКЛА ЗА СОБОЙ ДРУГОЕ ВАЖНОЕ ПОСЛЕДСТВИЕ - РЕЗКОЕ СУЖЕНИЕ СУДЕБНЫХ ФУНКЦИЙ ГЛАВЫ ГУБЕРНИИ. ОБ ЭТОМ БЫЛО ДВАЖДЫ ЗАЯВЛЕНО В СТАТЬЯХ 82 И 85 
«УЧРЕЖДЕНИЙ»: «ГОСУДАРЕВ НАМЕСТНИК НЕ ЕСТЬ СУДЬЯ». НО В НИХ ЖЕ ЕМУ ПРЕДПИСЫВАЛОСЬ БЫТЬ

ЗАСТУПНИКОМ УТЕСНЕННЫХ И ПОБУДИТЕЛЕМ БЕЗГЛАСНЫХ ДЕЛ», «ВСТУПАТЬСЯ ЗА ВСЯКОГО, КОГО ПО ДЕЛАМ ВОЛОЧАТ, И ПРИНУЖДАТЬ СУДЕБНЫЕ МЕСТА СВОЕГО НАМЕСТНИЧЕСТВА, РЕШИТЬ ТАКОЕ ТО ДЕЛО, НО ОТНЮД НЕ МЕШАТЬСЯ В ПРОИЗВОДСТВО ОНого.

ОДНАКО В СТАТЬЕ 86 ЗА НИМ БЫЛО СОХРАНЕНО САМОЕ ГЛАВНОЕ СУДЕБНОЕ ПРАВО, ПОЯВИВШЕЕСЯ ВМЕСТЕ С САМОЙ ДОЛЖНОСТЬЮ ЕЩЕ ПРИ ПЕТРЕ I, А ИМЕННО:

ЕСТЬЛИБ В СУДЕБНОМ МЕСТЕ ОПРЕДЕЛЕНО БЫЛО ЧТО НЕСПРАВЕДЛИВО, ТО (ГЛАВНОКОМАНДУЮЩИЙ) ГОСУДАРЕВ НАМЕСТНИК МОЖЕТ ОСТАВИТЬ ИСПОЛНЕНИЕ, И ДОНОСИТЬ СЕНАТУ, А О ВРЕМЕНИ НЕ ТЕРПЯЩИХ ДЕЛАХ И ИМПЕРАТОРСКОМУ ВЕЛИЧЕСТВУ. СИЕ НАИПАЧЕ КАСАЕТСЯ ДО ДЕЛ УГОЛОВНЫХ В ПРИСУЖДЕНИИ К ОТНЯТИЮ У КОГО ЖИЗНИ ИЛИ ЧЕСТИ ${ }^{14}$, И ПО ТАКИМ ДЕЛАМ ИСПОЛНЕНИЕ И ВОВСЕ БЫТЬ НЕ ДОЛЖНО НЕ ДОНОСЯ (ГЛАВНОКОМАНДУЮЩЕМУ) ГЕНЕРАЛ-ГУБЕРНАТОРУ.

\section{Разделение судебных полномочий между генерал- губернаторами и губернаторами}

7 КАК ИЗВЕСТНО, В ИЮНЕ 1781 Г. ЕКАТЕРИНА ВЕЛИКАЯ НЕОЖИДАННО СТАВИТ ГЕНЕРАЛГУБЕРНАТОРА ВО ГЛАВЕ НЕ ОДНОЙ, А 2-3 ГУБЕРНИЙ ${ }^{15}$. ЭТИМ, КАК ЗАМЕТИЛ ЕЩЕ А.Д. ГРАДОВСКИЙ, ОНА «НАРУШИЛА СВОЮ МЫСЛЬ», СОСТАВЛЯВШУЮ ГЛАВНУЮ ЦЕЛЬ ПРОВОДИМОЙ ЕЮ РЕФОРМЫ МЕСТНОГО УПРАВЛЕНИЯ, А ИМЕННО - УНИЧТОЖИТЬ МЕЖДУ ВЕРХОВНОЙ ВЛАСТЬЮ И МЕСТНЫМИ ОРГАНАМИ ВСЯКИХ ПОСРЕДНИКОВ И, В ПЕРВУЮ ОЧЕРЕДЬ, КОЛЛЕГИИ ${ }^{16}$. ВПРОЧЕМ, ОНА НЕ УСПЕЛА ЗАВЕРШИТЬ ЭТОТ ПРОЦЕСС, А ЕЕ СЫН ПАВЕЛ I НЕ ТОЛЬКО ЖЕСТКО ПРЕСЕК ЕГО, НО И ПРИСТУПИЛ С 1796 Г. К ЛИКВИДАЦИИ ИНСТИТУТА ГЕНЕРАЛ-ГУБЕРНАТОРОВ, НАЧАВ ЗАМЕНЯТЬ ЕГО ИНСТИТУТОМ ВОЕННЫХ ГУБЕРНАТОРОВ. В РЕЗУЛЬТАТЕ, В НАЧАЛЕ ХІХ В. СИСТЕМА МЕСТНОГО УПРАВЛЕНИЯ ЕЩЁ БОЛЕЕ УСЛОЖНИЛАСЬ: НА МЕСТАХ ОДНОВРЕМЕННО ФУНКЦИОНИРОВАЛИ ГОСУДАРЕВЫ НАМЕСТНИКИ, ГЕНЕРАЛ-ГУБЕРНАТОРЫ И ВОЕННЫЕ ГУБЕРНАТОРЫ, УПРАВЛЯЮЩИЕ ГРАЖДАНСКОЙ ЧАСТЬЮ ${ }^{17}$, КОТОРЫЕ В ДЕЛОПРОИЗВОДСТВЕННОМ ЯЗЫКЕ НАЧАЛИ ИМЕНОВАТЬСЯ «ГЛАВНЫМИ НАЧАЛЬНИКАМИ ГУБЕРНИИ». ПРИ ЭТОМ ОНИ МОГЛИ УПРАВЛЯТЬ НЕ ТОЛЬКО НЕСКОЛЬКИМИ ГУБЕРНИЯМИ ИЛИ ЦЕЛЫМИ НАЦИОНАЛЬНЫМИ ОКРАИНАМИ, НО ДАЖЕ ОДНОЙ ГУБЕРНИЕЙ ${ }^{18}$. В ТО ЖЕ ВРЕМЯ ВО ГЛАВЕ КАЖДОЙ ГУБЕРНИИ СТОЯЛ ЕЩЕ И ГУБЕРНАТОР. В СВЯЗИ С ЭТИМ ЗАКОНОДАТЕЛЮ ПРИШЛОСЬ ОБРАТИТЬ ОСОБОЕ ВНИМАНИЕ НА РАЗГРАНИЧЕНИЕ СУДЕБНЫХ ПОЛНОМОЧИЙ МЕЖДУ «ГЛАВНЫМИ НАЧАЛЬНИКАМИ ГУБЕРНИИ» И ПРОСТО «НАЧАЛЬНИКАМИ ГУБЕРНИИ» (ГУБЕРНАТОРАМИ). ТАК УЖЕ ПО УКАЗУ ОТ 4 АВГУСТА 1781 Г. В СЛУЧАЕ ОТСУТСТВИЯ ГЕНЕРАЛ-ГУБЕРНАТОРА ВО ВВЕРЕННЫХ ЕГО УПРАВЛЕНИЮ ГУБЕРНИЯХ ОСТАНАВЛИВАТЬ НЕСПРАВЕДЛИВЫЕ ПРИГОВОРЫ И РАЗРЕШАТЬ К ИСПОЛНЕНИЮ ТЯЖКИЕ ПРИГОВОРЫ УГОЛОВНЫХ ПАЛАТ БЫЛО ПОВЕЛЕНО ГУБЕРНАТОРАМ, «ДАБЫ ПРЕСТУПНИК НЕ МОГ ДОЛГО ОСТАВАТЬСЯ БЕЗ НАКАЗАНИЯ». ЦЕЛЕСООБРАЗНОСТЬ ЭТОГО РЕШЕНИЯ СТАЛА ЕЩЕ БОЛЕЕ ОЧЕВИДНОЙ, КОГДА С 1784 Г. НАЧАЛСЯ ПРОЦЕСС РАСШИРЕНИЯ КАТЕГОРИИ ДЕЛ, КОТОРЫЕ ПОДЛЕЖАТ УТВЕРЖДЕНИЮ «УПРАВЛЯЮЩИХ ГУБЕРНИЯМИ». В ЧАСТНОСТИ, В ЭТОМ ГОДУ БЫЛО УТОЧНЕНО, ЧТО ТЕПЕРЬ ОНИ ДОЛЖНЫ ЭТО ДЕЛАТЬ ПО ДОЛЖНОСТНЫМ ПРЕСТУПЛЕНИЯМ, ДАЖЕ ЕСЛИ ПОДСУДИМЫЙ ПРИГОВАРИВАЕТСЯ К ДРУГИМ МЕНЕЕ ТЯЖКИМ НАКАЗАНИЯМ, НЕЖЕЛИ ЛИШЕНИЕ ЖИЗНИ ИЛИ ЧЕСТИ И ТОРГОВАЯ КАЗНЬ. СОГЛАСНО ЖЕ УКАЗА ОТ 15 ОКТЯБРЯ 1785 Г. ОТНЫНЕ ВСЕ УГОЛОВНЫЕ ДЕЛА, ДОШЕДШИЕ 
ДО ПАЛАТЫ УГОЛОВНОГО СУДА, ДАЖЕ ЕСЛИ ПОДСУДИМЫЙ ПО ЭТИМ ДЕЛАМ НЕ ОСУЖДАЛСЯ К ТЯЖКИМ НАКАЗАНИЯМ, ДОЛЖНЫ БЫЛИ ИСПОЛНЯТЬСЯ «НЕ ИНАЧЕ, КАК С СОГЛАШЕНИЯ ВЫШЕ УПОМЯНУТЫХ ПЕРСОН». В 1803 Г. ЭТО УЗАКОНЕНИЕ БЫЛО НЕ ТОЛЬКО ЕЩЕ РАЗ ПОДТВЕРЖДЕНО, НО И РАСШИРЕНО ЗА СЧЕТ ПРЕДПИСАНИЯ ВНОСИТЬ К «НАЧАЛЬНИКАМ ГУБЕРНИЙ» ИЗ ПАЛАТ УГОЛОВНОГО СУДА НА РАССМОТРЕНИЕ «ВСЕ БЕЗ ИЗЪЯТИЯ» НЕ ТОЛЬКО УГОЛОВНЫЕ, НО И СЛЕДСТВЕННЫЕ ДЕЛА. В 1805 Г. БЫЛО РАЗЪЯСНЕНО, ЧТО ИХ УТВЕРЖДЕНИЮ НЕПРЕМЕННО ПОДЛЕЖАТ ДЕЛА, РЕШЕННЫЕ В СОВЕСТНЫХ СУДАХ ${ }^{19}$. ТАКОЕ РАСШИРЕНИЕ ЧИСЛА ДЕЛ, ТРЕБУЮЩИХ УТВЕРЖДЕНИЯ ВЫСШИХ ДОЛЖНОСТНЫХ ЛИЦ ГУБЕРНИИ, ПРИВЕЛО К ТОМУ, ЧТО, НАЧИНАЯ С 1818 Г., ОТДЕЛЬНЫМ ВОЕННЫМ ГУБЕРНАТОРАМ И ГЕНЕРАЛ-ГУБЕРНАТОРАМ (В ТОМ ЧИСЛЕ В 1820 Г. ОКАЗАЛСЯ И АРХАНГЕЛЬСКИЙ ГЕНЕРАЛ-ГУБЕРНАТОР А.Ф. КЛОКАЧЕВ - В.Е.) БЫЛО РАЗРЕШЕНО ПРИНИМАТЬ К СВОЕМУ РАССМОТРЕНИЮ ТОЛЬКО ТАКИЕ УГОЛОВНЫЕ ДЕЛА, « КОИ ПО ВАЖНОСТИ СВОЕЙ ИЛИ ПО ЖАЛОБАМ НА НЕСПРАВЕДЛИВОЕ РЕШЕНИЕ СУДЕБНЫХ МЕСТ, ОБРАТИЛИ БЫ НА СЕБЯ ОСОБОЕ ИХ ВНИМАНИЕ». АЛЕКСАНДР І ОБЪЯСНЯЛ СВОЕ РЕШЕНИЕ НЕОБХОДИМОСТЬЮ ОСВОБОДИТЬ ИХ ДЛЯ «ДЕЯТЕЛЬНОГО НАДЗОРА ПО ДРУГИМ ЧАСТЯМ». В 1823 Г. ЦАРЬ РАСПРОСТРАНИЛ ЭТО ПРАВО НА ВСЕХ ВОЕННЫХ ГУБЕРНАТОРОВ И ГЕНЕРАЛГУБЕРНАТОРОВ ${ }^{20}$. ТАКИМ ОБРАЗОМ, ИМЕННО В НАЧАЛЕ 1820 -Х ГГ. ГЕНЕРАЛ-ГУБЕРНАТОРЫ СТАЛИ ИСПОЛНЯТЬ ЭТУ ФУНКЦИЮ ФАКУЛЬТАТИВНО, ТАК КАК ОБЯЗАННОСТЬ УТВЕРЖДАТЬ УГОЛОВНЫЕ ПРИГОВОРЫ БЫЛА ОКОНЧАТЕЛЬНО ВОЗЛОЖЕНА НА ГУБЕРНАТОРОВ.

ОДНАКО В СВЯЗИ С ЭТИМ ВОЗНИКЛА ПРОБЛЕМА, НА КОТОРУЮ В 1826 Г. ВНИМАНИЕ ЗАКОНОДАТЕЛЯ ОБРАТИЛ ВСЕ ТОТ ЖЕ ГЕНЕРАЛ-ГУБЕРНАТОР С.И. МИНИЦКИЙ. ОН ПРОСИЛ СЕНАТ ДАТЬ РАЗЪЯСНЕНИЕ: ЧТО ДЕЛАТЬ, ЕСЛИ ОН

УСМОТРЕЛ ГДЕ-ЛИБО В СУДЕБНЫХ МЕСТАХ НИЖНЕЙ ИНСТАНЦИИ, ПО ДЕЛАМ УГОЛОВНЫМ ОТСТУПЛЕНИЕ ОТ ЗАКОНА И ПОРЯДКА, ИЛИ ПО ЖАЛОБАМ К НЕМУ ГЕНЕРАЛ-ГУБЕРНАТОРУ ОТКРЫЛОСЬ БЫ ПОСЛАБЛЕНИЕ ВИНОВНОМУ, А ПРАВОМУ УГНЕТЕНИЕ, НО РЕШЕНИЕ Б УЖЕ БЫЛО УТВЕРЖДЕНО ГРАЖДАНСКИМ ГУБЕРНАТОРОМ?

ЗАТРУДНЕНИЕ ВОЗНИКЛО, КАК ОБЪЯСНЯЛ МИНИЦКИЙ, В СВЯЗИ С ПОСТУПИВШИМ К НЕМУ РАПОРТОМ ВОЛОГОДСКОЙ ПОЛИЦИИ, В КОТОРОМ СООБЩАЛОСЬ, ЧТО ПО РЕЗУЛЬТАТАМ ПРОВЕДЕННОГО СЛЕДСТВИЯ ОСТАВИЛА ОНА «В ПОДОЗРЕНИИ» В ПОДЖОГЕ ДОМА МЕЩАНКУ КОЛЧИНУ, НО ГОРОДОВОЙ МАГИСТРАТ, ПРИЗНАВ ЕЁ НЕВИНОВНОЙ, ВНЕС СВОЕ ЗАКЛЮЧЕНИЕ, СОГЛАСНО ВЫСОЧАЙШЕ УТВЕРЖДЕННОГО МНЕНИЯ ГОСУДАРСТВЕННОГО СОВЕТА ОТ 28 ДЕКАБРЯ 1821 ГОДА ${ }^{21}$ НА ПРОСМОТР ГУБЕРНАТОРА, КОТОРЫЙ СОГЛАСИЛСЯ С НИМ. МИНИЦКИЙ, ССЫЛАЯСЬ НА ЭТОТ ЗАКОН, ПРЕДПИСАЛ ГУБЕРНАТОРУ ПЕРЕДАТЬ ЭТО ДЕЛО НА РЕВИЗИЮ В УГОЛОВНУЮ ПАЛАТУ, ЧТО ТОТ И СДЕЛАЛ. ОДНАКО УГОЛОВНАЯ ПАЛАТА ОТОЗВАЛАСЬ, ЧТО НЕ МОЖЕТ ПО СИЛЕ СТАТЬИ 130 «УЧРЕЖДЕНИЙ ДЛЯ ГУБЕРНИЙ» ВХОДИТЬ В НОВОЕ РАССМОТРЕНИЕ УЖЕ РЕШЕННОГО ЕЮ ДЕЛА. СЕНАТ, РАССМОТРЕВ СИТУАЦИЮ И, СОПОСТАВИВ СТАТЬЮ 86 «УЧРЕЖДЕНИЙ» 1775 Г. И УЗАКОНЕНИЕ ОТ 18 СЕНТЯБРЯ 1823 Г., ЗАКЛЮЧИЛ, ЧТО ПОСТАНОВЛЕНИЕ 1821 Г. НЕ ОТМЕНЯЕТ ИХ И ПОЭТОМУ ЗА ГЕНЕРАЛ-ГУБЕРНАТОРАМИ ОСТАЁТСЯ ПРАВО ОСТАНОВИТЬ ИСПОЛНЕНИЕ РЕШЕНИЯ ПО ДЕЛУ И ПОСЛЕ ЕГО УТВЕРЖДЕНИЯ ГУБЕРНАТОРОМ, А ЗАТЕМ ПРЕДСТАВИТЬ ЕГО СО СВОИМ МНЕНИЕМ В СЕНАТ ${ }^{22}$.

САМА ПРОЦЕДУРА ПРЕДСТАВЛЕНИЯ ДЕЛА В СЕНАТ БЫЛА ОБЩЕЙ КАК ДЛЯ ГЕНЕРАЛГУБЕРНАТОРА, ТАК И ГУБЕРНАТОРА. ЕСЛИ ВЗЯТЬ ТОМ ХV СВОДА ЗАКОНОВ 1832 Г., ЯВЛЯВШЕГОСЯ, КАК ЗАЯВЛЯЛИ ЕГО СОЗДАТЕЛИ, ВСЕГО ЛИШЬ ИНКОРПОРАЦИЕЙ 
ПРЕДЫДУЩЕГО ЗАКОНОДАТЕЛЬСТВА, ТО СТАТЬЯ 1111 ТРЕБОВАЛА ОТ «НАЧАЛЬНИКОВ ГУБЕРНИЙ», ЧТОБЫ ОНИ ПРИ УТВЕРЖДЕНИИ ПРИГОВОРОВ ОБРАЩАЛИ ВНИМАНИЕ «НА СУЩНОСТЬ ДЕЛ И ПРАВИЛЬНОСТЬ ПРОИЗВОДСТВА ОНЫХ И НА СОБЛЮДЕНИИ ФОРМ И ОБРЯДОВ, КОИХ НАРУШЕНИЕ [...] УНИЧТОЖАЕТ РЕШЕНИЕ». ОДНАКО ИЗ ТЕХ НОРМ, НА КОТОРЫЕ ЗАКОНОДАТЕЛЬ ССЫЛАЛСЯ В ЭТОЙ СТАТЬЕ, СЛЕДОВАЛО ТОЛЬКО ТО, ЧТО ОНИ ДОЛЖНЫ СОБЛЮДАТЬ УСТАНОВЛЕННЫЕ ЕЩЕ В «ВОИНСКОМ УСТАВЕ» СРОКИ РАССМОТРЕНИЯ ДЕЛ (НЕ БОЛЕЕ 6 НЕДЕЛЬ) И СМОТРЕТЬ, ЧТОБЫ В ЭКСТРАКТАХ И КРАТКИХ ЗАПИСКАХ, КОТОРЫЕ ПЕРЕСЫЛАЛИСЬ К НИМ ИЗ УГОЛОВНЫХ ПАЛАТ, В СЛУЧАЕ ИХ НЕСОГЛАСИЯ С ПРИГОВОРОМ ДЛЯ ПОСЛЕДУЮЩЕГО ПРЕДСТАВЛЕНИЯ ВМЕСТЕ СО СВОИМ МНЕНИЕМ В СЕНАТ, ИЗЛАГАЛИ СУТЬ ДЕЛА «ПО ПОРЯДКУ ПРОИЗВОДСТВА В ТЕЧЕНИИ ДЕЛ БЕЗ ВСЯКОГО УПУЩЕНИЯ И ИЗЛИШЕСТВА», В «ОБСТОЯТЕЛЬСТВАХ ДЕЛА И ЗАКОНАХ» ${ }^{23}$. КАК ЭТО МОГ СДЕЛАТЬ НА ПРАКТИКЕ ГУБЕРНАТОР, СОМНЕВАЛИСЬ УЖЕ ЧЛЕНЫ КОМИТЕТА 6 АВГУСТА 1826 ГОДА ${ }^{24}$. И, ТЕМ НЕ МЕНЕЕ, ЗАКОНОДАТЕЛЬ И ДАЛЕЕ НАСТОЙЧИВО ПРЕДЛАГАЛ ГУБЕРНАТОРУ ПРОИЗВЕСТИ ПО СУЩЕСТВУ ПОВТОРНУЮ РЕВИЗИЮ УЖЕ РЕШЁННОГО УГОЛОВНОЙ ПАЛАТОЙ ДЕЛА ${ }^{25}$, А ГЕНЕРАЛ-ГУБЕРНАТОРУ, ЕСЛИ ОН ПО КАКИМЛИБО ПРИЧИНАМ РЕШАЛ НЕ УТВЕРЖДАТЬ ПРИГОВОР, ПОВЕРИТЬ ИХ ОБОИХ.

\section{Различие в судебных правах генерал-губернаторов по отношению к лицам, относящимся к привилегированным сословиям и «нижнему состоянию»}

ПОМИМО ОГОВОРЕННЫХ В ПРЕДЫДУЩЕМ ОТДЕЛЕНИИ РАЗЛИЧИЯХ В СУДЕБНЫХ ПОЛНОМОЧИЯХ ГЕНЕРАЛ-ГУБЕРНАТОРОВ И ГУБЕРНАТОРОВ, СЛЕДУЕТ ТАКЖЕ ПОМНИТЬ И О СУЩЕСТВОВАВШИХ В 1-Й ТРЕТИ ХІХ В. РАЗЛИЧИЯХ В СУДЕБНЫХ ПРАВАХ ГЕНЕРАЛГУБЕРНАТОРОВ В ОТНОШЕНИИ ЛИЦ, ПРИНАДЛЕЖАВШИХ К РАЗНЫМ СОСЛОВИЯМ. В СВЯЗИ С ОГРАНИЧЕННЫМИ ВОЗМОЖНОСТЯМИ СТАТЬИ, МЫ УКАЖЕМ ЛИШЬ САМЫЕ СУЩЕСТВЕННЫЕ ИЗ ЭТИХ РАЗЛИЧИЙ, НЕ КАСАЯСЬ, НАПРИМЕР, ОСОБЕННОСТЕЙ СУДОПРОИЗВОДСТВА ПО НЕСОВЕРШЕННОЛЕТНИМ, ДУХОВЕНСТВУ И ИНОРОДЦАМ.

СОГЛАСНО ДЕЙСТВУЮЩЕМУ ЗАКОНОДАТЕЛЬСТВУ 1-Й ТРЕТИ ХІХ В. «НАЧАЛЬНИКИ ГУБЕРНИЙ» МОГЛИ ОКОНЧАТЕЛЬНО УТВЕРЖДАТЬ УГОЛОВНЫЕ ПРИГОВОРЫ ТОЛЬКО В ОТНОШЕНИИ НЕПРИВИЛЕГИРОВАННЫХ СЛОЕВ НАСЕЛЕНИЯ, К КАКОВЫМ ТОГДА ОТНОСИЛИСЬ ВСЕ КАТЕГОРИИ КРЕСТЬЯН, КУПЦЫ 3-Й ГИЛЬДИИ И МЕЩАНЕ, КОТОРЫЕ В СВОЕЙ СОВОКУПНОСТИ СОСТАВЛЯЛИ АБСОЛЮТНОЕ БОЛЬШИНСТВО НАСЕЛЕНИЯ РОССИЙСКОЙ ИМПЕРИИ. БОЛЕЕ ТОГО, ЕСЛИ ЛИЦА «НИЖНЕГО СОСТОЯНИЯ» СОВЕРШАЛИ ТЯЖКОЕ ПРЕСТУПЛЕНИЕ, ВЛЕКУЩЕЕ ЗА СОБОЙ ЛИШЕНИЕ ЖИЗНИ ИЛИ ЧЕСТИ ИЛИ ТЕЛЕСНОЕ НАКАЗАНИЕ, ТО С ИЮНЯ 1784 Г. ПО МАРТ 1823 Г. ОНИ ФОРМАЛЬНО БЫЛИ ВООБЩЕ ЛИШЕНЫ ПРАВА АПЕЛЛЯЦИИ НА ПРИГОВОРЫ УГОЛОВНЫХ ПАЛАТ, А ПОСЛЕ 1823 Г., ТЕ ИЗ НИХ, КОТОРЫЕ БЫЛИ ПРИСУЖДЕНЫ К ТЕЛЕСНОМУ НАКАЗАНИЮ И ССЫЛКЕ НА КАТОРГУ ИЛИ ПОСЕЛЕНИЕ, МОГЛИ ПРИНОСИТЬ ЖАЛОБЫ ТОЛЬКО ПОСЛЕ ИСПОЛНЕНИЯ НАД НИМИ ПРИГОВОРА ${ }^{26}$. ТАКИМ ОБРАЗОМ, ЕДИНСТВЕННЫМ СПОСОБОМ ДЛЯ ВЫХОДЦА ИЗ НЕПРИВИЛЕГИРОВАННЫХ СЛОЕВ НАСЕЛЕНИЯ ВЫСКАЗАТЬ СВОЕ НЕСОГЛАСИЕ С РЕШЕНИЕМ УГОЛОВНОЙ ПАЛАТЫ, ПРИГОВОРИВШЕЙ ЕГО К ТЯЖКОМУ УГОЛОВНОМУ НАКАЗАНИЮ, ДО ПРИВЕДЕНИЯ В ДЕЙСТВИЕ ПРИГОВОРА БЫЛО ПОДАТЬ ЖАЛОБУ ГЕНЕРАЛ-ГУБЕРНАТОРУ ИЛИ, В ОБХОД ВСЕХ ЗАКОНОВ, САМОМУ ИМПЕРАТОРУ 27 . РАЗУМЕЕТСЯ, ЧТО ОБРАТИТЬСЯ С ПРОШЕНИЕМ К ГЕНЕРАЛ-ГУБЕРНАТОРУ, ДАЖЕ ПОСЛЕ ТОГО, КАК ПРИГОВОР УТВЕРДИЛ ГУБЕРНАТОР, БЫЛО НЕ ТОЛЬКО ПСИХОЛОГИЧЕСКИ, НО И ТЕХНИЧЕСКИ ЛЕГЧЕ. ВСЕ ЭТО 
ДЕЛАЛО ЕГО ВЕСЬМА ЗНАЧИМОЙ ФИГУРОЙ В ГЛАЗАХ БОЛЬШИНСТВА НАСЕЛЕНИЯ ИМПЕРИИ. ОДНАКО ВНОВЬ ПОДЧЕРКНЕМ, ЕСЛИ ГЕНЕРАЛ-ГУБЕРНАТОР ПРИЗНАВАЛ ЖАЛОБУ ОСНОВАТЕЛЬНОЙ, ТО ОН НЕ ИМЕЛ ПРАВА ИЗМЕНИТЬ ПРИГОВОР, А МОГ ТОЛЬКО ВЫСКАЗАТЬ СВОЕ МНЕНИЕ НА НЕГО И ПЕРЕДАТЬ ВСЕ ПРОИЗВОДСТВО ПО ДЕЛУ НА ОКОНЧАТЕЛЬНОЕ РАЗРЕШЕНИЕ СЕНАТА. В ЭТОМ СЛУЧАЕ ОН КАК БЫ ПРИНИМАЛ НА СЕБЯ РОЛЬ АПЕЛЛЯТОРА.

В СВОЮ ОЧЕРЕДЬ, ДЛЯ ЛИЦ, ПРИНАДЛЕЖАВШИХ К ПРИВИЛЕГИРОВАННЫМ ГРУППАМ НАСЕЛЕНИЯ, А К ТАКОВЫМ ОТНОСИЛИСЬ ДВОРЯНЕ, ЧИНОВНИКИ, КУПЦЫ 1-Й ГИЛЬДИИ И ЛИЦА «НИЖНЕГО СОСТОЯНИЯ», ИМЕВШИМ «ВЫСОЧАЙШЕ ПОЖАЛОВАННЫЕ» НАГРАДЫ ИЛИ ИНЫЕ ЗНАКИ ОТЛИЧИЯ, ПОРЯДОК РАССМОТРЕНИЯ УГОЛОВНЫХ ПРЕСТУПЛЕНИЙ БЫЛ ИНЫМ. ПОСЛЕ ВЫНЕСЕНИЯ РЕШИТЕЛЬНОГО ОПРЕДЕЛЕНИЯ УГОЛОВНАЯ ПАЛАТА ВНОСИЛА СВОЙ ПРИГОВОР К ГЕНЕРАЛ-ГУБЕРНАТОРУ ИЛИ ГУБЕРНАТОРУ ДЛЯ ВЫСКАЗЫВАНИЯ ИМ СВОЕГО МНЕНИЯ НА ЕЕ РЕШЕНИЕ, А ЗАТЕМ ВСЕ ПРОИЗВОДСТВО ПО ДЕЛУ СЛЕДОВАЛО НА РЕВИЗИЮ В СЕНАТ И ОБЯЗАТЕЛЬНО УТВЕРЖДАЛОСЬ ИМПЕРАТОРОМ. ПРИ ЭТОМ ПОСТОЯННО ПОДТВЕРЖДАЛОСЬ ПРАВО ЭТИХ ЛИЦ ПРИНОСИТЬ СВОИ ОПРАВДАНИЯ И АПЕЛЛЯЦИИ ${ }^{28}$. ТАКИМ ОБРАЗОМ, В ОТНОШЕНИИ ВЫХОДЦЕВ ИЗ ПРИВИЛЕГИРОВАННЫХ СОСЛОВИЙ И ГРУПП ГЕНЕРАЛ-ГУБЕРНАТОР И ГУБЕРНАТОР ВООБЩЕ НЕ ОБЛАДАЛИ ПРАВОМ ОКОНЧАТЕЛЬНОГО УТВЕРЖДЕНИЯ ПРИГОВОРОВ. СЛЕДУЕТ ПОМНИТЬ, ЧТО В ГОСУДАРСТВАХ С АБСОЛЮТНОЙ МОНАРХИЕЙ ВСЕ ПРИВИЛЕГИИ И НАГРАДЫ ПРОИСТЕКАЮТ ИСКЛЮЧИТЕЛЬНО ОТ МОНАРХА, СЛЕДОВАТЕЛЬНО, ИХ ЛИШЕНИЕ, СОПРОВОЖДАВШЕЕ ЛЮБОЙ ТЯЖКИЙ ПРИГОВОР, ДОЛЖНО БЫЛО ТАКЖЕ УТВЕРЖДАТЬСЯ ИМ.

КАК МЫ ВИДИМ, ОСНОВНАЯ РАЗНИЦА РОЛИ ГЕНЕРАЛ-ГУБЕРНАТОРА В ОТНОШЕНИИ ЛИЦ, ПРИНАДЛЕЖАВШИХ К ПРИВИЛЕГИРОВАННЫМ И НЕПРИВИЛЕГИРОВАННЫМ СОСЛОВИЯМ СОСТОЯЛА В ТОМ, ЧТО В ПЕРВОМ СЛУЧАЕ ГЕНЕРАЛ-ГУБЕРНАТОР МОГ СТАТЬ ЗАВЕРШАЮЩЕЙ ИНСТАНЦИЕЙ В ПРОЦЕДУРЕ ПРИНЯТИЯ СУДЕБНОГО РЕШЕНИЯ, А ВО ВТОРОМ - ЛИШЬ ОДНОЙ ИЗ ИНСТАНЦИЙ, НО В ОБОИХ СЛУЧАЯХ, ОТ НЕГО ТРЕБОВАЛОСЬ ВЫСКАЗАТЬ СВОЕ МНЕНИЕ ПО ПОВОДУ ПРИГОВОРА. ЗАЧЕМ ЗАКОНОДАТЕЛЮ НУЖНО БЫЛО ЭТО МНЕНИЕ, МЫ ПОПЫТАЕМСЯ ВЫЯСНИТЬ В СЛЕДУЮЩЕМ ОТДЕЛЕНИИ.

\section{Оправдание необходимости утверждения генерал- губернаторами уголовных приговоров}

ПРЕДСТАВЛЯЕТСЯ, ЧТО ГЛАВНАЯ ПРИЧИНА, ПОБУДИВШАЯ ЕКАТЕРИНУ ІІ ПРЕДОСТАВИТЬ ГЕНЕРАЛ-ГУБЕРНАТОРАМ ПРАВО ОСТАНАВЛИВАТЬ НЕСПРАВЕДЛИВОЕ СУДЕБНОЕ РЕШЕНИЕ И УТВЕРЖДАТЬ ТЯЖКИЕ УГОЛОВНЫЕ ПРИГОВОРЫ, КРОЕТСЯ В ПРОИЗВЕДЕННОМ ИМПЕРАТРИЦЕЙ КАЧЕСТВЕННОМ ИЗМЕНЕНИИ СУЩНОСТИ ДОЛЖНОСТИ ГЛАВЫ ГУБЕРНИИ. ВПЕРВЫЕ ОНА ОЗВУЧИЛА ЕЕ В СТ. 1 «НАСТАВЛЕНИЙ ГУБЕРНАТОРАМ» ОТ 21 АПРЕЛЯ 1764 Г.:

ГУБЕРНАТОР, КАК ПОВЕРЕННАЯ ОТ НАС ОСОБА, И, КАК ГЛАВА И ХОЗЯИН ВСЕЙ ВРУЧЕННОЙ В СМОТРЕНИИ ЕГО ГУБЕРНИИ, СОСТОЯТЬ ИМЕЕТ ПОД СОБСТВЕННЫМ НАШИМ И СЕНАТА НАШЕГО ВЕДЕНИЕМ, ПОЧЕМУ И УКАЗЫ ТОЛЬКО ОТ НАС И СЕНАТА НАШЕГО ПРИЕМЛЕТ ${ }^{29}$.

И ХОТЯ В «УЧРЕЖДЕНИЯХ ДЛЯ ГУБЕРНИЙ» 1775 Г. ЦАРИЦА НЕ ИСПОЛЬЗОВАЛА ВЫРАЖЕНИЯ «ПОВЕРЕННАЯ ОТ НАС ОСОБА» В ОТНОШЕНИИ К ГЕНЕРАЛ-ГУБЕРНАТОРУ И ГУБЕРНАТОРУ, НО В ДАЛЬНЕЙШИХ СВОИХ УЗАКОНЕНИЯХ (ПО КРАЙНЕЙ МЕРЕ, ДО 1781 Г. В.Е.) ОНА ЧАСТО ПРИМЕНЯЛА ЕГО К ОБЕИМ ДОЛЖНОСТЯМ. В СИЛУ ЭТОГО СЕНАТ ПОРОЙ 
ДАЖЕ НЕ ВИДЕЛ ОСОБОЙ РАЗНИЦЫ МЕЖДУ НИМИ ${ }^{30}$. ОСНОВНОЕ ЖЕ ПРЕДНАЗНАЧЕНИЕ ГЕНЕРАЛ-ГУБЕРНАТОРА СОСТОЯЛО В ТОМ, ЧТОБЫ БЫТЬ НЕ ПРОСТО УПРАВЛЯЮЩИМ ГУБЕРНИЕЙ И БЕСПРЕКОСЛОВНЫМ ИСПОЛНИТЕЛЕМ ЦАРСКИХ ПОВЕЛЕНИЙ, КЕМ В XVII - 1Й ПОЛОВИНЕ XVIII В. ДЛЯ РУССКИХ ЦАРЕЙ БЫЛ НАМЕСТНИК, ВОЕВОДА ИЛИ ГУБЕРНАТОР, А ПРЕДСТАВИТЕЛЕМ ВЕРХОВНОЙ ВЛАСТИ, ЗНАЮЩИМ БОЛЕЕ ВСЕХ ДРУГИХ О НАМЕРЕНИЯХ ГОСУДАРЫНИ ${ }^{31}$. ПРЕДСТАВЛЯЕТСЯ, ЧТО ТАКОГО ЖЕ ВЗГЛЯДА НА ИНСТИТУТ ГЕНЕРАЛГУБЕРНАТОРОВ ПРИДЕРЖИВАЛСЯ И АЛЕКСАНДР І, КОТОРЫЙ, КАК ВИДНО ИЗ «ЗАПИСОК КАСАТЕЛЬНО МОЕЙ ЖИЗНИ» А.Д. БАЛАШОВА, ЕЩЕ БОЛЕЕ, НЕЖЕЛИ ЕГО ЦАРСТВЕННАЯ БАБКА, ИСПЫТЫВАЛ НЕДОСТАТОК В СПОСОБНЫХ И ДОВЕРЕННЫХ ЛЮДЯХ НА ЭТИХ ДОЛЖНОСТЯХ ${ }^{32}$. ПОЭТОМУ ИМЕННО ГЕНЕРАЛ-ГУБЕРНАТОРАМ ЭТИ МОНАРХИ РЕШИЛИСЬ ВВЕРИТЬ ЧАСТЬ СВОИХ ПРЕРОГАТИВ, В ТОМ ЧИСЛЕ И СУДЕБНЫХ.

17 А В ЧЕМ ЖЕ ВИДЕЛИ РОССИЙСКИЕ ИМПЕРАТОРЫ СВОИ СУДЕБНЫЕ ПРЕРОГАТИВЫ? КАК СЧИТАЮТ БОЛЬШИНСТВО АВТОРИТЕТНЫХ СОВРЕМЕННЫХ ИССЛЕДОВАТЕЛЕЙ ЭВОЛЮЦИИ РОССИЙСКОГО САМОДЕРЖАВИЯ В XVIII-XIX ВВ., ТАКОВЫЕ, ПРЕЖДЕ ВСЕГО, СОСТОЯЛИ В ОХРАНЕ ПРАВОСУДИЯ ${ }^{3}$. ОДНАКО ЕКАТЕРИНА ІІ ВНЕСЛА ОДНУ ВЕСЬМА СУЩЕСТВЕННУЮ ПОПРАВКУ В ПОНИМАНИЕ СТАТУСА РОССИЙСКОГО ИМПЕРАТОРА - В СТ.149 СВОЕГО ЗНАМЕНИТОГО «НАКАЗА» $1767 Г{ }^{34}$ ОНА НАПИСАЛА, ЧТО МОНАРХ «ДОЛЖЕН ВОЗДЕРЖИВАТЬСЯ [...] ЧТОБ САМОМУ НЕ СУДИТЬ ${ }^{35}$. ЭТО ТЕПЕРЬ ДОЛЖНЫ БЫЛИ ДЕЛАТЬ СУДЫ, КОТОРЫЕ СОГЛАСНО СТ. 99 «НАКАЗА», ПОДТВЕРЖДЕННОЙ ЗАТЕМ НЕОДНОКРАТНО И В «УЧРЕЖДЕНИЯХ ДЛЯ ГУБЕРНИЙ» 1775 Г., ОСУЩЕСТВЛЯЮТ СВОЮ ДЕЯТЕЛЬНОСТЬ «ИМЕНЕМ ГОСУДАРЯ И ПО ЗАКОНАМ». ОДНАКО ИМПЕРАТРИЦА НЕ ЗАКРЕПИЛА ЭТО ПОЛОЖЕНИЕ ОТНОСИТЕЛЬНО СЕБЯ В КАКОМ-ЛИБО ДРУГОМ УЗАКОНЕНИИ, ТЕМ САМЫМ СОХРАНИВ ЗА СОБОЙ РОЛЬ ВЫСШЕГО СУДЬИ ${ }^{36}$, НО ЗАТО ДВАЖДЫ В ГЛАВЕ «О ДОЛЖНОСТИ ГОСУДАРЕВА НАМЕСТНИКА» «УЧРЕЖДЕНИЙ ДЛЯ ГУБЕРНИЙ» НАПИСАЛА, ЧТО ОН «НЕ сУДья».

КРОМЕ ТОГО, КАК НАМ ПРЕДСТАВЛЯЕТСЯ, ИМПЕРАТРИЦА ПОПЫТАЛАСЬ РЕАЛИЗОВАТЬ В СТАТУСЕ ГЕНЕРАЛ-ГУБЕРНАТОРА (СТ. 81, 82, 83 «УЧРЕЖДЕНИЙ ДЛЯ ГУБЕРНИЙ») ЗАИМСТВОВАННОЕ У Ш. МОНТЕСКЬЕ И ОТРАЖЁННОЕ В СТ. 510 «НАКАЗА» ПОЛОЖЕНИЕ О ТОМ, ЧТО ГОСУДАРЬ ДОЛЖЕН ТОЛЬКО НАДЗИРАТЬ ЗА УПРАВЛЕНИЕМ, А НЕ УПРАВЛЯТЬ ${ }^{37}$. НО СДЕЛАЛА ЭТО НАСТОЛЬКО НЕОПРЕДЕЛЕННО, ЧТО УЖЕ НЕСКОЛЬКО ДЕСЯТИЛЕТИЙ СПУСТЯ ЕЕ ЗА ЭТО КРИТИКОВАЛ М.М. СПЕРАНСКИЙ. ВО «ВВЕДЕНИИ К НАМЕСТНИЧЕСКОМУ ОБЛАСТНОМУ УПРАВЛЕНИЮ» 1821 Г. ОН ПИСАЛ, ЧТО В «УЧРЕЖДЕНИЯХ ДЛЯ ГУБЕРНИЙ» ЗАКОНОДАТЕЛЬ НЕ СМОГ ОТВЕТИТЬ НА СЛЕДУЮЩИЕ ВОПРОСЫ: КАК ОТЛИЧИТЬ НАДЗОР ОТ УПРАВЛЕНИЯ, ДО КАКОЙ СТЕПЕНИ ДОЛЖНЫ ГЕНЕРАЛ-ГУБЕРНАТОРЫ ВХОДИТЬ В УПРАВЛЕНИЕ, В ЧЕМ СОСТОИТ ИХ ВЛАСТЬ И ГДЕ ТОЧНЫЕ ЕЁ ПРЕДЕЛЫ? В ИТОГЕ ВЫВОД ИЗВЕСТНОГО РЕФОРМАТОРА БЫЛ НЕУТЕШИТЕЛЬНЫМ:

ОТ СЕГО ПРОИЗОШЛО, ЧТО ЗВАНИЕ ГЕНЕРАЛ-ГУБЕРНАТОРОВ, УВАЖЕННОЕ СНАЧАЛА, КОГДА ОНИ ПРЕДСТАВЛЯЛИ В СЕБЕ НЕ ГУБЕРНСКИХ ПРАВИТЕЛЕЙ, А ВЕЛЬМОЖ, ПРИСЛАННЫХ И УПОЛНОМОЧЕННЫХ ПРАВИТЕЛЬСТВОМ НА ВРЕМЯ ДЛЯ ОТКРЫТИЯ ГУБЕРНИЙ, В ПОСЛЕДСТВИЕ ПРИНЯЛО ВСЕ ЛИЧНЫЕ СВОЙСТВА ТЕХ, КОИМ ОНО БЫЛО ВВЕРЕНО, В ОДНИХ ПРЕВРАТИЛОСЬ В САМОВЛАСТИЕ, В ДРУГИХ ПАЛО В БЕЗДЕЙСТВИЕ ${ }^{38}$.

НЕ ЭТО ЛИ МНЕНИЕ, КАК МЫ УЖЕ ОТМЕЧАЛИ В 1-Й ЧАСТИ НАШЕЙ СТАТЬИ, ДО СИХ ПОР ОКАЗЫВАЕТ ОГРОМНОЕ ВЛИЯНИЕ НА ОЦЕНКУ ИССЛЕДОВАТЕЛЯМИ ДЕЯТЕЛЬНОСТИ ГЕНЕРАЛ-ГУБЕРНАТОРОВ, ВКЛЮЧАЯ И СУДЕБНУЮ? 
АЛЕКСАНДР I, ПРИСТУПИВ В КОНЦЕ 1819 Г. К ВОЗРОЖДЕНИЮ ЭТОЙ ДОЛЖНОСТИ В КАЧЕСТВЕ ПОВСЕМЕСТНОЙ, РЕШИЛ РЕАНИМИРОВАТЬ ПЕРВОНАЧАЛЬНУЮ ИДЕЮ СВОЕЙ ЦАРСТВЕННОЙ БАБКИ. НЕ СЛУЧАЙНО В РАЗГОВОРЕ, СОСТОЯВШЕМСЯ МЕЖДУ АЛЕКСАНДРОМ I И А.Д. БАЛАШОВЫМ НАКАНУНЕ НАЗНАЧЕНИЯ ПОСЛЕДНЕГО 4 НОЯБРЯ 1819 Г. НА ДОЛЖНОСТЬ ГЕНЕРАЛ-ГУБЕРНАТОРА, ЦАРЬ ВНУШАЛ ЕМУ, ЧТО ОН «ДОЛЖЕН БЫТЬ ВСЕГДАШНИЙ НАБЛЮДАТЕЛЬ ВСЯКОГО РАСПОРЯДКА И ВСЯКОГО ИСПОЛНЕНИЯ В ПОРУЧЕННЫХ ИМ ГУБЕРНИЯХ ИЛИ ЕЖЕМИНУТНЫЙ ИНСПЕКТОР ВСЕХ ЧАСТЕЙ ВНУТРЕННЕГО УПРАВЛЕНИЯ В ЕГО ОКРУГЕ» ${ }^{39}$.

СРЕДИ ДРУГИХ ПРИЧИН, ЗАСТАВИВШИХ ЕКАТЕРИНУ II СОХРАНИТЬ ЗА ГЕНЕРАЛГУБЕРНАТОРАМИ ПРАВО УТВЕРЖДАТЬ ПРИГОВОРЫ, ИССЛЕДОВАТЕЛИ ОБЯЗАТЕЛЬНО НАЗЫВАЮТ ОСТРУЮ НЕХВАТКУ ЮРИДИЧЕСКИ ОБРАЗОВАННЫХ КАДРОВ, ЧТО, В СВОЮ ОЧЕРЕДЬ, РЕЗКО СНИЖАЛО КАЧЕСТВО ПРИНИМАЕМЫХ СУДЕБНЫХ РЕШЕНИЙ ${ }^{40}$. НО ЭТА ПРИЧИНА НАМ ПРЕДСТАВЛЯЕТСЯ ВСЕ ЖЕ ВТОРИЧНОЙ. ПЕРВИЧНОЙ СЛЕДУЕТ ПРИЗНАТЬ ЗАВЕРШИВШИЙСЯ В XVIII В. В РОССИЙСКОМ ГОСУДАРСТВЕ ПРОЦЕСС ФОРМИРОВАНИЯ АБСОЛЮТНОЙ МОНАРХИИ, КОТОРАЯ, КАК ЗАМЕЧАЮТ ИССЛЕДОВАТЕЛИ ИСТОРИИ СУДЕБНОГО ПРОЦЕССА, СОПРОВОЖДАЛАСЬ И В ЕВРОПЕ И В РОССИИ ВВЕДЕНИЕМ ПИСЬМЕННОГО ИНКВИЗИЦИОННОГО СУДОПРОИЗВОДСТВА ${ }^{41}$. Р.С. УОРТМАН ТАК ПИШЕТ О ПОСЛЕДСТВИЯХ СТАНОВЛЕНИЯ ДАННОЙ ФОРМЫ МОНАРХИИ ДЛЯ РОССИЙСКОГО СУДОПРОИЗВОДСТВА: «ЗАБОТА САМОДЕРЖЦА О ПРАВОСУДИИ И НЕДОВЕРИЕ К СУДЬЯМ ВЕЛИ К СОЗДАНИЮ ИНСТИТУТОВ НАДЗОРА ЗА ОТПРАВЛЕНИЕМ СУДА $»^{42}$. К ИМЕВШЕМУСЯ УЖЕ ИНСТИТУТУ ПРОКУРАТУРЫ ЕКАТЕРИНА ДОБАВИЛА ГЕНЕРАЛ-ГУБЕРНАТОРОВ. ОДНАКО МЫ ДУМАЕМ, ЧТО У ЕКАТЕРИНЫ II МОГЛИ БЫТЬ И ДРУГИЕ РЕЗОНЫ ДЛЯ ТОГО, ЧТОВЫ ОСТАВИТЬ ПРОЦЕДУРУ УТВЕРЖДЕНИЯ УГОЛОВНЫХ ПРИГОВОРОВ ЗА «НАЧАЛЬНИКАМИ ГУБЕРНИЙ». ЕЩЁ В СТ. 179 СВОЕГО «НАКАЗА» ОНА ЗАМЕТИЛА:

[...] ЧТОБЫ СУДИТЬ ПО ОКОНЧАТЕЛЬНОМУ СЕМУ ПОЛОЖЕНИЮ (ИМЕЕТСЯ В ВИДУ ОКОНЧАТЕЛЬНОЕ СУДЕБНОЕ РЕШЕНИЕ - В.Е.), НЕ ТРЕБУЕТСЯ БОЛЬШЕ НИЧЕГО, КАК ПРОСТОЕ ЗДРАВОЕ РАССУЖДЕНИЕ, КОТОРОЕ ВЕРНЕЙШИМ БУДЕТ ПРЕДВОДИТЕЛЕМ, НЕЖЕЛИ ЗНАНИЕ СУДЬИ, ПРИОБВЫКШЕГО НАХОДИТЬ ВЕЗДЕ ВИНОВАТЫХ.

ТАКИМ ОБРАЗОМ, МЫ ПОДОШЛИ К САМОМУ СЛОЖНОМУ С НАШЕЙ ТОЧКИ ЗРЕНИЯ ВОПРОСУ: КАКИМИ КРИТЕРИЯМИ ДОЛЖЕН БЫЛ РУКОВОДСТВОВАТЬСЯ ГЕНЕРАЛГУБЕРНАТОР 1-Й ТРЕТИ ХІХ В., ЕСЛИ РЕШАЛ НЕ УТВЕРЖДАТЬ УГОЛОВНЫЙ ПРИГОВОР? ЕДИНСТВЕННЫМ ОСНОВАНИЕМ ДЛЯ ЭТОГО, СУДЯ ПО СТ. 86 «УЧРЕЖДЕНИЙ ДЛЯ ГУБЕРНИЙ», БЫЛО НЕСПРАВЕДЛИВОЕ РЕШЕНИЕ СУДЕБНЫХ МЕСТ. НО ЧТО ЖЕ ПОНИМАЛОСЬ ПОД СПРАВЕДЛИВОСТЬЮ, ЗАКОНОДАТЕЛЬНИЦА В ЭТОЙ СТАТЬЕ НЕ ПОСЧИТАЛА НУЖНЫМ ПОЯСНИТЬ. ЕСЛИ ЖЕ ИСПОЛЬЗОВАТЬ ПОДХОДЫ, КОТОРЫЕ ПРИМЕНЯЕТ В СВОИХ РАБОТАХ Н.В. ПЕЧЕРСКАЯ, ТО ДЛЯ ТОГО, ЧТОБЫ ПОНЯТЬ ЗНАЧЕНИЕ ТОГО ИЛИ ИНОГО ПОНЯТИЯ, НЕОБХОДИМО ОБРАТИТЬСЯ К АНАЛИЗУ ФАКТОВ ЕГО СЛОВОУПОТРЕБЛЕНИЯ, КОТОРЫЙ ПРИ ЭТОМ ДОЛЖЕН БЫТЬ ВПИСАН «В ОПРЕДЕЛЕННУЮ ФОРМУ ЖИЗНИ КОНКРЕТНОГО ОБЩЕСТВА» $»^{43}$. ПРИ ВСЕЙ «МНОГОЛИКОСТИ» УПОТРЕБЛЕНИЯ ПОНЯТИЯ «СПРАВЕДЛИВОСТЬ» В XVIII И ХІХ ВВ., КОТОРЫЕ ПОДРОБНО ОПИСЫВАЕТ АВТОР, ДЛЯ НАС НАИБОЛЕЕ ВАЖНЫМ БЫЛО УЯСНИТЬ, КАК ПОНИМАЛАСЬ «СПРАВЕДЛИВОСТЬ» В «ЮРИДИЧЕСКОМ СМЫСЛЕ» И КАК ОНА БЫЛА ВЫРАЖЕНА ЕКАТЕРИНОЙ ІІ В ЗАКОНАХ. Н. ПЕЧЕРСКАЯ ПОЛАГАЕТ, ЧТО ДАННЫЙ ТЕРМИН СФОРМИРОВАЛСЯ ПОД ВЛИЯНИЕМ ИДЕЙ ФРАНЦУЗСКОЙ ПРАВОВОЙ И ФИЛОСОФСКОЙ НАУЧНОЙ ДОКТРИНЫ И «СЧИТАЛСЯ СЕМАНТИЧЕСКИМ ЭКВИВАЛЕНТОМ ФРАНЦУЗСКОГО «la justice», Т.Е. ПИСЬМЕННОГО ПРАВА» ${ }^{4}$. ПОЭТОМУ НЕ СЛУЧАЙНО В СТ. 81,82 И 83 «УЧРЕЖДЕНИЙ ДЛЯ ГУБЕРНИЙ» 
ПРОВОЗГЛАШАЛОСЬ, ЧТО «ГОСУДАРЕВ НАМЕСТНИК НЕ ЕСТЬ СУДЬЯ, НО ОБЕРЕГАТЕЛЬ ИМПЕРАТОРСКОГО ВЕЛИЧЕСТВА ИЗДАННОГО УЗАКОНЕНИЯ», ЧТО ОН ДОЛЖЕН «СТРОГОЕ И ТОЧНОЕ ВЗЫСКАНИЕ ЧИНИТЬ СО ВСЕХ ЕМУ ПОДЧИНЕННЫХ МЕСТ И ЛЮДЕЙ ОБ ИСПОЛНЕНИИ ЗАКОНОВ» И ДАВАТЬ СПОСОБ К УДОВОЛЬСТВИЮ КАЖДОГО ЗАКОННЫМ ОБРАЗОМ». ВЕРОЯТНО, ЦАРИЦА СЧИТАЛА ТАКОЕ ПОЯСНЕНИЕ ДОСТАТОЧНЫМ, ТАК КАК БОЛЕЕ ПРОСТРАННЫЕ И КОНЦЕПТУАЛЬНЫЕ ЗАЯВЛЕНИЯ БЫЛИ СДЕЛАНЫ ЕЮ ЕЩЕ В «НАКАЗЕ» 1767 ГОДА.

ИЗ «НАКАЗА» ЖЕ СЛЕДОВАЛО, ЧТО ПОД «СПРАВЕДЛИВЫМ» СУДЕБНЫМ РЕШЕНИЕМ ЕКАТЕРИНА ІІ ПОНИМАЛА ТАКОЕ РЕШЕНИЕ, КОТОРОЕ: ОСНОВЫВАЛОСЬ НА ЗАКОНЕ (СТ. 34 , 98, 129, 148, 149) ${ }^{45}$, ОХРАНЯЛО ИНТЕРЕСЫ ОБЩЕСТВА (СТ. 147), БЫЛО НЕ ЖЕСТОКО, СОРАЗМЕРНО СОДЕЯННОМУ И «НЕОТВРАТИМО» (СТ. 150, 198, 200, 205, 206, 220, 221-223, $225,226,228)$, А ТАКЖЕ ПРИНЯТО В РЕЗУЛЬТАТЕ ДОКАЗАННОЙ НА СУДЕ ВИНЫ ОБВИНЯЕМОГО, НО БЕЗ ПРИМЕНЕНИЯ СЛЕДСТВЕННОЙ ПЫТКИ (СТ. 162, 194-197), ВЫНЕСЕНО СУДОМ РАВНЫХ (СТ. 110, 127, 180), ИЗВЕСТНО НАРОДУ (СТ. 183, 220), А САМ ПРОЦЕСС ПРОВЕДЁН С СОБЛЮДЕНИЕМ ВСЕХ ФОРМ «СУДЕБНЫХ ОБРЯДОВ» (СТ. 112-114) ${ }^{46}$. ТАКИМ ОБРАЗОМ, В ОСНОВУ ПРИМЕНЕНИЯ НОРМ УГОЛОВНОГО ПРАВА И ПРОЦЕССА ИМПЕРАТРИЦА ЗАЛОЖИЛА ТАКИЕ ГУМАННЫЕ ПРИНЦИПЫ, КОТОРЫЕ ГОСПОДСТВУЮТ И В СОВРЕМЕННОМ РОССИЙСКОМ УГОЛОВНОМ СУДОПРОИЗВОДСТВЕ. ВЕДУЩИМ ЖЕ ИЗ НИХ ДЛЯ НЕЕ СТАЛ ПРИНЦИП ЗАКОННОСТИ. РУКОВОДСТВУЯСЬ ЭТИМ ПРИНЦИПОМ, ЗАИМСТВОВАННЫМ У Ч. БЕККАРИА, ЕКАТЕРИНА ІІ ХОТЕЛА ДОСТИЧЬ СРАЗУ ДВЕ ЦЕЛИ: ОГРАНИЧИТЬ ПРОИЗВОЛ СУДЕЙ ПРИ ПРИНЯТИИ РЕШЕНИЙ И ЗАЩИТИТЬ «СВОБОДУ И БЕЗОПАСНОСТЬ ГРАЖДАН». В РЕЗУЛЬТАТЕ СУДЬЯМ БЫЛО ЗАПРЕЩЕНО ТОЛКОВАТЬ ЗАКОНЫ. ТЕПЕРЬ, СОГЛАСНО СТ. 467 «НАКАЗА», «ВОЛЬНОСТЬ ГРАЖДАН» ДОЛЖНА ЗАВИСЕТЬ ЩОТ ИЗЯЩЕСТВА ЗАКОНОВ КРИМИНАЛЬНЫХ». А ВОТ САМИ КРИМИНАЛЬНЫЕ ЗАКОНЫ, ИМЕВШИЕ СВОИМ ИСТОЧНИКОМ ПРАВО ЕЩЕ МОСКОВСКОГО ЦАРСТВА («СОБОРНОЕ УЛОЖЕНИЕ» 1649 Г.) И ПЕТРОВСКОЙ ЭПОХИ («АРТИКУЛ ВОИНСКИЙ» И «КРАТКОЕ ИЗОБРАЖЕНИЕ ПРОЦЕСОВ ИЛИ СУДЕБНЫХ ТЯЖЕБ» 1716 Г.), БЫЛИ КРАЙНЕ РЕПРЕССИВНЫМИ И ДАЛЕКО НЕ СООТВЕТСТВОВАЛИ ИДЕАЛАМ ЭПОХИ ПРОСВЕЩЕНИЯ. В ДАННОМ СЛУЧАЕ МЫ ВСЕЦЕЛО ПРИСОЕДИНЯЕМСЯ К МНЕНИЮ ДЖ. ЛЕДОННА, КОТОРЫЙ, НАПОМНИМ, СЧИТАЕТ, ЧТО ВМЕШАТЕЛЬСТВО В УГОЛОВНЫЙ ПРОЦЕСС ГЕНЕРАЛГУБЕРНАТОРОВ «БЫЛО ВАЖНО, ПОСКОЛЬКУ, ПО ОБЩЕМУ ПРИЗНАНИЮ, УГОЛОВНОЕ ПРАВО БЫЛО СЛИШКОМ СУРОВЫМ». ВЕСЬМА ВЕРОЯТНО, ЧТО ЕКАТЕРИНА ПРЕДПОЛАГАЛА, ЧТО ПОСЛЕ ТОГО, КАК ЗАВЕРШИТ РАБОТУ НАД «УГОЛОВНЫМ УЛОЖЕНИЕМ» И ПРИМЫКАЮЩЕМУ К НЕМУ «ПОРЯДКОМ ИССЛЕДОВАНИЯ И СУДА УГОЛОВНОГО ДЕЛА», К РАЗРАБОТКЕ КОТОРЫХ ОНА ПРИСТУПИЛА СРАЗУ ПОСЛЕ ПРИНЯТИЯ В 1775 Г. «УЧРЕЖДЕНИЙ ДЛЯ ГУБЕРНИЙ ${ }^{47}$, НЕОБХОДИМОСТЬ ВМЕШАТЕЛЬСТВА ГЕНЕРАЛГУБЕРНАТОРОВ В СУДЕБНОЕ РЕШЕНИЕ ОТПАДЕТ ВООБЩЕ.

С ДРУГОЙ СТОРОНЫ, ПОНЯТИЕ СПРАВЕДЛИВОСТИ НЕЛЬЗЯ СВЕСТИ ТОЛЬКО К УКАЗАННЫМ В «НАКАЗЕ» 1767 Г. И «УЧРЕЖДЕНИЯХ ДЛЯ ГУБЕРНИЙ» 1775 Г. ПРИНЦИПАМ. КАК ЗАМЕЧАЕТ Н. ПЕЧЕРСКАЯ, ХОТЯ ТЕРМИН «СПРАВЕДЛИВОСТЬ» НЕ УПОТРЕБЛЯЛСЯ ШИРОКО ВПЛОТЬ ДО XVIII В., НО «БЫЛО БЫ ОШИБКОЙ ПОЛАГАТЬ, ЧТО В ДРЕВНЕЙ РУСИ ОТСУТСТВОВАЛИ ПРЕДСТАВЛЕНИЯ О ТЕХ ПРИЗНАКАХ И СВОЙСТВАХ, КОТОРЫЕ ВПОСЛЕДСТВИИ ВОШЛИ В СОСТАВ ПОНЯТИЯ «СПРАВЕДЛИВОСТЬ». В РУССКОМ ЯЗЫКЕ ДО XV В. ОНИ ВЫРАЖАЛИСЬ ШИРОКИМ СПЕКТРОМ СЛОВ, ОБЪЕДИНЕННЫХ ОБЩЕСЛАВЯНСКОЙ КОРНЕВОЙ МОРФЕМОЙ «-ПРАВ-»: «ПРАВДА, ПРАВЕДНЫЙ, ПРАВИЛО, ПРАВИЛЬНЫЙ ${ }^{48}$. ЕЕ ПОДДЕРЖИВАЮТ И ИСТОРИКИ ПРАВА. ТАК В.А. ТОМСИНОВ ПИШЕТ: «НА РУСИ ВО ВСЕ 
ВРЕМЕНА ВИДЕЛИ В ЗАКОНЕ ВЫРАЖЕНИЕ СОВЕСТИ ИЛИ, КАК ГОВОРИЛИ В ДРЕВНОСТИ ПРАВДЫ ${ }^{49}$. ОДНАКО, КАК НАПОМИНАЕТ Н. ПЕЧЕРСКАЯ, СЛЕДУЕТ НЕ ЗАБЫВАТЬ, ЧТО «ПРАВДА» ВПЛОТЬ ДО ПРИНЯТИЯ МОСКОВСКИХ СУДЕБНИКОВ, БОЛЬШЕ ПОНИМАЛАСЬ КАК НЕПИСАНЫЙ ЗАКОН, ПРОИСХОДЯЩИЙ ОТ ИДЕИ «БОЖЬЕГО СУДА ${ }^{50}$. И ХОТЯ НА РУБЕЖЕ XV-XVI ВВ. ПРОИСХОДИТ ИЗМЕНЕНИЕ ИСТОЧНИКА «ЗАКОНА», КОТОРЫЙ ТЕПЕРЬ ПРОИСХОДИТ ОТ ГОСУДАРЯ, В НОРМАТИВНО-ПРАВОВЫХ АКТАХ ХVII-ХIX ВВ. МЫ НАБЛЮДАЕМ АКТИВНОЕ УПОТРЕБЛЕНИЕ АРХАИЧЕСКОЙ ЛЕКСИКИ, ОТРАЖАЮЩЕЙ, КАК НАМ ПРЕДСТАВЛЯЕТСЯ, САМОЕ ДРЕВНЕЕ ПОНЯТИЕ «СПРАВЕДЛИВОГО» СУДЕБНОГО РЕШЕНИЯ. ЭТО ПОНЯТИЕ ВПЕРВЫЕ БЫЛО ОЗВУЧЕНО В ПСКОВСКОЙ СУДНОЙ ГРАМОТЕ, А ЗАТЕМ ПРАКТИЧЕСКИ БЕЗ ИЗМЕНЕНИЯ ПЕРЕНОСИЛОСЬ ИЗ ИСТОЧНИКА В ИСТОЧНИК, И, НАКОНЕЦ, ОКАЗАЛОСЬ В П. 4 «НАСТАВЛЕНИЙ ГУБЕРНАТОРАМ» 1764 ГОДА. В НЕМ ГУБЕРНАТОРУ ПРЕДПИСЫВАЛОСЬ НАБЛЮДАТЬ,

ЧТОБЫ ПРАВОСУДИЕ И ИСТИНА ВО ВСЕХ СУДЕБНЫХ ПОДЧИНЁННЫХ ЕМУ МЕСТАХ ОБИТАЛИ И ЧТОБ НИ ЗНАТНОСТЬ ВЕЛЬМОЖ, НИ СИЛА БОГАТЫХ, СОВЕСТИ И ПРАВДЫ ПОМРАЧАТЬ, А БЕДНОСТЬ ВДОВ И СИРОТ, ТЩЕТНО ПРОЛИВАЯ СЛЁЗЫ, В ДЕЛАХ СПРАВЕДЛИВЫХ УТЕСНЕНА НЕ БЫЛА.

СОГЛАСНО СТ. 82 «УЧРЕЖДЕНИЙ ДЛЯ ГУБЕРНИЙ» ГЕНЕРАЛ-ГУБЕРНАТОР ДОЛЖЕН БЫЛ ТАКЖЕ БЫТЬ «ЗАСТУПНИКОМ УТЕСНЕННЫХ» И В ПОСТУПКАХ СВОИХ ПОКАЗЫВАТЬ «ДОБРОХОТСТВО, ЛЮБОВЬ И СОБОЛЕЗНОВАНИЕ К НАРОДУ». ДУМАЕТСЯ, ТЕНДЕНЦИЯ ЯВНО ПРОСМАТРИВАЕТСЯ: СПРАВЕДЛИВЫМ ВСЕГДА СЧИТАЛОСЬ БЕСПРИСТРАСТНОЕ РЕШЕНИЕ. Н. ПЕЧЕРСКАЯ ЖЕ ПОЛАГАЕТ, ЧТО В ХІХ В. «ОСНОВНОЙ СМЫСЛООБРАЗУЮЩЕЙ ХАРАКТЕРИСТИКОЙ ЮРИДИЧЕСКОЙ СПРАВЕДЛИВОСТИ ВЫСТУПАЕТ ПРИНЦИП БЕСПРИСТРАСТНОСТИ ИЛИ АБСТРАКТНО-ФОРМАЛЬНОГО РАВЕНСТВА». НО ПРИ ЭТОМ СЛЕДУЕТ ПОМНИТЬ, ЧТО МЫСЛИТЕЛИ XVIII В. «РЕШАЛИ ПРОБЛЕМУ СПРАВЕДЛИВОСТИ НА ОСНОВЕ ПОЛИТИЧЕСКОГО РАВЕНСТВА. ИХ ПРЕДСТАВЛЕНИЯ О РАВЕНСТВЕ НЕ ПРОСТИРАЛИСЬ НИ НА ЭКОНОМИЧЕСКУЮ, НИ НА СОЦИАЛЬНУЮ СФЕРЫ ${ }^{51}$. В УГОЛОВНОПРАВОВОЙ ДОКТРИНЕ ЕКАТЕРИНЫ II, ОСНОВАННОЙ НА ЕСТЕСТВЕННО-ПРАВОВОЙ ТЕОРИИ, СПРАВЕДЛИВОСТЬ ВОСПРИНИМАЕТСЯ КАК РАВЕНСТВО ВСЕХ ПОДДАННЫХ ПЕРЕД КРИМИНАЛЬНЫМИ (ОСНОВНЫМИ) ЗАКОНАМИ, УСТАНОВЛЕННЫМИ ГОСУДАРЕМ. ТАКОЕ «ЕКАТЕРИНИНСКОЕ» ПОНИМАНИЕ СПРАВЕДЛИВОСТИ БЫЛО ВОСПРИНЯТО И В ПРАВЛЕНИЕ АЛЕКСАНДРА І, КОТОРЫМ ЗАВЕРШИЛАСЬ ЭПОХА ПРОСВЕЩЕНИЯ ${ }^{52}$.

ИТАК, В ЭТОЙ ЧАСТИ СВОЕЙ СТАТЬИ МЫ ВЫЯСНИЛИ, ЧТО В 1775 Г. ЕКАТЕРИНА II РЕЗКО СУЗИЛА СУДЕБНЫЕ ФУНКЦИИ ГЕНЕРАЛ-ГУБЕРНАТОРОВ КАК ГЛАВ ГУБЕРНИЙ, ВЫВЕДЯ ИХ ИЗ СОСТАВА СУДОВ. ОНА ОСТАВИЛА ЗА НИМИ ЛИШЬ ПРАВО НЕ СОГЛАСИТЬСЯ С НЕСПРАВЕДЛИВЫМ ПРИГОВОРОМ И В ОБЯЗАТЕЛЬНОМ ПОРЯДКЕ УТВЕРЖДАТЬ ТЯЖКИЕ УГОЛОВНЫЕ ПРИГОВОРЫ. В СЛУЧАЕ НЕСОГЛАСИЯ С ПРИГОВОРОМ ИМ ПРЕДПИСЫВАЛОСЬ ВНОСИТЬ ТАКИЕ ДЕЛА НА ОКОНЧАТЕЛЬНОЕ УСМОТРЕНИЕ СЕНАТА И ГОСУДАРЯ. ОДНАКО В СВЯЗИ С ПОЯВЛЕНИЕМ НА РУБЕЖЕ XVIII-XIX ВВ. РЕГИОНОВ, СОСТОЯЩИХ ИЗ 2-5 ГУБЕРНИЙ, ВОЗГЛАВЛЯЕМЫХ ГЕНЕРАЛ-ГУБЕРНАТОРАМИ, ПОСЛЕДНИМ СТАЛО ВЕСЬМА ЗАТРУДНИТЕЛЬНО В ПОЛНОМ ОБЪЕМЕ ОСУЩЕСТВЛЯТЬ ДАЖЕ ЭТИ ФУНКЦИИ. ТЕМ БОЛЕЕ ЧТО ЗАКОНОДАТЕЛЬ ПОСТОЯННО РАСШИРЯЛ КРУГ СУДЕБНЫХ ДЕЛ, КОТОРЫЕ ТРЕБОВАЛИ ИХ УТВЕРЖДЕНИЯ. ТАКОЕ ПОЛОЖЕНИЕ ДЕЛ СОХРАНЯЛОСЬ ДО 1823 Г., КОГДА АЛЕКСАНДР І РАЗРЕШИЛ «ГЛАВНЫМ НАЧАЛЬНИКАМ ГУБЕРНИЙ» ВМЕШИВАТЬСЯ В СУДЕБНЫЕ РЕШЕНИЯ ЛИШЬ ПО СОБСТВЕННОМУ УСМОТРЕНИЮ ИЛИ В СВЯЗИ С ЖАЛОБАМИ ПОТЕРПЕВШИХ ИЛИ ОБВИНЯЕМЫХ, ВОЗЛОЖИВ ОБЯЗАННОСТЬ УТВЕРЖДАТЬ ВСЕ УГОЛОВНЫЕ ПРИГОВОРЫ НЕПОСРЕДСТВЕННО НА ГУБЕРНАТОРОВ. НО ДАЖЕ ПОСЛЕ ЭТОГО ГЕНЕРАЛ-ГУБЕРНАТОР МОГ 
ОСТАНОВИТЬ ИСПОЛНЕНИЕ ЛЮБОГО УГОЛОВНОГО ПРИГОВОРА, ДАЖЕ УТВЕРЖДЕННОГО ГУБЕРНАТОРОМ. МЫ ПОЛАГАЕМ, ЧТО ИМПЕРАТОР СОХРАНИЛ ЭТО ПРАВО ЗА ГЕНЕРАЛГУБЕРНАТОРАМИ ПОТОМУ, ЧТО ТОЧНО ТАКЖЕ КАК И ЕГО ЦАРСТВЕННАЯ БАБКА, ПОНИМАЛ ДОЛЖНОСТЬ ГЕНЕРАЛ-ГУБЕРНАТОРА. ОНИ ОБА СЧИТАЛИ ИХ СВОИМИ «ПОВЕРЕННЫМИ ОСОБАМИ», КОМУ МОЖНО ПЕРЕДАТЬ ЧАСТЬ СВОИХ СУДЕБНЫХ ПРЕРОГАТИВ, А ИМЕННО: СТРОГИЙ НАДЗОР ЗА СОБЛЮДЕНИЕМ СУДАМИ ПРИНЦИПА «ВЕРХОВЕНСТВА ЗАКОНА»; СООТНЕСЕНИЕ ПРИНЯТОГО ПРИГОВОРА С ПОНЯТИЕМ «СПРАВЕДЛИВОСТИ», ПОНИМАВШЕГОСЯ КАК ФОРМАЛЬНОЕ РАВЕНСТВО ВСЕХ ПЕРЕД КРИМИНАЛЬНЫМИ ЗАКОНАМИ; ПРОЯВЛЕНИЕ МИЛОСЕРДИЯ В УСЛОВИЯХ ДЕЙСТВИЯ ЖЕСТОКОГО УГОЛОВНОГО ЗАКОНОДАТЕЛЬСТВА.

\section{Практика утверждения приговоров на примере деятельности архангельского, вологодского и олонецкого генерал-губернатора А.Ф. Клокачева и С.И. Миницкого (1820-1830 гг.)}

ИСТОЧНИКОВОЙ БАЗОЙ ДАННОЙ ЧАСТИ НАШЕЙ СТАТЬИ СТАЛИ МАТЕРИАЛЫ ТРЁХ АРХИВОВ, АБСОЛЮТНОЕ БОЛЬШИНСТВО КОТОРЫХ ВПЕРВЫЕ ВВОДЯТСЯ В НАУЧНЫЙ ОБОРОТ $^{53}$. ИЗ НИХ, В СВОЮ ОЧЕРЕДЬ, САМЫМИ РЕПРЕЗЕНТАТИВНЫМИ ДЛЯ НАС ЯВЛЯЛИСЬ СОХРАНИВШИЕСЯ ЗА 1820-1825 ГГ. «ЖУРНАЛЫ ИСХОДЯЩИХ БУМАГ» ИЗ КАНЦЕЛЯРИИ АРХАНГЕЛЬСКИХ ГЕНЕРАЛ-ГУБЕРНАТОРОВ, КОТОРЫЕ ПРЕДСТАВЛЯЮТ СОБОЙ ЕЖЕДНЕВНУЮ ЗАПИСЬ ОТДАННЫХ ИМИ ПРЕДЛОЖЕНИЙ И РАСПОРЯЖЕНИЙ ГУБЕРНСКИМ И УЕЗДНЫМ ПРИСУТСТВЕННЫМ МЕСТАМ, А ТАКЖЕ ПОСТУПИВШИХ ИЗ СЕНАТА И ДРУГИХ «ВЫСШИХ ПРАВИТЕЛЬСТВЕННЫХ МЕСТ» УКАЗОВ, ПРЕДПИСАНИЙ И ОТНОШЕНИЙ И, СООТВЕТСТВЕННО, ОТВЕТОВ НА НИХ. ПО ФОНДАМ ГУБЕРНСКИХ ПАЛАТ УГОЛОВНОГО СУДА МЫ ИЗУЧАЛИ СОХРАНИВШИЕСЯ УКАЗНЫЕ КНИГИ, ГДЕ ФИКСИРОВАЛИСЬ УКАЗЫ СЕНАТА И ПРЕДЛОЖЕНИЯ ГЕНЕРАЛ-ГУБЕРНАТОРОВ ПО КОНКРЕТНЫМ УГОЛОВНЫМ ДЕЛАМ, А ТАКЖЕ САМИ УГОЛОВНЫЕ ДЕЛА. В ФОНДЕ 5-ГО ДЕПАРТАМЕНТА СЕНАТА РГИА МЫ ВЫЯВИЛИ И ПРОСЛЕДИЛИ СУДЬБУ ТЕХ УГОЛОВНЫХ ДЕЛ, КОТОРЫЕ БЫЛИ ПРЕДСТАВЛЕНЫ ЕМУ ОТ ЛИЦА АРХАНГЕЛЬСКИХ ГЕНЕРАЛ-ГУБЕРНАТОРОВ. ПРИ ЭТОМ СРАЗУ ОГОВОРИМСЯ, ЧТО В ЭТОЙ СТАТЬЕЙ МЫ ПРОАНАЛИЗИРОВАЛИ ПРАКТИКУ НАДЗОРА АРХАНГЕЛЬСКИМИ ГЕНЕРАЛГУБЕРНАТОРАМИ ТОЛЬКО ЗА ТЯЖКИМИ УГОЛОВНЫМИ ПРЕСТУПЛЕНИЯМИ, НО НЕ ДОЛЖНОСТНЫМИ, ТАК КАК ИХ АНАЛИЗ, В СИЛУ ОСОБОЙ СПЕЦИФИКИ, ТРЕБУЕТ СПЕЦИАЛЬНОГО РАССМОТРЕНИЯ.

ДЛЯ НАЧАЛА, ВЫЯСНИМ, КАКИЕ УГОЛОВНЫЕ ДЕЛА ПРИВЛЕКАЛИ ВНИМАНИЕ АРХАНГЕЛЬСКИХ ГЕНЕРАЛ-ГУБЕРНАТОРОВ И КАКИМ ОБРАЗОМ ОНИ ПОЛУЧАЛИ ИНФОРМАЦИЮ О ПРИНИМАЕМЫХ СУДАМИ РЕШЕНИЯХ И ПРИГОВОРАХ? КАК ВИДНО ИЗ АРХИВНЫХ ДОКУМЕНТОВ, ГЕНЕРАЛ-ГУБЕРНАТОР А.Ф. КЛОКАЧЕВ (1820-1823) И С.И. МИНИЦКИЙ (1823-1830), ПРЕЖДЕ ВСЕГО, ОБРАЩАЛИ ВНИМАНИЕ НА УГОЛОВНЫЕ ПРЕСТУПЛЕНИЯ, СОПРЯЖЁННЫЕ «С КАЗЁННЫМ ИНТЕРЕСОМ» (НАПРИМЕР, ПОДЖОГАМИ В КАЗЕННЫХ ЛЕСАХ), А ТАКЖЕ УБИЙСТВА, ГРАБЕЖИ, ПРИСТАНОДЕРЖАТЕЛЬСТВО И НЕПОВИНОВЕНИЕ ВЛАСТЯМ. ТАКЖЕ ВЫЯСНИЛОСЬ, ЧТО ИХ ОСНОВНЫМИ ИНФОРМАТОРАМИ БЫЛИ НЕ ГУБЕРНСКИЕ ПРОКУРОРЫ 3-Х СЕВЕРНЫХ ГУБЕРНИЙ, КАК ЭТО ДОЛЖНО БЫ БЫЛО БЫТЬ, ЕСЛИ СТРОГО СЛЕДОВАТЬ НОРМАМ «УЧРЕЖДЕНИЙ ДЛЯ ГУБЕРНИЙ» И ПОСЛЕДОВАВШИХ ЗА НИМИ РАЗЪЯСНЯЮЩИМИ ПРАВОВЫМИ АКТАМИ ${ }^{54}$. КАК ПОКАЗЫВАЮТ 
«ЖУРНАЛЫ ИСХОДЯЩИХ БУМАГ» ОТ АРХАНГЕЛЬСКИХ ГЕНЕРАЛ-ГУБЕРНАТОРОВ, ПОСЛЕДНИЕ КРАЙНЕ РЕДКО ОБРАЩАЛИСЬ К НИМ ПО УКАЗАННЫМ ВЫШЕ ПОВОДАМ. ТАК, НАПРИМЕР, ПО ОЛОНЕЦКОЙ ГУБЕРНИИ ЭТО ПРОИЗОШЛО ЗА 6 ЛЕТ ТОЛЬКО 3 РАЗА. ИЗ НИХ, В СВОЮ ОЧЕРЕДЬ, ТОЛЬКО 2 ПРЕДСТАВЛЕНИЯ ИМЕЛИ ОТНОШЕНИЕ К УГОЛОВНЫМ ПРЕСТУПЛЕНИЯМ. ТАК В МАЕ 1821 Г. ИСПОЛНЯЮЩИЙ ДОЛЖНОСТЬ ОЛОНЕЦКОГО ГУБЕРНСКОГО ПРОКУРОРА ГУБЕРНСКИЙ СТРЯПЧИЙ УГОЛОВНЫХ ДЕЛ КАРАБУТОВ, КОТОРОМУ ГЕНЕРАЛ-ГУБЕРНАТОР КЛОКАЧЕВ ЕЩЕ В 1820 Г. ПОРУЧИЛ «ПРИВЕСТИ В ИЗВЕСТНОСТЬ» ИСТИННОЕ КОЛИЧЕСТВО НЕРЕШЕННЫХ И НЕИСПОЛНЕННЫХ ДЕЛ ПО ПЕТРОЗАВОДСКОМУ УЕЗДНОМУ СУДУ, В РАПОРТЕ К НЕМУ СООБЩИЛ, ЧТО ПРИ РАССМОТРЕНИИ ДЕЛА ОБ УБИТОЙ КРЕСТЬЯНКЕ ЕГОРОВОЙ ОН ОБНАРУЖИЛ, ЧТО ЗЕМСКИЙ СУД «СДЕЛАЛ ПОСЛАБЛЕНИЕ К РАСКРЫТИЮ ВИНОВНЫХ, В ЧИСЛЕ КОТОРЫХ СОСТОЯЛА ТЁТКА ПО МУЖУ ЕГОРОВОЙ, ЕЁ МУЖ И СВЁКОР». ОДНАКО НИ УЕЗДНЫЙ СУД, НИ УГОЛОВНАЯ ПАЛАТА, НЕ ПОТРЕБОВАВ НИКАКИХ ДОПОЛНЕНИЙ В СЛЕДСТВИИ, СВОИМИ РЕШЕНИЯМИ ОСТАВИЛИ ИХ ЛИШЬ «В ПОДОЗРЕНИИ». КОГДА ЖЕ КАРАБУТОВ ПРЕДСТАВИЛ СВОЙ РАПОРТ В ПАЛАТУ, ТО ОНА ОТОЗВАЛАСЬ, ЧТО, ТАК КАК ДЕЛО ЕЮ УЖЕ РЕШЕНО И С НИМ СОГЛАСИЛСЯ ГУБЕРНСКИЙ ПРОКУРОР, ТО ОН ОПОЗДАЛ. ТОГДА СТРЯПЧИЙ ОБРАТИЛСЯ К ГУБЕРНАТОРУ, НО И НА ЕГО ПРЕДЛОЖЕНИЕ ПАЛАТА ОТВЕТИЛА ТЕМ ЖЕ. ВСЕ ЭТО ПОНУДИЛО КАРАБУТОВА ОБРАТИТЬСЯ К А.Ф. КЛОКАЧЕВУ. В ОТВЕТ НА ЕГО РАПОРТ ГЕНЕРАЛ-ГУБЕРНАТОР ИСТРЕБОВАЛ ЭТО ДЕЛО ИЗ ПАЛАТЫ И ПРЕДСТАВИЛ ЕГО В СЕНАТ ${ }^{55}$. В ДЕКАБРЕ ЭТОГО ЖЕ ГОДА ГУБЕРНСКИЙ ПРОКУРОР КОЗИН ПРЕДСТАВИЛ КЛОКАЧЕВУ КОПИЮ С ЕГО ПРОТЕСТА ПО ДЕЛУ, РЕШЕННОМУ В ОЛОНЕЦКОЙ УГОЛОВНОЙ ПАЛАТЕ «О ПОСТУПКАХ ПРИКАЗЩИКА ТЕРЕХОВА ПРОТИВ ИСПРАВНИКА СИНЕБАТОВА», КОТОРЫЙ ПАЛАТА ННЕ УВАЖИЛА ${ }^{56}$. В СОХРАНИВШИХСЯ ЖЕ В ФОНДЕ КАНЦЕЛЯРИИ АРХАНГЕЛЬСКОГО ГЕНЕРАЛГУБЕРНАТОРА ВЕДОМОСТЯХ О ПРОТЕСТАХ АРХАНГЕЛЬСКОГО ГУБЕРНСКОГО ПРОКУРОРА НА ПРИГОВОРЫ УГОЛОВНОЙ ПАЛАТЫ ЗА 1821, 1822, 1824, 1827 И 1829 ГГ. ТАКИХ ПРОТЕСТОВ МЫ НЕ НАШЛИ ${ }^{57}$. ОКАЗАЛОСЬ, ЧТО ОСНОВНУЮ ИНФОРМАЦИЮ ОБО ВСЕХ ПРОИСХОДИВШИХ В ГУБЕРНИЯХ УГОЛОВНЫХ ПРЕСТУПЛЕНИЯХ И ИДУЩИХ ПО НИМ ПРОИЗВОДСТВАМ АРХАНГЕЛЬСКИЕ ГЕНЕРАЛ-ГУБЕРНАТОРЫ ПОЛУЧАЛИ ИЗ РАЗНОГО РОДА ВЕДОМОСТЕЙ. ИМЕННО ИХ 8 И 15 АПРЕЛЯ 1820 Г., БУКВАЛЬНО ЧЕРЕЗ НЕСКОЛЬКО ДНЕЙ ПОСЛЕ ВСТУПЛЕНИЯ В ДОЛЖНОСТЬ ГЕНЕРАЛ-ГУБЕРНАТОРА 3-Х СЕВЕРНЫХ ГУБЕРНИЙ, ПРЕДЛОЖИЛ К СЕБЕ РЕГУЛЯРНО ПРЕДСТАВЛЯТЬ ВИЦЕ-АДМИРАЛ А.Ф. КЛОКАЧЕВ, А ИМЕННО: 1) КАЖДЫЕ 2 НЕДЕЛИ - О ПРОИСШЕСТВИЯХ В ГУБЕРНИЯХ, КРАТКИЕ МЕМОРИИ ОБО ВСЕХ ЖУРНАЛАХ И ПРОТОКОЛАХ ГУБЕРНСКИХ ПРАВЛЕНИЙ И ПАЛАТ, 2) НЕМЕДЛЕННО - О ДЕЛАХ И СЛУЧАЯХ ОСОБЕННОЙ ВАЖНОСТИ; 3) ЕЖЕМЕСЯЧНО - КРАТКИЕ ВЕДОМОСТИ О РЕШЕННЫХ И НЕРЕШЕННЫХ ДЕЛАХ ПО ВСЕМ ПРИСУТСТВЕННЫМ МЕСТАМ, В Т. Ч. ПО ИМЕННЫМ, ВЫСОЧАЙШИМ И СЕНАТСКИМ УКАЗАМ, А ТАКЖЕ О ДЕЛАХ ПО УГОЛОВНЫМ ПАЛАТАМ И ОБ АРЕСТАНТАХ И ПОДСУДИМЫХ С ОБЪЯСНЕНИЕМ, «КАКИЕ ПОНУЖДЕНИЯ ПО МЕДЛИТЕЛЬНОСТИ В ИХ ОКОНЧАНИИ ПРИНЯТЫ МЕРЫ ОТ ГУБЕРНСКИХ НАЧАЛЬСТВ». ЛЕТОМ 1823 Г. ОБ ЭТОМ ЖЕ ПОДТВЕРДИЛ ЕГО ПРЕЕМНИК С.И. МИНИЦКИЙ, А 19 СЕНТЯБРЯ 1824 Г. ОН ПОТРЕБОВАЛ ПРИСЫЛАТЬ К СЕБЕ «ДЛЯ СВЕДЕНИЯ» И ЕЖЕМЕСЯЧНЫЕ ВЕДОМОСТИ О РЕШЕННЫХ ДЕЛАХ ПО ПРОИСШЕСТВИЯМ ${ }^{58}$ ВМЕСТЕ С МНЕНИЯМИ НА НИХ ГУБЕРНАТОРА ${ }^{59}$.

31 О ТОМ, ЧТО ЭТИ ВЕДОМОСТИ К ГЕНЕРАЛ-ГУБЕРНАТОРАМ РЕГУЛЯРНО ПРИСЫЛАЛИСЬ, НО, ГЛАВНОЕ, ПРОВЕРЯЛИСЬ, СВИДЕТЕЛЬСТВУЮТ КАК СОХРАНИВШИЕСЯ В ФОНДЕ ИХ КАНЦЕЛЯРИИ ОБЪЕМНЫЕ ПОДШИВКИ ТАКИХ ВЕДОМОСТЕЙ ${ }^{60}$, ТАК И МНОГОЧИСЛЕННЫЕ 
ПРЕДЛОЖЕНИЯ ГЕНЕРАЛ-ГУБЕРНАТОРОВ УГОЛОВНЫМ ПАЛАТАМ И ГУБЕРНСКИМ ПРАВЛЕНИЯМ ПО РЕЗУЛЬТАТАМ ИХ ПРОСМОТРА. ОДНАКО ИЗУЧЕНИЕ ПОСЛЕДНИХ ПОКАЗАЛО, ЧТО, В ОСНОВНОМ, ЭТО БЫЛИ ТРЕБОВАНИЯ УСКОРИТЬ РАССМОТРЕНИЕ ДЕЛ ${ }^{6}$. ВПРОЧЕМ, ВСТРЕЧАЮТСЯ УКАЗАНИЯ И ПО ХОДУ КОНКРЕТНЫХ ДЕЛ. ТАК, НАПРИМЕР, КОГДА ГЕНЕРАЛ-ГУБЕРНАТОР МИНИЦКИЙ ПОЛУЧИЛ РАПОРТ ОТ ПИНЕЖСКОГО ГОРОДНИЧЕГО О ПРОИЗОШЕДШЕЙ У НЕГО В ГОРОДЕ КРАЖЕ, ТО 27 АПРЕЛЯ 1824 Г. ПРИКАЗАЛ ЕМУ НЕМЕДЛЕННО «ОТКРЫТЬ ВОРА». А 30 АПРЕЛЯ 1824 Г., УЗНАВ ИЗ ДОНЕСЕНИЯ СОЛЬВЫЧЕГОДСКОГО УЕЗДНОГО СУДА О ТОМ, ЧТО ОН ОПРАВДАЛ КРЕСТЬЯНИНА РУСАНОВА, ПОДОЗРЕВАЕМОГО В НАНЕСЕНИИ ТЯЖКИХ ПОБОЕВ КРЕСТЬЯНИНУ НОВИНСКОМУ, ПРЕДЛОЖИЛ ВОЛОГОДСКОМУ ГУБЕРНАТОРУ ПРЕДСТАВИТЬ ДЕЛО НА РЕВИЗИЮ В УГОЛОВНУЮ ПАЛАТУ, ТАК КАК ПОЛАГАЛ, ЧТО УЕЗДНЫЙ СУД ПРОИЗВЕЛ «СЛАБЫЕ ДЕЙСТВИЯ К ОТКРЫТИЮ ВИНОВНОГО» И ПОЭТОМУ НЕОБХОДИМО УЧИНИТЬ СТРОГОЕ ИССЛЕДОВАНИЕ И НАЙТИ ВИНОВНОГО, «ДАБЫ ТО НЕ МОГЛО ПОСЛУЖИТЬ ПОВОДОМ К САМИМ СМЕРТОУБИЙСТВАМ», А ЕГО ИЗВЕСТИТЬ О РЕШЕНИИ ПАЛАТЫ ${ }^{62}$.

КРОМЕ ВЕДОМОСТЕЙ УГОЛОВНЫЕ ПАЛАТЫ ПРИСЫЛАЛИ НЕПОСРЕДСТВЕННО К ГЕНЕРАЛГУБЕРНАТОРАМ СВОИ УГОЛОВНЫЕ ПРИГОВОРЫ. ОДНАКО, ПРОИСХОДИЛО ЭТО ЛИШЬ В СЛУЧАЯХ, КОГДА В ГУБЕРНИИ ОТСУТСТВОВАЛ ГУБЕРНАТОР И ЗАМЕЩАЮЩИЙ ЕГО ВИЦЕГУБЕРНАТОР, А ПРЕДСЕДАТЕЛЮ УГОЛОВНОЙ ПАЛАТЫ, КАК ЛИЦУ, КОТОРЫЙ ДОЛЖЕН БЫЛ СЛЕДУЮЩИМ ЗАМЕЩАТЬ ГУБЕРНАТОРА, УТВЕРЖДАТЬ ПРИГОВОРЫ ПО ПОНЯТНЫМ ПРИЧИНАМ БЫЛО ЗАПРЕЩЕНО. ВОЗЬМЕМ ДЛЯ ПРИМЕРА ЕДИНСТВЕННОЕ СОХРАНИВШЕЕСЯ В ФОНДЕ АРХАНГЕЛЬСКОЙ ПАЛАТЫ УГОЛОВНОГО СУДА ДЕЛО С ПРЕДЛОЖЕНИЯМИ ГУБЕРНАТОРА И ГЕНЕРАЛ-ГУБЕРНАТОРА НА ПРИГОВОРЫ ПАЛАТЫ ЗА 1828 Г.: ОКАЗАЛОСЬ, ЧТО С ЯНВАРЯ ПО СЕРЕДИНУ МАРТА, В СВЯЗИ С ОТСУТСТВИЕМ ГУБЕРНАТОРА И ВИЦЕГУБЕРНАТОРА В ГУБЕРНИИ, ВСЕ ПРИГОВОРЫ ОБРАЩАЛИСЬ ПАЛАТОЙ К ГЕНЕРАЛГУБЕРНАТОРУ. В РЕЗУЛЬТАТЕ ОН УТВЕРДИЛ ВСЕ 25 ПРИГОВОРОВ И ЛИШЬ ОДНАЖДЫ СДЕЛАЛ ЗАМЕЧАНИЕ ПАЛАТЕ ПО ДЕЛУ ОБ УДАВИВШЕМСЯ КРЕСТЬЯНИНЕ МАТРЕХИНЕ, УПРЕКНУВ ЕЕ В ТОМ, ЧТО ОНА ПРИ РЕВИЗИИ УПУСТИЛА ИЗ ВИДУ ВАЖНОЕ ОБСТОЯТЕЛЬСТВО - «ПОЧЕМУ ВСКРЫТИЕ ТЕЛА ПРОИЗОШЛО БЕЗ ЛЕКАРЯ» ${ }^{63}$ ?

ДЛЯ РЕПРЕЗЕНТАТИВНОСТИ АНАЛИЗА МЫ ПРОСМОТРЕЛИ ТАКЖЕ ДЕЛО, СОДЕРЖАЩЕЕ ПРИГОВОРЫ АРХАНГЕЛЬСКОЙ ПАЛАТЫ УГОЛОВНОГО СУДА ЗА 1827 Г., ОТПРАВЛЯЕМЫХ НА УТВЕРЖДЕНИЕ К ГУБЕРНАТОРУ. ОКАЗАЛОСЬ, ЧТО ВСЕГО ЗА ЭТОТ ГОД ОН УТВЕРДИЛ 186 ПРИГОВОРОВ, А ГЕНЕРАЛ-ГУБЕРНАТОР МИНИЦКИЙ ВМЕШАЛСЯ ВСЕГО ДВА РАЗА. В ПЕРВЫЙ РАЗ 18 ФЕВРАЛЯ, КОГДА УСМОТРЕЛ ИЗ ВЕДОМОСТИ УГОЛОВНОЙ ПАЛАТЫ ЗА ЯНВАРЬ 1827 Г., ЧТО ДЕЛО ОБ ОСЛУШАНИИ КРЕСТЬЯН ПИНЕЖСКОГО УЕЗДА «ЗАКОНЧЕНО СИЛОЙ» МАНИФЕСТА ОТ 22 АВГУСТА 1826 ГОДА. ГЕНЕРАЛ-ГУБЕРНАТОР ОБРАТИЛ ВНИМАНИЕ ГУБЕРНАТОРА НА ТО, ЧТО «НЕПОВИНОВЕНИЕ ПРОТИВУ НАЧАЛЬСТВА» ЭТИМ МАНИФЕСТОМ НЕ ПРОЩАЕТСЯ И ПОЭТОМУ ПРЕДЛОЖИЛ ЕМУ «О СУЩЕСТВЕ СЕГО ДЕЛА И РЕШЕНИЕ ПО НЕМУ» ДОСТАВИТЬ ЕМУ СВЕДЕНИЕ, ОСТАНОВИВШИСЬ ИСПОЛНЕНИЕМ ПРИГОВОРА. В РЕЗУЛЬТАТЕ, 7 МАРТА, ОЗНАКОМИВШИСЬ С ИСПОЛНИТЕЛЬНЫМ РАПОРТОМ ГУБЕРНАТОРА, МИНИЦКИЙ ПРЕДЛОЖИЛ ГУБЕРНАТОРУ НЕ ОСТАНАВЛИВАТЬСЯ ДАЛЕЕ ПО СЕМУ ИСПОЛНЕНИЕМ». ВТОРОЙ РАЗ ГЕНЕРАЛ-ГУБЕРНАТОР, ПЕРЕДАВ ПРИ СВОЕМ ПРЕДЛОЖЕНИИ ОТ 27 МАРТА ГУБЕРНАТОРУ ПРОШЕНИЕ КРЕСТЬЯНИНА РОЧЕВА О ПОДОЗРЕНИЯХ В УБИЙСТВЕ ЕГО БРАТА КРЕСТЬЯНИНОМ СМЕТАНИНЫМ, ПРОСИЛ ЕГО УВЕДОМИТЬ О РЕЗУЛЬТАТАХ ЕЕ РАССМОТРЕНИЯ. В ОТВЕТ ГУБЕРНАТОР НАПИСАЛ, ЧТО 8 МАРТА ОН УЖЕ УТВЕРДИЛ ПРИГОВОР ПАЛАТЫ И ПОЭТОМУ ПРЕДСТАВЛЯЕТ ПРИГОВОР 
ПАЛАТЫ ГЕНЕРАЛ-ГУБЕРНАТОРУ. ИЗ НЕГО ВИДНО, ПИСАЛ ГУБЕРНАТОР, ЧТО СМЕТАНИН ОСТАВЛЕН В СИЛЬНОМ ПОДОЗРЕНИИ, ТАК КАК НИКТО НЕ МОГ ПРЕДСТАВИТЬ НЕОСПОРИМЫХ ДОКАЗАТЕЛЬСТВ УБИЙСТВА ИМ БРАТА РОЧЕВА. ГУБЕРНАТОР ПРЕДЛАГАЛ ЭТО ДЕЛО НЕ ПЕРЕРАССЛЕДОВАТЬ, «ИБО УЖ ЕСЛИ ПРИ САМОМ НАЧАЛЕ НЕ БЫЛО ОТКРЫТ ПРЯМОЙ ПРЕСТУПНИК, ТО И НЫНЕ ПРОИЗОЙДЕТ НАПРАСНАЯ ПЕРЕПИСКА И ПОТЕРЯ ВРЕМЕНИ». МИНИЦКИЙ, СОГЛАСИВШИСЬ, ПРИКАЗАВ ОТВЕТИТЬ РОЧЕВУ, ЧТО ЕСЛИ У НЕГО НЕТ ЯСНЫХ ДОКАЗАТЕЛЬСТВ, ТО ОН САМ, ЕСЛИ НЕ ПРЕКРАТИТ ДОМОГАТЕЛЬСТВ, БУДЕТ НАКАЗАН ЗА «ПОНОШЕНИЕ» СМЕТАНИНА В УБИЙСТВЕ ${ }^{64}$.

ДРУГИМ ВАЖНЫМ ОСНОВАНИЕМ К ПРИОСТАНОВКЕ АРХАНГЕЛЬСКИМИ ГЕНЕРАЛГУБЕРНАТОРАМИ ИСПОЛНЕНИЯ УЖЕ РЕШЕННЫХ УГОЛОВНЫМИ ПАЛАТАМИ ДЕЛ БЫЛИ ПРОШЕНИЯ ПОТЕРПЕВШИХ И ОБВИНЯЕМЫХ ИЛИ ИХ РОДСТВЕННИКОВ, А ТАКЖЕ ПРЕДСТАВЛЕНИЯ НАЧАЛЬНИКОВ ПО ПОДВЕДОМСТВЕННЫМ ИМ ОСОБЫМ КАТЕГОРИЯМ НАСЕЛЕНИЯ ${ }^{65}$. СДЕЛАЕМ ВЫБОРКУ ПО «ЖУРНАЛУ ИСХОДЯЩИХ БУМАГ» ЗА 1825 Г.

25 ФЕВРАЛЯ ПО ПРОШЕНИЮ КРЕСТЬЯНИНА АРХАНГЕЛЬСКОЙ ГУБЕРНИИ В. БУГАЕВА, КОТОРЫЙ ЖАЛОВАЛСЯ НА УГОЛОВНУЮ ПАЛАТУ ЗА ТО, ЧТО ОНА ЕГО НЕВИННО ПРИГОВОРИЛА К НАКАЗАНИЮ ПЛЕТЬМИ ПО ДЕЛУ УСТЬСЫСОЛЬСКОГО МЕЩАНИНА СУХАНОВА, С.И. МИНИЦКИЙ ПРЕДЛОЖИЛ ВОЛОГОДСКОЙ УГОЛОВНОЙ ПАЛАТЕ «ДОСТАВИТЬ ОБЪЯСНЕНИЕ И ОСТАНОВИТЬСЯ ИСПОЛНЕНИЕМ». УСТЮЖСКАЯ МЕЩАНСКАЯ ВДОВА ПИНЕСКИНОВА ПОЖАЛОВАЛАСЬ ЕМУ НА ТО, ЧТО АРХАНГЕЛЬСКАЯ УГОЛОВНАЯ ПАЛАТА НЕ УЧЛА ПОКАЗАНИЯ СВИДЕТЕЛЕЙ В ЕЁ ПОЛЬЗУ И ПРИГОВОРИЛА ЕЁ К НАКАЗАНИЮ ЗА ЛЖИВЫЙ ДОНОС ОБ ЕЕ ИЗБИЕНИИ МЕЩАНИНОМ КОЛОБОВЫМ. В ОТВЕТ 28 ОКТЯБРЯ ГЕНЕРАЛ-ГУБЕРНАТОР ПРЕДЛОЖИЛ ВОЛОГОДСКОМУ ГУБЕРНАТОРУ РАЗОБРАТЬСЯ «СО ВСЕЙ СПРАВЕДЛИВОСТЬЮ» И ЕСЛИ ПРОСИТЕЛЬНИЦА НЕ ЗАСЛУЖИВАЕТ НАКАЗАНИЯ, ТО ЗАЩИТИТЬ ЕЁ И УВЕДОМИТЬ ОБО ВСЕМ ЕГО. ПОСЛУШНИК СОЛОВЕЦКОГО МОНАСТЫРЯ П. СУББОТИН ПРОСИЛ ГЕНЕРАЛ-ГУБЕРНАТОРА ОБ ОСВОБОЖДЕНИИ ОТ НАКАЗАНИЯ, НАЛОЖЕННОГО НА НЕГО ЗА ВОРОВСТВО АРХАНГЕЛЬСКОЙ УГОЛОВНОЙ ПАЛАТОЙ. В ОТВЕТ 5 НОЯБРЯ ГЕНЕРАЛ-ГУБЕРНАТОР ПРИКАЗАЛ КЕМСКОМУ ГОРОДНИЧЕМУ ОБЪЯСНИТЬ ЕМУ, ЧТО, ТАК КАК ДЕЛО ЕГО ЩОБСУЖДЕНО ПАЛАТОЙ И УТВЕРЖДЕНО ГРАЖДАНСКИМ ГУБЕРНАТОРОМ, ТО И МОЖЕТ ОН ЖАЛОВАТЬСЯ В СЕНАТ, ЕЖЕЛИ СЧИТАЕТ НЕСПРАВЕДЛИВО». 18 НОЯБРЯ ГЕНЕРАЛ-ГУБЕРНАТОР ПО ПРЕДСТАВЛЕНИЮ УПРАВЛЯЮЩЕГО АРХАНГЕЛЬСКОЙ УДЕЛЬНОЙ КОНТОРОЙ ПОТРЕБОВАЛ ОТ АРХАНГЕЛЬСКОЙ УГОЛОВНОЙ ПАЛАТЫ ПРЕДСТАВИТЬ К НЕМУ ВМЕСТЕ С ЕЕ РЕШЕНИЕМ ДЕЛО «ОБ УДЕЛЬНОМ КРЕСТЬЯНИНЕ СЕНЧУКОВЕ, ПРИСУЖДЕННОМУ К ТЕЛЕСНОМУ НАКАЗАНИЮ» И ОСТАНОВИТЬСЯ ИСПОЛНЕНИЕМ ${ }^{66}$. ТЕПЕРЬ ЗАДАДИМСЯ ТАКИМ ВОПРОСОМ - НАСКОЛЬКО ЧАСТО АРХАНГЕЛЬСКИЕ ГЕНЕРАЛГУБЕРНАТОРЫ НЕ СОГЛАШАЛИСЬ С ПРИГОВОРАМИ УГОЛОВНЫХ ПАЛАТ И ВНОСИЛИ (ИЛИ СОБИРАЛИСЬ ВНЕСТИ) ИХ НА ОКОНЧАТЕЛЬНОЕ РАЗРЕШЕНИЕ В СЕНАТ. ЕСЛИ СУДИТЬ ПО «ЖУРНАЛАМ ИСХОДЯЩИХ БУМАГ» ЗА 1820-1825 ГГ., ТО ТАКИЕ ПЕРЕНОСЫ ДЕЛАЛИСЬ ЧРЕЗВЫЧАЙНО РЕДКО. НАПРИМЕР, ПО ОЛОНЕЦКОЙ ГУБЕРНИИ НАМИ ЗАФИКСИРОВАНО ВСЕГО 2 ДЕЛА. ПЕРВОЕ ИЗ НИХ - ДЕЛО ОБ УБИЙСТВЕ КРЕСТЬЯНКИ ЕГОРОВОЙ (О НЕМ МЫ УЖЕ УПОМИНАЛИ ВЫШЕ), БЫЛО ПЕРЕДАНО А.Ф.КЛОКАЧЕВЫМ В СЕНАТ В АВГУСТЕ 1821 ГОДА. ВТОРОЕ ДЕЛО - «О КРАЖЕ КРЕСТЬЯНИНОМ ГЕРАСИМОВЫМ У КУПЦА КЛИМОВА ВЕЩЕЙ» - БЫЛО ЗАТРЕБОВАНО ГЕНЕРАЛ-ГУБЕРНАТОРОМ С.И. МИНИЦКИМ К СЕБЕ ПО СЛЕДУЮЩИМ ОБСТОЯТЕЛЬСТВАМ. В АВГУСТЕ 1824 Г. КРЕСТЬЯНИН ВЫТЕГОРСКОГО УЕЗДА А. ГЕРАСИМОВ ПРИНЁС НА ВЫСОЧАЙШЕЕ ИМЯ ПРОШЕНИЕ О ПЕРЕСМОТРЕ ВЫНЕСЕННОГО 
ЕМУ УГОЛОВНОЙ ПАЛАТОЙ ПРИГОВОРА ПО ОБВИНЕНИЮ ЕГО В ПОКРАЖЕ В 1821 Г. У КУПЦА КЛИМОВА ВЕЩЕЙ НА 479 РУБЛЕЙ. ПАЛАТА ПРИГОВОРИЛА ЕГО К ТЕЛЕСНОМУ НАКАЗАНИЮ И ОТДАЧЕ НА ПОСЕЛЕНИЕ. ИМПЕРАТОР ПРИКАЗАЛ ЭТО ПРОШЕНИЕ ПЕРЕДАТЬ МИНИЦКОМУ «НА ОКОНЧАТЕЛЬНОЕ ЗАКЛЮЧЕНИЕ И НАДЛЕЖАЩЕЕ ПО ОНОМУ РАСПОРЯЖЕНИЕ». В ИТОГЕ, ПОСЛЕ ВЫЯСНЕНИЯ ВСЕХ ОБСТОЯТЕЛЬСТВ ДЕЛА, ГЕНЕРАЛ-ГУБЕРНАТОР СОГЛАСИЛСЯ С МНЕНИЕМ ГУБЕРНАТОРА О ТОМ, ЧТО ОН ДОСТОИН СМЯГЧЕНИЯ НАКАЗАНИЯ ЗА НЕПОЛНЫМ ДОКАЗАТЕЛЬСТВОМ ЕГО ВИНЫ И ПРИКАЗАЛ ОЛОНЕЦКОЙ УГОЛОВНОЙ ПАЛАТЕ ПРИГОТОВИТЬ ДЕЛО ДЛЯ ПЕРЕДАЧИ НА РАССМОТРЕНИЕ В СЕНАТ ${ }^{67}$. ВОЗМОЖНО, ЧТО ТАКОЕ МАЛОЕ КОЛИЧЕСТВО ВНЕСЕННЫХ АРХАНГЕЛЬСКИМИ ГЕНЕРАЛГУБЕРНАТОРАМИ ДЕЛ В СЕНАТ ОБЪЯСНЯЕТСЯ ТЕМ, ЧТО ПОДСУДИМЫЕ, КАК ВИДНО ИЗ ТОГО ЖЕ «ДЕЛА ГЕРАСИМОВА», ДОВОЛЬНО ЧАСТО ИСПОЛЬЗОВАЛИ ДРУГОЙ СПОСОБ, Т. Е. ПОДАВАЛИ ЖАЛОБЫ ИМПЕРАТОРУ ИЛИ СЕНАТУ, ХОТЯ, КАК МЫ ПОМНИМ, ТАКИЕ ЖАЛОБЫ ОТ ЛИЦ «НИЖНЕГО СОСТОЯНИЯ» СЕНАТ ДО 1823 Г. НЕ ДОЛЖЕН БЫЛ ВООБЩЕ ПРИНИМАТЬ, А ПОСЛЕ - ТОЛЬКО ПОСЛЕ ПРИВЕДЕНИЯ НАКАЗАНИЯ В ИСПОЛНЕНИЕ. И, ТЕМ НЕ МЕНЕЕ, КОГДА, НАПРИМЕР, В 1821 Г. МИНИСТР ЮСТИЦИИ ПЕРЕСЛАЛ А.Ф. КЛОКАЧЕВУ ЖАЛОБУ, КОТОРУЮ ПРИНЁС В СЕНАТ КРЕСТЬЯНИН ВЫТЕГОРСКОГО УЕЗДА ПИМЕНОВ НА ЯКОБЫ НЕСПРАВЕДЛИВОЕ ЕГО ПРИСУЖДЕНИЕ УГОЛОВНОЙ ПАЛАТОЙ К 10 УДАРАМ ПЛЕТЬМИ И ССЫЛКЕ НА ПОСЕЛЕНИЕ В СИБИРЬ, ТО В СВОЕМ ОТВЕТЕ ОТ 24 НОЯБРЯ ГЕНЕРАЛГУБЕРНАТОР, ОБЪЯСНИВ МИНИСТРУ ЮСТИЦИИ, ЧТО ПИМЕНОВ И К НЕМУ В 1820 Г. ПРИНОСИЛ ЖАЛОБУ, НО ОЛОНЕЦКАЯ УГОЛОВНАЯ ПАЛАТА, НАЙДЯ ЕЕ ЛОЖНОЙ, СВОИМ РЕШИТЕЛЬНЫМ ПРИГОВОРОМ ОТ 17 АВГУСТА 1820 Г. «ЕГО ЯКО 3-МЯ ПОВАЛЬНЫМИ ОБЫСКАМИ НЕОДОБРЕННОГО» ПРИГОВОРИЛА К ЭТОМУ НАКАЗАНИЮ, КОТОРОЕ ОДОБРИЛ И ГУБЕРНАТОР, ПРЕДЛОЖИЛ ПЕРЕНЕСТИ ДЕЛО В СЕНАТ ${ }^{68}$. ДРУГУЮ ПРИЧИНУ СТОЛЬ МАЛОГО ЧИСЛА ПЕРЕНОСОВ В СЕНАТ УГОЛОВНЫХ ДЕЛ НЕПОСРЕДСТВЕННО АРХАНГЕЛЬСКИМИ ГЕНЕРАЛ-ГУБЕРНАТОРАМИ ПОМОГУТ ПОНЯТЬ СЛЕДУЮЩИЕ ИХ ПРЕДЛОЖЕНИЯ. ПОСЛЕ УПОМИНАВШЕГО НАМИ ВЫШЕ СЛУЧАЯ ВНЕСЕНИЯ ОЛОНЕЦКИМ ГУБЕРНСКИМ ПРОКУРОРОМ КОЗИНЫМ К ГЕНЕРАЛ-ГУБЕРНАТОРУ РАПОРТА С ПРОТЕСТОМ НА ПРИГОВОР ПО ДЕЛУ ЩО ПОСТУПКАХ ПРИКАЗЩИКА ТЕРЕХОВА ПРОТИВ ИСПРАВНИКА СЕНИБАТОВА», 4 ЯНВАРЯ 1822 Г. А.Ф. КЛОКАЧЕВ ПРЕДЛОЖИЛ ОЛОНЕЦКОМУ ГУБЕРНАТОРУ: «ВОЙТИ В ПОДРОБНОСТИ ДЕЛА И ЕСЛИ НАЙДЕТЕ РЕШЕНИЕ ПАЛАТЫ ПРОТИВУРЕЧАЩИМ, А ПРОТЕСТ ПРОКУРОРА ЗАСЛУЖИВАЮЩИМ ЗАКОННОГО УВАЖЕНИЯ, В ТАКОМ СЛУЧАЕ НЕ ОСТАВИТЕ ПРЕДСТАВИТЬ СО СВОИМ МНЕНИЕМ В ПРАВИТЕЛЬСТВУЮЩИЙ СЕНАТ И УВЕДОМИТЬ МЕНЯ». 26 АПРЕЛЯ 1829 Г. С.И. МИНИЦКИЙ ПРЕДЛОЖИЛ АРХАНГЕЛЬСКОЙ УГОЛОВНОЙ ПАЛАТЕ «О ВСЕХ ТЕХ ДЕЛАХ, ПО КОИМ РЕШЕНИЯ ЕЯ НЕ БЫЛИ СОГЛАСОВАНЫ УТВЕРЖДЕНИЕМ Г. НАЧАЛЬНИКА ГУБЕРНИИ, И, СЛЕДОВАТЕЛЬНО, ПРЕДСТАВЛЯЮТСЯ ИМ В СЕНАТ, УВЕДОМЛЯТЬ МЕНЯ В ТО ЖЕ ВРЕМЯ, КАК ДЕЛО БУДЕТ ВНОСИТЬСЯ В СЕНАТ ${ }^{69}$. ТАКИМ ОБРАЗОМ, АРХАНГЕЛЬСКИЕ ГЕНЕРАЛГУБЕРНАТОРЫ В ПОЛНОМ СОГЛАСИИ С УКАЗОМ 1820 Г. ВОЗЛАГАЛИ ОСНОВНЫЕ ДЕЙСТВИЯ ПО ВНЕСЕНИЮ УГОЛОВНЫХ ДЕЛ В СЕНАТ НА ГУБЕРНАТОРОВ, ОСТАВЛЯЯ ЗА СОБОЙ ЛИШЬ ПРАВО БЫТЬ В КУРСЕ ВСЕХ ТАКИХ ДЕЛ.

И ВСЕ ЖЕ В НЕКОТОРЫХ СЛУЧАЯХ АРХАНГЕЛЬСКИЕ ГЕНЕРАЛ-ГУБЕРНАТОРЫ ЭТО ДЕЛАЛИ САМИ. ДЛЯ УСТАНОВЛЕНИЯ ТАКИХ ФАКТОВ МЫ ОБРАТИЛИ СВОЕ ВНИМАНИЕ НА ФОНДЫ V И VI ДЕПАРТАМЕНТОВ СЕНАТА, КУДА В 1820-Е ГОДЫ, СОГЛАСНО УСТАНОВЛЕННОЙ ПРОЦЕДУРЕ, ИЗ ТРЁХ СЕВЕРНЫХ ГУБЕРНИЙ ПОСТУПАЛИ РАПОРТЫ АРХАНГЕЛЬСКИХ ГЕНЕРАЛ-ГУБЕРНАТОРОВ И ГУБЕРНАТОРОВ ПО УГОЛОВНЫМ И СЛЕДСТВЕННЫМ 
(ДОЛЖНОСТНЫМ) ДЕЛАМ ${ }^{70}$. НА СЕГОДНЯШНИЙ ДЕНЬ ПО ОПИСЯМ ЭТИХ ФОНДОВ НАМИ ВЫЯВЛЕНО ВСЕГО 8 ТАКИХ РАПОРТОВ, ПОСТУПИВШИХ НЕПОСРЕДСТВЕННО ОТ АРХАНГЕЛЬСКИХ ГЕНЕРАЛ-ГУБЕРНАТОРОВ. ИЗ НИХ, В СВОЮ ОЧЕРЕДЬ, 2 ВЫБЫЛО, А ОСТАЛЬНЫЕ БЫЛИ ПОДАНЫ ГЕНЕРАЛ-ГУБЕРНАТОРОМ С.И. МИНИЦКИМ. ИЗ ЭТИХ 6 РАПОРТОВ 2 БЫЛИ ПОДАНЫ НА СЛЕДСТВЕННЫЕ (ДОЛЖНОСТНЫЕ), А ОСТАЛЬНЫЕ - НА ТЯЖКИЕ УГОЛОВНЫЕ ПРЕСТУПЛЕНИЯ. ДУМАЕТСЯ, ЧТО КРАТКОЕ ИЗЛОЖЕНИЕ МНЕНИЙ МИНИЦКОГО НА 4 ПОСЛЕДНИХ ДЕЛА ДАСТ НАМ ВОЗМОЖНОСТЬ ВЫЯСНИТЬ, ЧЕМ ОН РУКОВОДСТВОВАЛСЯ, СОГЛАШАЯСЬ ИЛИ НЕ СОГЛАШАЯСЬ С РЕШЕНИЕМ УГОЛОВНЫХ ПАЛАТ, А ТАКЖЕ, КАКОЕ ВЛИЯНИЕ ОКАЗЫВАЛО ЕГО МНЕНИЕ НА ОКОНЧАТЕЛЬНОЕ РЕШЕНИЕ СЕНАТА И ИМПЕРАТОРА, КОГДА ЕГО УЧАСТИЕ БЫЛО НЕОБХОДИМО. В КОНЕЧНОМ СЧЕТЕ, ЭТО ПОЗВОЛИТ ОТВЕТИТЬ НАМ НА ВОПРОС - А БЫЛО ЛИ РАЦИОНАЛЬНОЕ ЗЕРНО В ТОМ, ЧТОБЫ СОХРАНЯТЬ ЗА ГЕНЕРАЛ-ГУБЕРНАТОРАМИ ПРАВО УТВЕРЖДЕНИЯ УГОЛОВНЫХ ПРИГОВОРОВ?

СНАЧАЛА РАССМОТРИМ УГОЛОВНЫЕ ДЕЛА, КАСАЮЩИЕСЯ ПРИВИЛЕГИРОВАННЫХ ЛИЦ. К ТАКОВЫМ ОТНОСИТСЯ ЕДИНСТВЕННОЕ «ДЕЛО О ГУБЕРНСКОМ СЕКРЕТАРЕ А. МИХАЙЛОВЕ И КОЛЛЕЖСКОМ РЕГИСТРАТОРЕ М. ВИДЯКИНЕ». АРХАНГЕЛЬСКАЯ УГОЛОВНАЯ ПАЛАТА «ЗА ПРОЛОМЛЕНИЕ ГОРОДОВОМУ А. ЛЮБОВУ ПОЛУШТОФОМ ГОЛОВЫ» НА ОСНОВАНИИ СТАТЕЙ «ВОИНСКОГО АРТИКУЛА», «ВОИНСКОГО УСТАВА» И «ЖАЛОВАННОЙ ГРАМОТЫ ДВОРЯНСТВУ» ПРИГОВОРИЛА ЭТИХ ЧИНОВНИКОВ К ЛИШЕНИЮ ЧИНОВ И ДВОРЯНСТВА И «ОТДАЧЕ В ВОИНСКУЮ СЛУЖБУ С ВЫСЛУГОЙ, А В СЛУЧАЕ НЕСПОСОБНОСТИ К ОНОЙ ОТОСЛАТЬ В СИБИРЬ НА ПОСЕЛЕНИЕ». СВОИМ РАПОРТОМ ОТ 8 ИЮНЯ 1829 Г. С.И. МИНИЦКИЙ, СОГЛАСИВШИСЬ С ПРИГОВОРОМ УГОЛОВНОЙ ПАЛАТЫ, ВНЁС ЭТО ДЕЛО В СЕНАТ. РАПОРТ БЫЛ ПОДАН ВО ВРЕМЯ ОДНОВРЕМЕННОГО ОТСУТСТВИЯ В ГУБЕРНИИ ГУБЕРНАТОРА И ВИЦЕ-ГУБЕРНАТОРА. ДУМАЕТСЯ, ЧТО ОСНОВНЫМ МОТИВОМ, КОТОРЫМ РУКОВОДСТВОВАЛСЯ В ЭТОМ СЛУЧАЕ МИНИЦКИЙ, БЫЛО ЖЕЛАНИЕ ПОДДЕРЖАТЬ ПРЕСТИЖ ГОСУДАРСТВЕННОЙ ДОЛЖНОСТИ, ТЕМ БОЛЕЕ ЧТО ЭТИ ЧИНОВНИКИ УЖЕ РАНЕЕ СУДИЛИСЬ ЗА ПЬЯНСТВО И БУЙНЫЕ ПОСТУПКИ ${ }^{71}$. СЕНАТ СОГЛАСИЛСЯ С РЕШЕНИЕМ ПАЛАТЫ И МНЕНИЕМ ГЕНЕРАЛ-ГУБЕРНАТОРА, А ИМПЕРАТОР УТВЕРДИЛ ЭТОТ ПРИГОВОР ${ }^{72}$. ОСТАЛЬНЫЕ 3 ДЕЛА КАСАЛИСЬ ЛИЦ НИЗШЕГО СОСТОЯНИЯ. ПЕРВЫМ БЫЛО «ДЕЛО КОЛЧИНА». В СВОЁМ РАПОРТЕ СЕНАТУ ОТ 16 МАРТА 1828 Г. ГЕНЕРАЛ-ГУБЕРНАТОР МИНИЦКИЙ ПИСАЛ, ЧТО ДВОРЯНСКИЙ ЗАСЕДАТЕЛЬ ОНЕЖСКОГО ЗЕМСКОГО СУДА КОЛЧИН ПОЖАЛОВАЛСЯ ЕМУ НА РЕШЕНИЕ АРХАНГЕЛЬСКОЙ УГОЛОВНОЙ ПАЛАТЫ ПО ДЕЛУ ОБ ОСКОРБЛЕНИИ ЕГО ПРИ ИСПОЛНЕНИИ ДОЛЖНОСТИ КРЕСТЬЯНИНОМ И. СЕРЕБРЯКОВЫМ, КОТОРОЕ УЖЕ УТВЕРДИЛ ГУБЕРНАТОР. ПАЛАТА, ОСНОВЫВАЯСЬ НА СТАТЬЯХ «ВОИНСКОГО АРТИКУЛА», НО «ПО УВАЖЕНИЮ СТАРОСТИ ЛЕТ, КОИХ 59, СЛАБОГО И НЕЗДОРОВОГО ТЕЛОСЛОЖЕНИЯ И ЧТО В СЕЙ ПОСТУПОК ОН ВОВЛЕКСЯ КОНЕЧНО НЕ НАМЕРЕННО, НО ПО ПРОСТОТЕ КРЕСТЬЯНСКОЙ», РЕШИЛА ВЫДЕРЖАТЬ СЕРЕБРЯКОВА ПОД АРЕСТОМ ПРИ ЗЕМСКОЙ ИЗБЕ НА ХЛЕБЕ И ВОДЕ 2 НЕДЕЛИ И «СВЕРХ ТОГО» ПРОСИТЬ У КОЛЧИНА, «СТОЯ НА КОЛЕНЯХ, ХРИСТИАНСКОГО ПРОЩЕНИЯ». С.И. МИНИЦКИЙ НЕ СОГЛАСИЛСЯ С ТАКИМ РЕШЕНИЕМ ПАЛАТЫ И ГУБЕРНАТОРА, ОБРАТИВ ВНИМАНИЕ СЕНАТА НА ТО, ЧТО КРЕСТЬЯНИН ОСКОРБИЛ ЗАСЕДАТЕЛЯ НАМЕРЕННО, ПРИДЯ ДЛЯ ЭТОГО К НЕМУ НА КВАРТИРУ В ПЬЯНОМ ВИДЕ; ЧТО ПО РЕЗУЛЬТАТАМ ПРОВЕДЁННОГО ПО ЕГО ТРЕБОВАНИЮ МЕДИЦИНСКОГО ОСВИДЕТЕЛЬСТВОВАНИЯ ОКАЗАЛОСЬ, ЧТО СЕРЕБРЯКОВ В ЦЕЛОМ ЗДОРОВ; ЧТО ЕГО ПОВЕДЕНИЕ НЕ ОДОБРИЛИ НА ПОВАЛЬНОМ ОБЫСКЕ 40 «СОСЕДЕЙОДНОВОЛОСТНИКОВ». ПОЭТОМУ, КАК ПИСАЛ ДАЛЕЕ ГЕНЕРАЛ-ГУБЕРНАТОР, СЕРЕБРЯКОВ НЕ ЗАСЛУЖИВАЕТ «ОКАЗАННОГО ЕМУ УГОЛОВНОЙ ПАЛАТОЮ СНИСХОЖДЕНИЯ И ДАБЫ 
УДЕРЖАТЬ ЕГО НА БУДУЩЕЕ ВРЕМЯ ОТ ПЬЯНСТВА И ДЕРЗОСТЕЙ И В СТРАХ КАК ЕМУ СОБСТВЕННО, ТАК И ДРУГИМ ЕМУ ПОДОБНЫМ, ЧТОБ НЕ ОСМЕЛИВАЛСЯ ОСКОРБЛЯТЬ ПОЛИЦЕЙСКИХ ЧИНОВНИКОВ», ОН ПРЕДЛАГАЛ НАКАЗАТЬ ЕГО 50 УДАРАМИ РОЗОГ. МОТИВ, ДВИГАВШИЙ ГЕНЕРАЛ-ГУБЕРНАТОРОМ ПРИ ОСПАРИВАНИИ ЭТОГО ПРИГОВОРА, ОЧЕВИДЕН. ГЛАВНЫМ АРГУМЕНТОМ ПРОТИВ РЕШЕНИЯ ПАЛАТЫ СТАЛИ НЕКОТОРЫЕ ДОПУЩЕННЫЕ ЕЮ УПУЩЕНИЯ В ПРОЦЕДУРЕ СБОРА ДОКАЗАТЕЛЬСТВ. ОДНАКО СЕНАТ, РАССМОТРЕВ ЭТО ДЕЛО 17 ЯНВАРЯ 1829 Г., НАШЁЛ РЕШЕНИЕ УГОЛОВНОЙ ПАЛАТЫ ПРАВИЛЬНЫМ, ПРИНЯВ ВО ВНИМАНИЕ ТАКИЕ ПРИВЕДЕННЫЕ ЕЮ СМЯГЧАЮЩИЕ ОБСТОЯТЕЛЬСТВА КАК ВОЗРАСТ ПРЕСТУПНИКА И ЕГО КРЕСТЬЯНСКУЮ «ПРОСТОТУ» ${ }^{73}$.

В СВОЁМ ВТОРОМ РАПОРТЕ СЕНАТУ ОТ 26 ОКТЯБРЯ 1828 Г. С.И. МИНИЦКИЙ НЕ СОГЛАСИЛСЯ С РЕШЕНИЕМ АРХАНГЕЛЬСКОЙ УГОЛОВНОЙ ПАЛАТЫ ПО ДЕЛУ «О НЕПОЗВОЛИТЕЛЬНОМ ПРИВОЗЕ КРЕСТЬЯНИНОМ АФОНАСИЕМ КОРКОНОСОВЫМ ИЗ НОРВЕГИИ В АРХАНГЕЛЬСК РЫБЫ И О КУПЦЕ ЕРМОЛИНЕ». ГЕНЕРАЛ-ГУБЕРНАТОР ПИСАЛ, ЧТО К НЕМУ ОБРАТИЛИСЬ С ЖАЛОБАМИ ОТЕЦ И СЫН КОРКОНОСОВЫ, СЧИТАВШИЕ, ЧТО ПАЛАТА НЕСПРАВЕДЛИВО ПРИГОВОРИЛА ЗА ПРОВОЗ КОНТРАБАНДНОГО ТОВАРА ТОЛЬКО ОДНОГО КОРКОНОСОВА, КОТОРОМУ, К ТОМУ ЖЕ, ПО ЕГО НЕСОСТОЯТЕЛЬНОСТИ, ИМУЩЕСТВЕННОЕ НАКАЗАНИЕ В ВИДЕ ПЛАТЕЖА В КАЗНУ ПОЛОЖЕННЫХ ПЕНИ И ШТРАФА «НА МНОГОТЫСЯЧНУЮ СУММУ» БЫЛО ЗАМЕНЕНО 10 УДАРАМ ПЛЕТЕЙ И ССЫЛКОЙ В СИБИРЬ НА ПОСЕЛЕНИЕ. НАСТОЯЩИМ ВЛАДЕЛЬЦЕМ ТОВАРА, ПИСАЛИ ОНИ, БЫЛ КУПЕЦ ЕРМОЛИН, КОТОРЫЙ БЫЛ ВООБЩЕ ОСВОБОЖДЕН ОТ ВЗЫСКАНИЯ. ВЫТРЕБОВАВ К СЕБЕ И ПРОСМОТРЕВ ЭТО ДЕЛО, МИНИЦКИЙ ПРЕДЛАГАЛ: ПРИЗНАТЬ КУПЦА ЕРМОЛИНА ТАКЖЕ ХОЗЯИНОМ ГРУЗА И ПОДВЕРГНУТЬ ЕГО ПОЛОЖЕННОМУ ВЗЫСКАНИЮ «В ПОЛНОМ КОЛИЧЕСТВЕ, ПРЕДОСТАВИВ, ВПРОЧЕМ, ЕМУ ВЗЯТЬ С КОРКОНОСОВА ПОЛОЖЕННУЮ ЕМУ ЧАСТЬ», А САМОМУ КОРКОНОСОВУ СМЯГЧИТЬ ХОТЯ БЫ ВТОРУЮ ЧАСТЬ ПРИГОВОРА (ТЕЛЕСНОЕ НАКАЗАНИЕ БЫЛО С СОГЛАСИЯ ГУБЕРНАТОРА УЖЕ ПРИВЕДЕНО В ИСПОЛНЕНИЕ) «ПО УВАЖЕНИЮ ДОБРОВОЛЬНОГО ПРИЗНАНИЯ ЕГО», А ИМЕННО - ОСТАВИТЬ ЕГО В СЕЛЕНИИ «БЕЗ ПРАВА ВПРЕДЬ ОТЪЕЗДА ИЗ НЕГО». МОТИВЫ ТАКОГО МНЕНИЯ ГЕНЕРАЛГУБЕРНАТОРА НАМ ОЧЕВИДНЫ. ЭТО, ВО-ПЕРВЫХ, ЗАБОТА О РЕАЛЬНОМ ПОПОЛНЕНИИ КАЗНЫ ЗА СЧЕТ СРЕДСТВ СОСТОЯТЕЛЬНОГО КУПЦА ЕРМОЛИНА - НАСТОЯЩЕГО ХОЗЯИНА ГРУЗА. И, ВО-ВТОРЫХ, СЛЕДУЕТ ИМЕТЬ В ВИДУ, ЧТО АДМИНИСТРАЦИЯ АРХАНГЕЛЬСКОЙ ГУБЕРНИИ ВЕСЬМА НЕГАТИВНО ОТНОСИЛАСЬ К РАЗРЕШЕННОЙ ПРАВИТЕЛЬСТВОМ МЕНОВОЙ ТОРГОВЛЕ С НОРВЕГИЕЙ, ПОД ВИДОМ КОТОРОЙ ВЕСЬМА ЧАСТО ПРОИЗВОДИЛАСЬ КОНТРАБАНДНАЯ ТОРГОВЛЯ ЗАПРЕЩЕННЫМИ ТОВАРАМИ, С КОТОРЫМИ И БЫЛО ПОЙМАНО СУДНО ПОД УПРАВЛЕНИЕМ КОРКОНОСОВА. ОДНАКО СЕНАТ, РАССМОТРЕВ 13 ФЕВРАЛЯ 1830 Г. ЭТО ДЕЛО И НЕ НАЙДЯ ПОЛНОСТЬЮ ДОКАЗАННЫМ ФАКТ ПРИНАДЛЕЖНОСТИ ГРУЗА КУПЦУ ЕРМОЛИНУ, ОСТАВИЛ ПРИГОВОР УГОЛОВНОЙ ПАЛАТЫ В ЕГО ОТНОШЕНИИ В СИЛЕ, А С КОРКОНОСОВЫМ ВЕЛЕЛ ПОСТУПИТЬ «КАК С КАЗЕННЫМ ДОЛЖНИКОМ». В РЕЗУЛЬТАТЕ ВЗАМЕН ССЫЛКИ В СИБИРЬ ОН БЫЛ ОТДАН АРХАНГЕЛЬСКИМ ГУБЕРНСКИМ ПРАВЛЕНИЕМ В ЧАСТНУЮ РАБОТУ К КРЕСТЬЯНИНУ АНЦИФИРОВУ «ИЗ ПЛАТЕЖА В КАЗНУ ПО 100 РУБЛЕЙ В ГОД» В ОБЕСПЕЧЕНИЕ НАЛОЖЕННОГО НА НЕГО ВЗЫСКАНИЯ ${ }^{74}$.

СВОИМ ТРЕТЬИМ РАПОРТОМ ОТ 17 АВГУСТА 1829 Г. С.И. МИНИЦКИЙ ОСПОРИЛ РЕШЕНИЕ ОЛОНЕЦКОЙ УГОЛОВНОЙ ПАЛАТЫ ПО «ДЕЛУ О КРЕСТЬЯНСКОЙ ДЕВКЕ ФЕДОСЬЕ ПАВЛОВОЙ». ГЕНЕРАЛ-ГУБЕРНАТОР ПИСАЛ, ЧТО УСМОТРЕВ ИЗ МЕМОРИИ ПАЛАТЫ О РЕШЕНИИ ЭТОГО ДЕЛА И ВЫТРЕБОВАВ ЕГО К СЕБЕ, НАШЕЛ ПРИГОВОР ПАЛАТЫ «НЕСОВЕРШЕННО СОГЛАСНЫМ С СУЩЕСТВОМ САМОГО ДЕЛА И ОСНОВАННЫМ НЕ НА СТРОГОЙ СПРАВЕДЛИВОСТИ». ПАВЛОВА, БЫВШАЯ С 14 ЛЕТ БОЛЕЕ ДВУХ ЛЕТ В 
РАБОТНИЦАХ У КРЕСТЬЯНИНА ЕГОРА ЕВДОКИМОВА, СОЖГЛА В 1828 Г. ЕГО ДОМ В ОТМЕСТКУ ЗА ТО, ЧТО ЕГО БРАТ ГЕРАСИМ, ЖИВШИЙ В ДОМЕ Е. ЕВДОКИМОВА И РАСТЛИВШИЙ ЕЕ ОБЕЩАНИЕМ «ВЗЯТЬ В ЗАМУЖЕСТВО», ЖЕНИЛСЯ НА ДРУГОЙ. МИНИЦКИЙ СЧИТАЛ, ЧТО ХОТЯ ПАЛАТА И НЕ ИМЕЛА ПРАВА СОГЛАСНО СТАТЬЯМ «ВОИНСКОГО ПРОЦЕССА» ПРОВОДИТЬ ПЕРЕДОПРОС ГЛАВНОГО СВИДЕТЕЛЯ - МАТЕРИ СОБЛАЗНИТЕЛЯ, ТАК КАК ОНА УЖЕ БЫЛА РАНЕЕ ДОПРОШЕНА ЗЕМСКИМ ИСПРАВНИКОМ МАЛЕВИНСКИМ БЕЗ ПРИСЯГИ (ИМЕННО ЭТО И ПОЗВОЛИЛО МАТЕРИ, КАК ПОЛАГАЛ ГЕНЕРАЛ-ГУБЕРНАТОР, ПОКАЗАТЬ В ПОЛЬЗУ СЫНА), ВСЕ ЖЕ ДОЛЖНА БЫЛА ПРИНЯТЬ ВО ВНИМАНИЕ ЭТО ОБСТОЯТЕЛЬСТВО. В РЕЗУЛЬТАТЕ, ТАКОЕ «ОТСТУПЛЕНИЕ» ИСПРАВНИКА, ПОДЧЕРКИВАЛ ГЕНЕРАЛ-ГУБЕРНАТОР, «ЗАТМИЛО ИСТИНУ И ПРЕСТУПНИК, РАСТЛИВШИЙ МАЛОЛЕТНЮЮ ПАВЛОВУ [...], ИЗБЕЖАЛ ЗАСЛУЖЕННОГО НАКАЗАНИЯ», ТАК КАК «НЕ СОЗНАВШИСЬ НИ В ЧЕМ», БЫЛ ПАЛАТОЮ ОПРАВДАН, А «ВСЯ ТЯЖЕСТЬ ОБВИНЕНИЯ ПАЛА НА ПАВЛОВУ, ВЕРОЯТНОСТЬ ПОКАЗАНИЙ КОЕЙ В СДЕЛАННОЙ ЕЙ НАСИЛИИ, НЕ ОПРОВЕРГАЕТСЯ И САМОЮ ПАЛАТОЮ». В ЗАКЛЮЧЕНИИ МИНИЦКИЙ ПРЕДЛАГАЛ ЗА ДОБРОВОЛЬНОЕ ПРИЗНАНИЕ ОСВОБОДИТЬ ПАВЛОВУ, ПРИГОВОРЕННУЮ ПАЛАТОЙ К НАКАЗАНИЮ КНУТОМ И ССЫЛКЕ В КАТОРЖНУЮ РАБОТУ, «ВМЕНИТЬ ЕЙ В ОНОЕ ПРОДОЛЖИТЕЛЬНОЕ СОДЕРЖАНИЕ В ТЮРЬМЕ И СОСЛАТЬ НА ПОСЕЛЕНИЕ». 4 СЕНТЯБРЯ 1829 Г. СЕНАТ, РАССМОТРЕВ ЭТО ДЕЛО, СОГЛАСИЛСЯ С РЕШЕНИЕМ УГОЛОВНОЙ ПАЛАТЫ, КОТОРАЯ СОВЕРШЕННО НА ЗАКОННЫХ ОСНОВАНИЯХ ВЫНУЖДЕНА БЫЛА ПРИЗНАТЬ ФАКТ СОБЛАЗНЕНИЯ ПАВЛОВОЙ НЕДОКАЗАННЫМ, НО ПРИ ЭТОМ СЧЕЛ НУЖНЫМ, ПРОЯВЛЯЯ НЕКОТОРОЕ МИЛОСЕРДИЕ К НЕЙ, СОКРАТИТЬ ЧИСЛО УДАРОВ КНУТОМ С ДЕСЯТИ ДО одного ${ }^{75}$.

ВАЖНО ТАКЖЕ ЗАМЕТИТЬ, ЧТО ПРИВЕДЕННЫЕ ВЫШЕ ПРИМЕРЫ, КАЖЕТСЯ, НЕ ИСЧЕРПЫВАЮТ СОБОЙ ВСЕ УГОЛОВНЫЕ ПРИГОВОРЫ, КОТОРЫЕ ПО РАПОРТАМ АРХАНГЕЛЬСКИХ ГЕНЕРАЛ-ГУБЕРНАТОРОВ РАССМОТРЕЛ СЕНАТ. НАПРИМЕР, МЫ НАШЛИ ДЕЛО, КОТОРОЕ НЕ ЗНАЧИТСЯ В ОПИСЯХ 5-ГО ДЕПАРТАМЕНТА СЕНАТА, ХОТЯ И БЫЛО РЕШЕНО ИМ. ЭТО УЖЕ УПОМЯНУТОЕ НАМИ ВЫШЕ «ДЕЛО УДЕЛЬНОГО КРЕСТЬЯНИНА СЕНЧУКОВА». СЕНЧУКОВ ОТНОСИЛСЯ К ГРУППЕ ПРИВИЛЕГИРОВАННЫХ ЛИЦ, ТАК КАК ИМЕЛ ЗНАК ОТЛИЧИЯ ВОЕННОГО ОРДЕНА И СЕРЕБРЯНУЮ МЕДАЛЬ ЗА УЧАСТИЕ В ВОЙНЕ 1812 ГОДА. ОБВИНЯЛСЯ В ПОДЖОГЕ СВОЕГО ДОМА И ОСКОРБЛЕНИИ РОДИТЕЛЕЙ. КАК УКАЗЫВАЛ В СВОЕМ ОТНОШЕНИИ К ГЕНЕРАЛ-ГУБЕРНАТОРУ МИНИЦКОМУ УПРАВЛЯЮЩИЙ УДЕЛЬНОЙ КОНТОРОЙ, АРХАНГЕЛЬСКАЯ УГОЛОВНАЯ ПАЛАТА, НЕ СМОТРЯ НА ОТСУТСТВИЕ ЕГО СОБСТВЕННОГО ПРИЗНАНИЯ И «ОДОБРЕНИЯ» ЕГО ПОВЕДЕНИЯ 42 ОДНОСЕЛЬЧАНАМИ, ПРИНЯВ «В УВАЖЕНИЕ» ТОЛЬКО УДОСТОВЕРЕНИЕ ЕГО РОДИТЕЛЕЙ, РОДНОГО БРАТА И ЖЕНЫ БРАТА, НА ОСНОВАНИИ СТАТЕЙ СОБОРНОГО УЛОЖЕНИЯ 1649 Г. И «ВОИНСКОГО АРТИКУЛА» ПРИГОВОРИЛА ЕГО К 25 УДАРАМ КНУТА, ЛИШЕНИЮ НАГРАД И ССЫЛКЕ В КАТОРЖНЫЕ РАБОТЫ. УПРАВЛЯЮЩИЙ ОБРАЩАЛ ВНИМАНИЕ ГЕНЕРАЛ-ГУБЕРНАТОРА НА «ЧРЕЗМЕРНО ОТЯГОТИТЕЛЬНОЕ НАКАЗАНИЕ» ДАЖЕ ПО СРАВНЕНИЮ С РЕШЕНИЕМ УЕЗДНОГО СУДА ${ }^{76}$, КОТОРОЕ, В СВОЮ ОЧЕРЕДЬ, УДЕЛЬНАЯ КОНТОРА НАХОДИЛА ТАКЖЕ «ТЯГОСТНЫМ». В РЕЗУЛЬТАТЕ, КАК ПИСАЛ ДАЛЬШЕ УПРАВЛЯЮЩИЙ, ОН ПРОСИЛ УГОЛОВНУЮ ПАЛАТУ СМЯГЧИТЬ ПРИГОВОР, НО ОНА ЕЩЕ БОЛЕЕ ОТЯГОТИЛА ЕГО. В СВЯЗИ С ЭТИМ УПРАВЛЯЮЩИЙ ПРОСИЛ ГЕНЕРАЛ-ГУБЕРНАТОРА ВНОВЬ ВОЙТИ В РАССМОТРЕНИЕ ОБСТОЯТЕЛЬСТВ ДЕЛА, А ДО ЭТОГО ПРИОСТАНОВИТЬ ИСПОЛНЕНИЕ ПРИГОВОРА. С.И. МИНИЦКИЙ, ВЫТРЕБОВАВ К СЕБЕ ДЕЛО, СОГЛАСИЛСЯ С ДОВОДАМИ СТРЯПЧЕГО УДЕЛЬНОЙ КОНТОРЫ, ОПРОТЕСТОВАВШЕГО ПРИГОВОР НА ОСНОВАНИИ ПРОТИВОРЕЧИЯ В ПОКАЗАНИЯХ РОДНЫХ СЕНЧУКОВА. В СВОЕМ МНЕНИИ СЕНАТУ МИНИЦКИЙ ПОЛАГАЛ, ЧТО 
ВИНА СЕНЧУКОВА В ПОДЖОГЕ НЕ ДОКАЗАНА И ПОЭТОМУ НА ОСНОВАНИИ СТАТЕЙ «ВОИНСКОГО АРТИКУЛА И ПРОЦЕССА» ${ }^{77}$ ОН ДОЛЖЕН БЫТЬ ВООБЩЕ ОСВОБОЖДЕН ОТ ОТВЕТСТВЕННОСТИ. ЧТО ЖЕ КАСАЕТСЯ ПРЕДЪЯВЛЕННОГО ЕМУ ОБВИНЕНИЯ В ОСКОРБЛЕНИИ РОДИТЕЛЕЙ, ТО ОНИ, ЕСЛИ ЗАХОТЯТ, ПОЛАГАЛ ГЕНЕРАЛ-ГУБЕРНАТОР, МОГУТ ОБРАТИТЬСЯ В СОВЕСТНЫЙ СУД. СЕНАТ СОГЛАСИЛСЯ С МНЕНИЕМ ГЕНЕРАЛГУБЕРНАТОРА В 1-Й ЧАСТИ, А ПО 2-Й УКАЗАЛ, ЧТО ЭТО ОСКОРБЛЕНИЕ ПОКРЫВАЕТСЯ МАНИФЕСТОМ ОТ 22 АВГУСТА 1826 ГОДА. ГОСУДАРЬ УТВЕРДИЛ ЭТО РЕШЕНИЕ БЕЗ ИЗМЕНЕНИЯ ${ }^{78}$. ДАННОЕ ДЕЛО ЯВЛЯЕТСЯ ЯРКИМ ПРИМЕРОМ НАРУШЕНИЯ СО СТОРОНЫ УЕЗДНОГО СУДА И УГОЛОВНОЙ ПАЛАТЫ ПРОЦЕДУРЫ ОЦЕНИВАНИЯ ДОКАЗАТЕЛЬСТВ. ДУМАЕМ, ЧТО НЕ ПОСЛЕДНЮЮ РОЛЬ ЗДЕСЬ СЫГРАЛИ И ЗАСЛУГИ ОБВИНЯЕМОГО.

ИТАК, В ЭТОЙ ЧАСТИ НАШЕЙ СТАТЬИ МЫ ВЫЯСНИЛИ, ЧТО ОСНОВНЫМ ИСТОЧНИКОМ ИНФОРМАЦИИ ДЛЯ АРХАНГЕЛЬСКИХ ГЕНЕРАЛ-ГУБЕРНАТОРОВ ОБО ВСЕХ СОВЕРШАЕМЫХ В ИХ ГУБЕРНИЯХ УГОЛОВНЫХ ПРЕСТУПЛЕНИЯХ БЫЛИ РЕГУЛЯРНО ПРЕДСТАВЛЯЕМЫЕ К НИМ НА ПРОСМОТР ВЕДОМОСТИ ОТ УЕЗДНЫХ, ГУБЕРНСКИХ ПОЛИЦЕЙСКИХ, ПРОКУРОРСКИХ И СУДЕБНЫХ МЕСТ, А ТАКЖЕ ЖАЛОБЫ УЧАСТНИКОВ ПРОЦЕССА ИЛИ ИХ РОДСТВЕННИКОВ, А ТАКЖЕ УПРАВЛЯЮЩИХ ОСОБЫМИ КАТЕГОРИЯМИ НАСЕЛЕНИЯ. ДАЖЕ В СЛУЧАЕ, ЕСЛИ ЭТИ ЖАЛОБЫ БЫЛИ ОБРАЩАЕМЫ НЕ К САМИМ ГЕНЕРАЛ- ГУБЕРНАТОРАМ, А К СЕНАТУ ИЛИ ИМПЕРАТОРУ, ТО ОНИ ВСЕ РАВНО СТАНОВИЛИСЬ ИЗВЕСТНЫМ ИМ. ВСЕ ЭТО ПОЗВОЛЯЛО ГЕНЕРАЛ-ГУБЕРНАТОРАМ ОТСЛЕЖИВАТЬ ХОД ЛЮБОГО УГОЛОВНОГО ПРЕСТУПЛЕНИЯ, НАЧИНАЯ С МОМЕНТА ЕГО СОВЕРШЕНИЯ, И ЗАКАНЧИВАЯ ВЫНЕСЕНИЕМ УГОЛОВНОЙ ПАЛАТОЙ ПРИГОВОРА ПО НЕМУ. ТАКЖЕ МЫ УСТАНОВИЛИ, ЧТО ТОЛЬКО В СЛУЧАЯХ ОТСУТСТВИЯ ГУБЕРНАТОРА ИЛИ ЗАМЕЩАЮЩИХ ИХ ПО ЗАКОНУ ЛИЦ, АРХАНГЕЛЬСКИЕ ГЕНЕРАЛ-ГУБЕРНАТОРЫ БРАЛИ НА СЕБЯ ФУНКЦИИ ПО УТВЕРЖДЕНИЮ УГОЛОВНЫХ ПРИГОВОРОВ. ОДНАКО СЛУЧАИ ПОДАЧИ ОТ ИХ ЛИЦА РАПОРТОВ В СЕНАТ КРАЙНЕ РЕДКИ. ВСЕГО МЫ СМОГЛИ ОБНАРУЖИТЬ ЗА 10 ЛЕТ СУЩЕСТВОВАНИЯ АРХАНГЕЛЬСКОГО ГЕНЕРАЛГУБЕРНАТОРСТВА (1820-1830 ГГ.) ПО ОПИСЯМ СЕНАТА 8 ТАКИХ ДЕЛ И ЕЩЕ ОДНО ДЕЛО, РЕШЕННОЕ СЕНАТОМ, НО НЕ ЗАФИКСИРОВАННОЕ В ЕГО ОПИСЯХ. ИСКЛЮЧИВ ИЗ СВОЕГО РАССМОТРЕНИЯ 2 ВЫБЫВШИХ ДЕЛА, А ТАКЖЕ 2 ДЕЛА, ЗАКЛЮЧАВШИХ В СЕБЕ ДОЛЖНОСТНЫЕ ПРЕСТУПЛЕНИЯ, МЫ ПРОСЛЕДИЛИ В СВОЕЙ СТАТЬЕ СУДЬБУ 5 УГОЛОВНЫХ ПРИГОВОРОВ. В РЕЗУЛЬТАТЕ, ОКАЗАЛОСЬ, ЧТО ГЕНЕРАЛ-ГУБЕРНАТОР МИНИЦКИЙ СОГЛАСИЛСЯ ТОЛЬКО С ОДНИМ ИЗ НИХ, А В ОСТАЛЬНЫЕ 4 ОСПОРИЛ. В ПЕРВОМ СЛУЧАЕ ОН ПОЛНОСТЬЮ СОГЛАСИЛСЯ С ПРИГОВОРОМ, ОСУДИВШИМ ЧИНОВНИКОВ МИХАЙЛОВА И ВИДЯКИНА, ТАК КАК НЕ МОГ НЕ ЗАБОТИТЬСЯ О ДОСТОИНСТВЕ ГОСУДАРСТВЕННОЙ ДОЛЖНОСТИ, В ЧЕМ С НИМ СОГЛАСИЛИСЬ СЕНАТ И ЦАРЬ. ОДНАКО КОГДА ПО ЖАЛОБЕ ЧИНОВНИКА КОЛЧИНА ГЕНЕРАЛ-ГУБЕРНАТОР ПРЕДЛОЖИЛ УЖЕСТОЧИТЬ НАКАЗАНИЕ КРЕСТЬЯНИНУ, ОСКОРБИВШЕМУ КОЛЧИНА ПРИ ИСПОЛНЕНИИ ИМ СВОИХ СЛУЖЕБНЫХ ОБЯЗАННОСТЕЙ, СЕНАТ НЕ СОГЛАСИЛСЯ С ТАКИМ ПРЕДЛОЖЕНИЕМ, ПРИНЯВ ВО ВНИМАНИЕ СМЯГЧАЮЩИЕ ОБСТОЯТЕЛЬСТВА, ИСПОЛЬЗОВАВШИЕСЯ УГОЛОВНОЙ ПАЛАТОЙ ПРИ ПОСТАНОВКЕ ПРИГОВОРА. В «ДЕЛАХ» ЖЕ КРЕСТЬЯН КОРКОНОСОВА И ПАВЛОВОЙ ГЕНЕРАЛ-ГУБЕРНАТОР ПРЕДЛОЖИЛ СЕНАТУ СМЯГЧИТЬ, А В СЛУЧАЕ С УДЕЛЬНЫМ КРЕСТЬЯНИНОМ СЕНЧУКОВЫМ ДАЖЕ ОТМЕНИТЬ НАКАЗАНИЕ, ССЫЛАЯСЬ НА ЖЕСТОКОСТЬ ДЕЙСТВОВАВШИХ УГОЛОВНЫХ ЗАКОНОВ И НАРУШЕНИЕМ СУДАМИ ПРОЦЕССУАЛЬНЫХ НОРМ ПРИ РАССМОТРЕНИИ ЭТИХ ДЕЛ. В РЕЗУЛЬТАТЕ СЕНАТ ПОШЕЛ НА НЕКОТОРОЕ СМЯГЧЕНИЕ УЧАСТИ КОРКОНОСОВА И ПАВЛОВОЙ, А СЕНЧУКОВА ВООБЩЕ ОСВОБОДИЛ ОТ ОТВЕТСТВЕННОСТИ. ТАКИМ ОБРАЗОМ, СЛЕДУЕТ ПРИЗНАТЬ, ЧТО В ЦЕЛОМ ГЕНЕРАЛГУБЕРНАТОРЫ ВЫПОЛНИЛИ СВОЕ ПРЕДНАЗНАЧЕНИЕ, ПРЕДПИСАННОЕ ИМ ЕЩЕ 
ЕКАТЕРИНИНСКИМ ЗАКОНОДАТЕЛЬСТВОМ ПО ОТНОШЕНИЮ К ЛИЦАМ «НИЖНЕГО СОСТОЯНИЯ», КОТОРЫЕ С 1784 Г. БЫЛИ ВООБЩЕ ЛИШЕНЫ ПРАВА АПЕЛЛЯЦИИ ДО МОМЕНТА СОВЕРШЕНИЯ НАД НИМИ НАКАЗАНИЯ.

\section{Заключение}

ОСНОВНАЯ ИДЕЯ НАШЕЙ СТАТЬИ СОСТОЯЛА В ТОМ, ЧТОБЫ НЕСКОЛЬКО ПОКОЛЕБАТЬ УСТОЯВШЕЕСЯ В ОТЕЧЕСТВЕННОЙ ИСТОРИОГРАФИИ МНЕНИЕ О ТОМ, ЧТО СОХРАНЕННОЕ ЕКАТЕРИНОЙ ІІ В «УЧРЕЖДЕНИЯХ ДЛЯ ГУБЕРНИЙ» 1775 Г. ЗА ГЕНЕРАЛ-ГУБЕРНАТОРАМИ ПРАВО УТВЕРЖДАТЬ УГОЛОВНЫЕ ПРИГОВОРЫ ЕЩЕ БОЛЕЕ УСУГУБЛЯЛО НЕДОСТАТКИ ГОСПОДСТВОВАВШЕГО В РОССИЙСКОЙ ИМПЕРИИ СЛЕДСТВЕННОГО (ИНКВИЗИЦИОННОГО) ПРОЦЕССА. ДЛЯ ЭТОГО МЫ ИЗУЧИЛИ ИСТОРИЮ ЗАРОЖДЕНИЯ ЭТОГО ПРАВА, НАЧАВ С ПОИСКА ИДЕИ, ПОСЛУЖИВШЕЙ ЕКАТЕРИНЕ II ОСНОВАНИЕМ ДЛЯ СОХРАНЕНИЯ ЕГО В РУССКОМ УГОЛОВНОМ ПРОЦЕССЕ, ЗАТЕМ ПРОСЛЕДИЛИ ЭВОЛЮЦИЮ ЭТОГО ПРАВА В ЗАКОНОДАТЕЛЬСТВЕ КОНЦА ХVIII - 1-Й ТРЕТИ ХІХ ВЕКА, И, НАКОНЕЦ, ПОСМОТРЕЛИ, КАК РЕАЛИЗОВЫВАЛИ ЕГО НА ПРАКТИКЕ АРХАНГЕЛЬСКИЕ ГЕНЕРАЛ-ГУБЕРНАТОРЫ. В РЕЗУЛЬТАТЕ МЫ ПРИШЛИ К СЛЕДУЮЩИМ ВЫВОДАМ.

ПРЕДСТАВЛЯЕТСЯ, ЧТО СЛЕДУЕТ БОЛЕЕ ТОНКО ПОДХОДИТЬ К ТОМУ, ЧТО ЖЕ ЕКАТЕРИНА ІІ ПОНИМАЛА ПОД ПРАВОМ УТВЕРЖДЕНИЯ УГОЛОВНЫХ ПРИГОВОРОВ ГЕНЕРАЛГУБЕРНАТОРАМИ В «УЧРЕЖДЕНИЯХ ДЛЯ ГУБЕРНИЙ» 1775 ГОДА. ПРАВО ЭТО СОСТОЯЛО В СЛЕДУЮЩЕМ - ГЕНЕРАЛ-ГУБЕРНАТОРЫ: 1) МОГЛИ ОСТАНОВИТЬ ЛЮБОЕ НЕСПРАВЕДЛИВОЕ РЕШЕНИЕ СУДЕБНЫХ МЕСТ, 2) ДОЛЖНЫ БЫЛИ В ОБЯЗАТЕЛЬНОМ ПОРЯДКЕ УТВЕРЖДАТЬ ТОЛЬКО ТАКИЕ УГОЛОВНЫЕ ПРИГОВОРЫ, КОТОРЫМИ ОБВИНЯЕМЫЕ ПРИСУЖДАЛИСЬ К НАКАЗАНИЮ В ВИДЕ СМЕРТНОЙ КАЗНИ, ЛИШЕНИЯ СОСЛОВНЫХ ПРАВ И ПРИВИЛЕГИЙ, ТЕЛЕСНОГО НАКАЗАНИЯ. НО В ОБОИХ СЛУЧАЯХ ОНИ БЫЛИ НЕ ВПРАВЕ ИЗМЕНИТЬ СУДЕБНОЕ РЕШЕНИЕ, А ОБЯЗЫВАЛИСЬ ПЕРЕДАВАТЬ ЕГО СО СВОИМ МНЕНИЕМ НА ОКОНЧАТЕЛЬНОЕ РАССМОТРЕНИЕ СЕНАТА И ИМПЕРАТОРА. ГЛАВНЫМ КРИТЕРИЕМ НЕСОГЛАСИЯ ВЫСТУПАЛА НЕСПРАВЕДЛИВОСТЬ СУДЕБНОГО ПОСТАНОВЛЕНИЯ. В СВОЮ ОЧЕРЕДЬ, СПРАВЕДЛИВЫЙ УГОЛОВНЫЙ ПРИГОВОР, ИМЕЯ СВОИМИ КОРНЯМИ, КАК СОБСТВЕННОЕ ОРИГИНАЛЬНОЕ РУССКОЕ ПРАВО, ТАК И ЕСТЕСТВЕННО-ПРАВОВУЮ ТЕОРИЮ, ЗАИМСТВОВАННУЮ ЕКАТЕРИНОЙ II ИЗ УЧЕНИЙ ФРАНЦУЗСКИХ ПРОСВЕТИТЕЛЕЙ, ПОНИМАЛСЯ КАК БЕСПРИСТРАСТНЫЙ ПРИГОВОР, ПРИНЯТЫЙ БЕЗОТНОСИТЕЛЬНО ПРИНАДЛЕЖНОСТИ ОБВИНЯЕМОГО К СОСЛОВИЮ. ОТНЫНЕ ВСЕ ПОДДАННЫЕ РОССИЙСКИХ ИМПЕРАТОРОВ СЧИТАЛИСЬ ФОРМАЛЬНО РАВНЫМИ ПЕРЕД ЛИЦОМ КРИМИНАЛЬНЫХ ЗАКОНОВ.

ДЛЯ РЕАЛИЗАЦИИ ИМЕННО ТАКОГО ПОНЯТИЯ СПРАВЕДЛИВОСТИ И ПРЕДНАЗНАЧАЛИСЬ ГЕНЕРАЛ-ГУБЕРНАТОРЫ, КОТОРЫЕ, НАЧИНАЯ С ЕКАТЕРИНЫ II, РЕКРУТИРОВАЛИСЬ ИСКЛЮЧИТЕЛЬНО ИЗ КРУГА ОСОБО ДОВЕРЕННЫХ ЛИЦ. ПОЭТОМУ ИМПЕРАТОРЫ И МОГЛИ ИМ ДОВЕРИТЬ ЧАСТЬ СОБСТВЕННЫХ, В ТОМ ЧИСЛЕ И СУДЕБНЫХ, ПРЕРОГАТИВ. К ГЛАВНЫМ ИЗ НИХ СЛЕДУЕТ ОТНЕСТИ НАДЗОР ЗА ИСПОЛНЕНИЕМ СУДАМИ ЕГО ЩИМПЕРАТОРСКОГО ВЕЛИЧЕСТВА ИЗДАННОГО УЗАКОНЕНИЯ», ОЦЕНКУ ЛЮБОГО СУДЕБНОГО РЕШЕНИЯ С ПОЗИЦИЙ ВЫШЕУКАЗАННОГО ПОНЯТИЯ СПРАВЕДЛИВОСТИ. ДУМАЕТСЯ ТАКЖЕ, ЧТО ЕКАТЕРИНА II СТРЕМИЛАСЬ ПОСРЕДСТВОМ ВЫВЕДЕНИЯ ГЕНЕРАЛ-ГУБЕРНАТОРОВ ИЗ СОСТАВА СУДОВ СДЕЛАТЬ ИХ КАК БЫ СТОРОННИМИ НАБЛЮДАТЕЛЯМИ, НЕ «ПРИОБВЫКШИМИ», В ОТЛИЧИЕ ОТ СУДЕЙ, «НАХОДИТЬ ВЕЗДЕ ВИНОВАТЫХ». ОНИ МОГЛИ 
ОСТАНОВИТЬ ИСПОЛНЕНИЕ ПРИГОВОРА, КОТОРЫЙ БЫЛ ПРИНЯТ В СТРОГОМ СООТВЕТСТВИИ С ГОСПОДСТВОВАВШИМИ В РОССИЙСКОЙ ПРАВОВОЙ ДЕЙСТВИТЕЛЬНОСТИ ЖЕСТОКИМИ УГОЛОВНЫМИ ЗАКОНАМИ И ТЕОРИЕЙ ФОРМАЛЬНЫХ ДОКАЗАТЕЛЬСТВ, НО НЕ ОТВЕЧАЮЩИМ ГЛАВНЫМИ ПРИНЦИПАМ ЭПОХИ ПРОСВЕЩЕНИЯ - УВАЖЕНИЕ К ЛИЧНОСТИ, ГУМАННОСТЬ И ЦЕЛЕСООБРАЗНОСТЬ НАКАЗАНИЙ, РАВЕНСТВО ПЕРЕД ЗАКОНОМ. АЛЕКСАНДР І ЕЩЕ БОЛЕЕ ОБЛЕГЧИЛ ГЕНЕРАЛ-ГУБЕРНАТОРАМ ЭТУ ЗАДАЧУ, ПРЕДОСТАВИВ ИМ ПРАВО ОЦЕНИВАТЬ НЕ ВСЕ УГОЛОВНЫЕ ПРИГОВОРЫ, А ТОЛЬКО ТАКИЕ, «КОИ ПО ВАЖНОСТИ СВОЕЙ ИЛИ ПО ЖАЛОБАМ НА НЕСПРАВЕДЛИВОЕ РЕШЕНИЕ СУДЕБНЫХ МЕСТ, ОБРАТИЛИ БЫ НА СЕБЯ ОСОБОЕ ИХ ВНИМАНИЕ». С ДРУГОЙ СТОРОНЫ, ЯВЛЯЯСЬ ПОВЕРЕННЫМИ ОСОБАМИ РОССИЙСКИХ ИМПЕРАТОРОВ, ГЕНЕРАЛ-ГУБЕРНАТОРЫ ДОЛЖНЫ БЫЛИ СТОЯТЬ НА СТРАЖЕ ИНТЕРЕСОВ КОРОНЫ, ТОНКО ЧУВСТВОВАТЬ НАСТРОЕНИЯ ГОСУДАРЯ И ПРАВИТЕЛЬСТВЕННЫХ КРУГОВ. ТАКИМ ОБРАЗОМ, НА ОЦЕНКУ ПРИГОВОРА ГЕНЕРАЛ-ГУБЕРНАТОРАМИ МОГЛИ ВЛИЯТЬ И ДРУГИЕ ВЕСЬМА СУБЪЕКТИВНЫЕ ФАКТОРЫ. ИЗУЧИВ СУДЕБНУЮ ДЕЯТЕЛЬНОСТЬ АРХАНГЕЛЬСКОГО, ВОЛОГОДСКОГО И ОЛОНЕЦКОГО ГЕНЕРАЛ-ГУБЕРНАТОРА А.Ф. КЛОКАЧЕВА И С.И. МИНИЦКОГО В 20-Е ГГ. ХІХ В., МЫ МОЖЕМ КОНСТАТИРОВАТЬ, ЧТО ОНИ БЫЛИ В КУРСЕ ПРОИЗВОДСТВА ВСЕХ УГОЛОВНЫХ ПРЕСТУПЛЕНИЙ, СОВЕРШЕННЫХ НА ПОДВЕДОМСТВЕННОЙ ИМ ТЕРРИТОРИИ. НО ПРИ ЭТОМ ОНИ ВЕСЬМА РЕДКО ПОЛЬЗОВАЛИСЬ ПРЕДОСТАВЛЕННЫМ ИМ ПРАВОМ УТВЕРЖДАТЬ УГОЛОВНЫЕ ПРИГОВОРЫ. ИЗ 5 РАССМОТРЕННЫХ НАМИ ПРИМЕРОВ УГОЛОВНЫХ ПРЕСТУПЛЕНИЙ, В КОТОРЫЕ ВМЕШАЛИСЬ АРХАНГЕЛЬСКИЕ ГЕНЕРАЛ-ГУБЕРНАТОРЫ, В ДВУХ СЛУЧАЯХ СЕНАТ ВОСПРИНЯЛ ИХ АРГУМЕНТЫ И ПОШЕЛ НА НЕКОТОРОЕ ОСЛАБЛЕНИЕ УЧАСТИ ПОДСУДИМЫХ, А В ОДНОМ - ВООБЩЕ ОСВОБОДИЛ ОСУЖДЕННОГО ОТ ОТВЕТСТВЕННОСТИ. ВО ВСЕХ ЭТИХ ДЕЛАХ ПОДСУДИМЫМИ БЫЛИ КРЕСТЬЯНЕ. ТАКОЙ РЕЗУЛЬТАТ МОЖНО БЫЛО БЫ ПРИЗНАТЬ ДОСТАТОЧНО ЭФФЕКТИВНОЙ РЕАЛИЗАЦИЕЙ СТ. 82 «УЧРЕЖДЕНИЙ ДЛЯ ГУБЕРНИЙ», В КОТОРОЙ БЫЛО ЗАЯВЛЕНО, ЧТО «ГОСУДАРЕВ НАМЕСТНИК НЕ ЕСТЬ СУДЬЯ, НО... ЗАСТУПНИК УТЕСНЕННЫХ», КОТОРЫЙ ДОЛЖЕН «ПОКАЗАТЬ В ПОСТУПКАХ СВОИХ ДОБРОХОТСТВО, ЛЮБОВЬ И СОБОЛЕЗНОВАНИЕ К НАРОДУ». ТЕМ БОЛЕЕ ЧТО С 1784 Г. САМА ЖЕ ЕКАТЕРИНА ІІ ЗАПРЕТИЛА ВЫХОДЦАМ ИЗ НИЖНЕГО СОСТОЯНИЯ ПОДАВАТЬ АПЕЛЛЯЦИИ НА РЕШЕНИЯ УГОЛОВНЫХ СУДОВ. ОДНАКО, В ДРУГОЙ РАЗ, КОГДА ДЕЛО КОСНУЛОСЬ ПОСЯГАТЕЛЬСТВА КРЕСТЬЯНИНА НА ДОСТОИНСТВО ЧИНОВНИКА ПРИ ИСПОЛНЕНИИ ИМ СВОИХ СЛУЖЕБНЫХ ОБЯЗАННОСТЕЙ, ГЕНЕРАЛ-ГУБЕРНАТОР ДАЖЕ ПОТРЕБОВАЛ УЖЕСТОЧИТЬ НАКАЗАНИЕ, С ЧЕМ, ПРАВДА, НЕ СОГЛАСИЛИСЬ СЕНАТ И ЦАРЬ. В ОТНОШЕНИИ ЖЕ ПРИВИЛЕГИРОВАННЫХ ЛИЦ РАССМОТРЕННЫЙ НАМИ СЛУЧАЙ С ЧИНОВНИКАМИ МИХАЙЛОВЫМ И ВИДЯКИНЫМ ДАЕТ ОСНОВАНИЕ ДУМАТЬ, ЧТО ГЕНЕРАЛ-ГУБЕРНАТОРЫ НЕ БЫЛИ СКЛОННЫ ДЕЛАТЬ КАКИЕ-ТО ПРЕФЕРЕНЦИИ УГОЛОВНЫМ ПРЕСТУПНИКАМИ И ИЗ ЭТИХ СЛОЕВ, ТАК КАК ЭТО НАНОСИЛО УЩЕРБ ДОСТОИНСТВУ ГОСУДАРСТВЕННОЙ СЛУЖБЫ. ЕГО МНЕНИЕ В ЭТОМ СЛУЧАЕ БЫЛО ТАКЖЕ ПОДДЕРЖАНО СЕНАТОМ И ЦАРЕМ. ВПРОЧЕМ, ДАННЫЙ ВЫВОД НЕЛЬЗЯ ПРИЗНАТЬ ВПОЛНЕ ОБЪЕКТИВНЫМ, ТАК КАК ОН СДЕЛАН НА ОСНОВАНИИ ВСЕГО ЛИШЬ ОДНОГО УГОЛОВНОГО ДЕЛА. СЧИТАЕМ, ЧТО НАМ ПОТРЕБУЕТСЯ ПРОВЕСТИ В ЭТОМ НАПРАВЛЕНИИ ДОПОЛНИТЕЛЬНОЕ ИССЛЕДОВАНИЕ. А ЧТОБЫ НАШИ ВЫВОДЫ БЫЛИ БОЛЕЕ РЕПРЕЗЕНТАТИВНЫМИ И ОБЪЕКТИВНЫМИ, В ДАЛЬНЕЙШЕМ БУДЕТ НЕОБХОДИМО СРАВНИТЬ ИХ С ВЫВОДАМИ, СДЕЛАННЫМИ НА ОСНОВЕ АНАЛИЗА СУДЕБНОЙ ПРАКТИКИ ГЕНЕРАЛ- ГУБЕРНАТОРОВ ДРУГИХ РЕГИОНОВ, И ЗАТЕМ ПОВЕРИТЬ ЭТИ ПРАКТИКИ С МАТЕРИАЛАМИ СЕНАТОРСКИХ РЕВИЗИЙ. 


\section{NOTES}

2. ЗАКОНОДАТЕЛЬСТВО ПЕТРА I, М.: ЮРИДИЧЕСКАЯ ЛИТЕРАТУРА, 1997, С. 809; А.В. СМИРНОВ, МОДЕЛИ УГОЛОВНОГО ПРОЦЕССА, СПБ., 2000, С. 120, 124-131, 191.

3. МОЯ ОСОБАЯ БЛАГОДАРНОСТЬ Г.О.БАБКОВОЙ, КОТОРАЯ ЗАДАЛА МНЕ ВО ВРЕМЯ ДИСКУССИИ, ВОЗНИКШЕЙ ПОСЛЕ МОЕГО ДОКЛАДА НА ПРОШЕДШЕЙ В МАЕ 2011 Г. В МОСКВЕ МЕЖДУНАРОДНОЙ КОНФЕРЕНЦИИ «ПРАВОВАЯ ПРАКТИКА И ПРАВОСУДИЕ В РОССИИ С XVIII В. ДО НАСТОЯЩЕГО ВРЕМЕНИ», ИМЕННО ТОТ ВОПРОС, КОТОРЫЙ ЗАСТАВИЛ МЕНЯ БОЛЕЕ ВНИМАТЕЛЬНО РАССМОТРЕТЬ ИДЕОЛОГИЧЕСКИЙ АСПЕКТ ПРОБЛЕМЫ, ТАК КАК ДО ЭТОГО Я ИЗУЧАЛА СВОЮ ПРОБЛЕМУ ТОЛЬКО В ПРАКТИЧЕСКОЙ ПЛОСКОСТИ (В.В. ЕФИМОВА, «НАДЗОРНЫЕ ФУНКЦИИ ГЕНЕРАЛ-ГУБЕРНАТОРОВ В СУДОПРОИЗВОДСТВЕ ПО ТЯЖКИМ ПРЕСТУПЛЕНИЯМ В ПЕРВОЙ ТРЕТИ ХІХ ВЕКА: ЗАКОН И ПРАКТИКА», ВЕСТНИК БАЛТИЙСКОГО ФЕДЕРАЛЬНОГО УНИВЕРСИТЕТА ИМ. И. КАНТА, ВЫП. 9, СЕР. ЭКОНОМИЧЕСКИЕ И ЮРИДИЧЕСКИЕ НАУКИ, 2011, С. 21-31).

4. СМ., НАПР.: В. ГРИГОРЬЕВ, РЕФОРМА МЕСТНОГО УПРАВЛЕНИЯ ПРИ ЕКАТЕРИНЕ ІІ. УЧРЕЖДЕНИЕ О ГУБЕРНИЯХ 1775 Г., СПБ., 1910; Ю.В. ГОТЬЕ, ИСТОРИЯ ОБЛАСТНОГО УПРАВЛЕНИЯ В РОССИИ ОТ ПЕТРА I ДО ЕКАТЕРИНЫ II, В 2 Х Т, Т. 2, СПБ., 1948; И. МАДАРИАГА, РОССИЯ В ЭПОХУ ЕКАТЕРИНЫ ВЕЛИКОЙ, М., 2002 (ПЕРЕВОД ИЗД-Я 1981 Г.); О.А. ОМЕЛЬЧЕНКО, МОНАРХИЯ ПРОСВЕЩЕННОГО АБСОЛЮТИЗМА В РОССИИ (ПОЛИТИЧЕСКАЯ ДОКТРИНА. - ПРАВОВАЯ ПОЛИТИКА. ГОСУДАРСТВЕННЫЕ РЕФОРМЫ), ДИСС. ...Д.Ю.Н. М., 2001; Т.Л. МИГУНОВА, АДМИНИСТРАТИВНОСУДЕБНАЯ И ПРАВОВАЯ РЕФОРМЫ ЕКАТЕРИНЫ ВЕЛИКОЙ (ИСТОРИКО-ПРАВОВОЙ АСПЕКТ), ДИСС. ... Д.Ю.Н. ВЛАДИМИР, 2008.

5. СМ., НАПР.: А.Ф. КОНИ, ОТЦЫ И ДЕТИ СУДЕБНОЙ РЕФОРМЫ, М., 1914; А.Ф. КОНИ, ИСТОРИЯ РАЗВИТИЯ УГОЛОВНО-ПРОЦЕССУАЛЬНОГО ЗАКОНОДАТЕЛЬСТВА В РОССИИ, СОБР. СОЧ. В 8 Т., Т. 4. М., 1967; И.Я. ФОЙНИЦКИЙ, КУРС УГОЛОВНОГО сУДоПРОИзВодСТВА, в 2-Х Т, т. 1, СПБ., 1996 (ПЕРЕИЗД. 1910 Г.); Н.Н. РОЗИН, УГОЛОВНОЕ СУДОПРОИЗВОДСТВО, 3-Е ИЗД., ПГ., 1916; М.А. ЧЕЛЬЦЕВ-БЕБУТОВ, КУРС УГОЛОВНО-ПРОЦЕССУАЛЬНОГО ПРАВА: ОЧЕРКИ ПО ИСТОРИИ СУДА И УГОЛОВНОГО ПРОЦЕССА В РАБОВЛАДЕЛЬЧЕСКИХ, ФЕОДАЛЬНЫХ И БУРЖУАЗНЫХ ГОСУДАРСТВАХ, СПБ., 1995 (ПЕРЕИЗД. 1947 Г.); Б.В. ВИЛЕНСКИЙ, О.И. ЧИСТЯКОВ, «ВВЕДЕНИЕ», В РОССИЙСКОЕ ЗАКОНОДАТЕЛЬСТВО Х-ХХ ВЕКОВ, В 9 Т., Т. 8. СУДЕБНАЯ РЕФОРМА. М.: ЮРИДИЧЕСКАЯ ЛИТЕРАТУРА, 1991; РАЗВИТИЕ РУССКОГО ПРАВА В 1-Й ПОЛОВИНЕ ХІХ В., М., 1994; Э. АННЕРС, ИСТОРИЯ ЕВРОПЕЙСКОГО ПРАВА (ПЕРЕВОД СО ШВЕД. ЯЗ.), М., 1996; А.И. АЛЕКСАНДРОВ, УГОЛОВНО-ПРОЦЕССУАЛЬНАЯ ПОЛИТИКА В РОССИИ (ТЕОРЕТИЧЕСКИЙ И ИСТОРИКО-ПРАВОВОЙ АНАЛИЗ), ДИСС. ... Д.Ю.Н., СПБ., 1999; СМИРНОВ, МОДЕЛИ УГОЛОВНОГО ПРОЦЕССА; Н.Н. ЕФРЕМОВА, СТАНОВЛЕНИЕ И РАЗВИТИЕ СУДЕБНОГО ПРАВА В РОССИИ. ХVIII- НАЧАЛО ХХ (ИСТОРИКО-ПРАВОВОЕ ИССЛЕДОВАНИЕ), М., 2007; Т.Ю. АМПЛЕЕВА, ИСТОРИЯ СУДОУСТРОЙСТВА И УГОЛОВНОГО СУДОПРОИЗВОДСТВА В РОССИИ. (ІХ-ХІХ ВВ.), В 2-Х КН., КН. 2, ИМПЕРАТОРСКАЯ Россия, М., 2008.

6. СМ., НАПР.: И.Е. АНДРЕЕВСКИЙ, О НАМЕСТНИКАХ, ВОЕВОДАХ И ГУБЕРНАТОРАХ, СПБ., 1864; А.Д. ГРАДОВСКИЙ, ИСТОРИЧЕСКИЙ ОЧЕРК УЧРЕЖДЕНИЯ ГЕНЕРАЛ-ГУБЕРНАТОРСТВ В РОССИИ, В СОБР. СОЧ. В 9 Т, Т. 1, СПБ., 1899; И.А. БЛИНОВ, ГУБЕРНАТОРЫ: ИСТОРИКО-ЮРИДИЧЕСКИЙ ОЧЕРК, СПБ., 1905; ИНСТИТУТ ГЕНЕРАЛ-ГУБЕРНАТОРСТВА И НАМЕСТНИЧЕСТВА В 
РОССИЙСКОЙ ИМПЕРИИ: В 2 Т., Т. 1. СПБ., 2001; В.Г. АРУТЮНЯН, ГЕНЕРАЛ-ГУБЕРНАТОРСТВА ПРИ АЛЕКСАНДРЕ І, ДИСС... К.И.Н., М., 2008 И ДР.

7. СМ., НАПР.: БЛИНОВ, ГУБЕРНАТОРЫ, С. 147-148; КОНИ, ИСТОРИЯ РАЗВИТИЯ, С. 324-325, 335; ФОЙНИЦКИЙ, КУРС, С. 33-37; РОЗИН, УГОЛОВНОЕ СУДОПРОИЗВОДСТВО, С. 56-59; ЧЕЛЬЦЕВБЕБУТОВ, КУРС, С. 709, 720-722, 736-739; РАЗВИТИЕ РУССКОГО ПРАВА В 1-Й ПОЛОВИНЕ ХІХ В., С. 254; АННЕРС, ИСТОРИЯ ЕВРОПЕЙСКОГО ПРАВА, С. 358-359; АЛЕКСАНДРОВ, УГОЛОВНОПРОЦЕССУАЛЬНАЯ ПОЛИТИКА В РОССИИ, С. 83-92; СМИРНОВ, МОДЕЛИ, С. 120, 124-131, 191; Р.С. УОРТМАН ВЛАСТИТЕЛИ И СУДИИ: РАЗВИТИЕ ПРАВОВОГО СОЗНАНИЯ В ИМПЕРАТОРСКОЙ РОССИИ, М., 2004, С. 403-404; ЕФРЕМОВА, СТАНОВЛЕНИЕ И РАЗВИТИЕ СУДЕБНОГО ПРАВА В РОССИИ, С. 103, 115, 148-155; МИГУНОВА, АДМИНИСТРАТИВНО-СУДЕБНАЯ И ПРАВОВАЯ РЕФОРМЫ ЕКАТЕРИНЫ ВЕЛИКОЙ, С. 402-403; АМПЛЕЕВА, ИСТОРИЯ СУДОУСТРОЙСТВА (КН. 2), C. 155.

8. ПРЕЖДЕ ВСЕГО, ЭТА УЖЕ УПОМЯНУТАЯ НАМИ РАБОТА УОРТМАНА «ВЛАСТИТЕЛИ И СУДИИ 》, НАПИСАННАЯ ЕЩЕ В 1975 Г., НО СТАВШАЯ ОБЩЕДОСТУПНОЙ ПОСЛЕ ЕЕ ПЕРЕВОДА НА РУССКИЙ ЯЗЫК В 2004 г.

9. J.P. LeDonne, «Russian governors general, 1775-1825. Territorial or functional administration?», Cahiers du monde russe, 42 (1), 2001, p. 19-20, 30.

10. Н.М. ЯДРИНЦЕВ, СИБИРЬ КАК КОЛОНИЯ В ГЕОГРАФИЧЕСКОМ, ЭТНОГРАФИЧЕСКОМ И ИСТОРИЧЕСКОМ ОТНОШЕНИИ, СПБ., 1982, С. 484.

11. П.В. АКУЛЬШИН, ПРОСВЕЩЕННАЯ БЮРОКРАТИЯ И РУССКАЯ ПРОВИНЦИЯ В ПЕРВОЙ ПОЛОВИНЕ ХІХ В. (ПО МАТЕРИАЛАМ ПЕНЗЕНСКОЙ, РЯЗАНСКОЙ, ТАМБОВСКОЙ И ТУЛЬСКОЙ ГУБЕРНИЙ), ДИСС... Д.И.Н., М., 2004; АРУТЮНЯН, ГЕНЕРАЛ-ГУБЕРНАТОРСТВА ПРИ АЛЕКСАНДРЕ І.

12. В.А. ВОРОПАНОВ, РЕГИОНАЛЬНЫЙ ФАКТОР СТАНОВЛЕНИЯ СУДЕБНОЙ СИСТЕМЫ РОССИЙСКОЙ ИМПЕРИИ НА УРАЛЕ И В ЗАПАДНОЙ СИБИРИ (ПОСЛЕДНЯЯ ТРЕТЬ ХVIII - ПЕРВАЯ ПОЛОВИНА ХІХ ВВ.): ИСТОРИКО-ЮРИДИЧЕСКОЕ ИССЛЕДОВАНИЕ, ЧЕЛЯБИНСК, 2011, С. 251-252.

13. ПОЛНОЕ СОБРАНИЕ ЗАКОНОВ РОССИЙСКОЙ ИМПЕРИИ: СОБРАНИЕ 1 (ДАЛЕЕ ПСЗ-1), Т. 20, № 14392 .

14. В СТ. 110 «УЧРЕЖДЕНИЙ ДЛЯ ГУБЕРНИЙ» 1775 Г. К ЭТИМ НАКАЗАНИЯМ БЫЛА ДОБАВЛЕНА ТОРГОВАЯ КАЗНЬ, КОТОРАЯ ЗАМЕНЯЛА СМЕРТНУЮ КАЗНЬ В СВЯЗИ С ЕЁ ФОРМАЛЬНОЙ ОТМЕНОЙ ПО УКАЗАМ ОТ 29 МАРТА 1753 И 30 СЕНТЯБРЯ 1754 Г. В СВОЮ ОЧЕРЕДЬ, ПОД ТОРГОВОЙ КАЗНЬЮ, СОГЛАСНО МАНИФЕСТА ОТ 17 МАРТА 1775 Г., ПОНИМАЛОСЬ, ПОМИМО НАКАЗАНИЯ КНУТОМ, КАК ЭТО БЫЛО УСТАНОВЛЕНО ЕЩЕ В СОБОРНОМ УЛОЖЕНИИ 1649 Г., НАКАЗАНИЕ ПЛЕТЬМИ И БАТОГАМИ. В 1787 Г. БЫЛО ЕЩЕ РАЗ ПОДТВЕРЖДЕНО, ЧТОБЫ ВСЕ ТАКИЕ ПРИГОВОРЫ БЫЛИ ОБЯЗАТЕЛЬНО УТВЕРЖДАЕМЫ «ГОСУДАРЕВЫМИ НАМЕСТНИКАМИ», В ПСЗ-1, Т. 13, № 10087; Т. 14, № 10306; Т. 22, № 16513 .

15. ПСз-1, Т. 21, № 15171.

16. ГРАДОВСКИЙ, ИСТОРИЧЕСКИЙ ОЧЕРК, С. 308-311.

17. С 1803 Г. ОНИ БЫЛИ ПРИРАВНЕНЫ В ПРАВАХ К ГЕНЕРАЛ-ГУБЕРНАТОРАМ, В ПСЗ-1, Т. 27, № 20713.

18. НАПРИМЕР, ПО УКАЗУ ОТ 9 СЕНТЯБРЯ 1801 Г. В ОДНУ АРХАНГЕЛЬСКУЮ ГУБЕРНИЮ, НО В 2 БЕЛОРУССКИЕ И 3 ПРИБАЛТИЙСКИЕ ГУБЕРНИИ БЫЛИ НАЗНАЧЕНЫ ВОЕННЫЕ ГУБЕРНАТОРЫ. БЫЛИ И ОСОБЫЕ СЛУЧАИ: 30 ИЮНЯ 1822Г. СЕНАТОР СОЙМОНОВ, ПРОВОДИВШИЙ В КАЗАНСКОЙ ГУБЕРНИИ РЕВИЗИЮ, БЫЛ НАДЕЛЕН ПРАВАМИ ГЕНЕРАЛ- 
ГУБЕРНАТОРА И ЕМУ БЫЛО ПРЕДПИСАНО ОСТАВАТЬСЯ В ЭТОЙ ДОЛЖНОСТИ «ДО СОВЕРШЕННОГО УСТРОЙСТВА ТОЙ ГУБЕРНИИ», В ПСЗ-1, Т. 26, № 20004; Т. 38, № 29098; А.Н. БИКТАШЕВА, КАЗАНСКИЕ ГУБЕРНАТОРЫ В ДИАЛОГАХ ВЛАСТЕЙ (ПЕРВАЯ ПОЛОВИНА ХІХ ВЕКА), КАЗАНЬ, 2008, С. 125.

19. ПС3-1, т. 21, № 15204; т. 22, № 16022, 16276; т. 27, № 20745; т. 28, № 21777.

20. ИНТЕРЕСНО ЗАМЕТИТЬ, ЧТО ПОВОДОМ К ЭТОМУ УКАЗУ СТАЛ ТАКЖЕ РАПОРТ АРХАНГЕЛЬСКОГО ГЕНЕРАЛ-ГУБЕРНАТОРА С.И. МИНИЦКОГО, ПРОСИВШЕГО РАСПРОСТРАНИТЬ И НА НЕГО ПРАВО, ПРЕДОСТАВЛЕННОЕ ЕГО УМЕРШЕМУ ПРЕДШЕСТВЕННИКУ А.Ф. КЛОКАЧЕВУ (ПСЗ-1, Т. 35, № 27253; Т. 37, № 28106, 28202; Т. 38, № 29610).

21. ЭТИМ УЗАКОНЕНИЕМ, С ЦЕЛЬЮ ВЫСВОБОЖДЕНИЯ УГОЛОВНЫХ ПАЛАТ ДЛЯ РЕШЕНИЯ БОЛЕЕ ВАЖНЫХ ДЕЛ, ОТМЕНЯЛАСЬ ПРОЦЕДУРА ВНЕСЕНИЯ К НИМ НА РЕВИЗИЮ УГОЛОВНЫХ ДЕЛ, ПО КОТОРЫМ «ПО ИССЛЕДОВАНИЮ НЕ БЫЛО ОТКРЫТО ПРЕСТУПНИКА». ТЕПЕРЬ ОНИ ДОЛЖНЫ БЫЛИ ОКОНЧАТЕЛЬНО РАЗРЕШАТЬСЯ В НИЖНИХ СУДЕБНЫХ МЕСТАХ, КОТОРЫЕ ПО ИХ ОКОНЧАНИЮ ДОНОСИЛИ ГУБЕРНАТОРАМ СВОИ РЕШЕНИЯ, А ПОСЛЕДНИЕ, В СЛУЧАЕ, ЕСЛИ НАХОДИЛИ ПРОИЗВОДСТВО КАКОГО-ЛИБО ДЕЛА «НЕПРАВИЛЬНЫМ, ИЛИ НЕУДОВЛЕТВОРИТЕЛЬНЫМ, ИЛИ ПОЛУЧИЛИ ОТ КОГО-ЛИБО ПО ТАКОВОМУ ДЕЛУ ЖАЛОБУ», ОБЯЗАНЫ БЫЛИ ПРЕДСТАВЛЯТЬ ЕГО НА РЕВИЗИЮ УГОЛОВНОЙ ПАЛАТЫ, В ПСЗ-1, Т. 37, № 28852.

22. ПСЗ-2, Т. 2, № 1143.

23. ПСз-1, Т. 5, № 3006 (гЛ. 49, СТ. 6); т. 26, № 19622; т. 29, № 22543; т. 39, № 30028.

24. ВОТ КАК ВОСПРОИЗВОДИТ ЭТО МНЕНИЕ ЧЛЕНОВ КОМИТЕТА 6 АВГУСТА 1826 Г. И. БЛИНОВ: «ЕСЛИ СУДЕБНЫЕ ПРИГОВОРЫ ТРЕБУЮТ ИСПРАВЛЕНИЯ, ТО ДЛЯ СЕГО СУЩЕСТВУЕТ ПО ГРАЖДАНСКИМ ДЕЛАМ - АПЕЛЛЯЦИЯ, ПО УГОЛОВНЫМ - РЕВИЗИЯ В ВЫСШИХ СТЕПЕНЯХ СУДА. НА ЧТО ЖЕ ВМЕШЕНИЕ ГУБЕРНАТОРА, МАЛО, ЕСЛИ НЕ СОВСЕМ НЕСВЕДУЩЕГО В ЗАКОНАХ, ИЛИ ПО КРАЙНЕЙ МЕРЕ НЕ ЗНАЮЩЕГО О ПРОИЗВОДСТВЕ ВСЕГО ДЕЛА, О КОТОРОМ ОН СУДИТЬ ДОЛЖЕН» (БЛИНОВ, ГУБЕРНАТОРЫ, С. 152). НАПОМНИМ, ЧТО ЭТОТ КОМИТЕТ БЫЛ СОЗДАН НИКОЛАЕМ І, КАК ГЛАСИЛ ВЫСОЧАЙШИЙ РЕСКРИПТ ОТ 6 ДЕКАБРЯ 1826 Г., ДАННЫЙ НА ИМЯ ЕГО ПРЕДСЕДАТЕЛЯ В.П. КОЧУБЕЯ, ДЛЯ «ОБОЗРЕНИЯ РАЗНЫХ ПРЕДПОЛОЖЕНИЙ, НАЙДЕННЫХ В БУМАГАХ ПОКОЙНОГО ГОСУДАРЯ ИМПЕРАТОРА» И «НАСТОЯЩЕГО ПОЛОЖЕНИЯ ВСЕХ ЧАСТЕЙ УПРАВЛЕНИЯ, ДАБЫ ИЗ СИХ СООБРАЖЕНИЙ ВЫВЕСТИ ПРАВИЛА К ЛУЧШЕМУ ИХ УСТРОЙСТВУ И ИСПРАВЛЕНИЮ» (СБОРНИК ИМПЕРАТОРСКОГО РУССКОГО ИСТОРИЧЕСКОГО ОБЩЕСТВА, Т. 74, СПБ., 1891, C. XVI).

25. РЕВИЗИЯ ЖЕ УГОЛОВНЫХ ДЕЛ, СОГЛАСНО СТ. 108 «УЧРЕЖДЕНИЙ ДЛЯ ГУБЕРНИЙ» «НИ ЧТО ИНОЕ ЕСТЬ, КАК ПРИЛЕЖНОЕ РАЗСМОТРЕНИЕ, ПРОИЗВЕДЕНО ЛИ ДЕЛО ПОРЯДОЧНО И СХОДСТВЕННО С ЗАКОНАМИ, СКОЛЬ ДЛЯ ОПРАВДАНИЯ НЕВИННОСТИ, СТОЛЬ И ДЛЯ ПРИВЕДЕНИЯ В ЯСНОСТЬ ПРЕСТУПЛЕНИЯ, ИЛИ ДЛЯ ОБЛИЧЕНИЯ ПРЕСТУПНИКА».

26. ПРАВО АПЕЛЛЯЦИИ БЫЛО ВОЗВРАЩЕНО В СВЯЗИ С НЕКАЧЕСТВЕННЫМ ПРОВЕДЕНИЕМ СЛЕДСТВИЯ ПОЛИЦЕЙСКИМИ ЧИНОВНИКАМИ (ПСЗ-1, Т. 22, № 16022; т. 38, № 29391; ПС3-2, Т. 3, № 2470A).

27. ЕСЛИ ТАКОВАЯ ПРИЗНАВАЛАСЬ ЦАРЁМ ОСНОВАТЕЛЬНОЙ, ТО ДЕЛО ПЕРЕДАВАЛОСЬ В СООТВЕТСТВУЮЩИЕ ИНСТАНЦИИ В ЗАВИСИМОСТИ ОТ ТОГО, НА ЧТО ИЛИ НА КОГО 
ЖАЛОВАЛСЯ ОБВИНЯЕМЫЙ. НО, В ЛЮБОМ СЛУЧАЕ, КАК РАЗЪЯСНЯЛОСЬ В УЗАКОНЕНИЯХ НАЧАЛА ХІХ В., ЕСЛИ ДЕЛО ПО «ВЫСОЧАЙШЕМУ УКАЗУ» БЫЛО ПЕРЕДАНО НЕ ЧЕРЕЗ СЕНАТ, А «ПРЯМО НА ИМЯ ГЕНЕРАЛ-ГУБЕРНАТОРОВ ИЛИ ОДНИМ УГОЛОВНЫМ ПАЛАТАМ (ДЛЯ ВЫСКАЗЫВАНИЯ НА НЕГО ИХ МНЕНИЯ - В.Е.) И, НАКОНЕЦ, ДОШЛО УСТАНОВЛЕННЫМ ПОРЯДКОМ» ДО СЕНАТА, ТО ОБ ОКОНЧАТЕЛЬНОМ СВОЁМ РЕШЕНИИ ПОСЛЕДНИЙ ДОЛЖЕН БЫЛ «ПОДНОСИТЬ» ИМПЕРАТОРУ «НА АПРОБАЦИЮ» ВСЕПОДДАННЕЙШИЕ РАПОРТЫ, В СООТВЕТСТВИИ С ПОРЯДКОМ, КОТОРЫЙ СУЩЕСТВУЕТ В СЕНАТЕ «В РАССУЖДЕНИИ ДЕЛ, НА КОТОРЫЕ ОБЪЯВЛЕНЫ ЕМУ ВЫСОЧАЙШИЕ ПОВЕЛЕНИЯ» (ПСЗ-1, Т. 30, № 23660; Т. 31, № 24711; т. 32, № 25349; т. 34, № 27005).

28. ПСз-1, т. 22, № 16022; т. 25, № 18875, 18894 (ст. 13); т. 27, № 20405 (ст. 20); т. 29, № 21983, 21991; т. 30, № 23405; т. 32, № 25349, 25668 (ст. 4); т. 37, № 28358; т, 39. № 29890; ПСЗ-2, Т. 4, № 3261.

29. ПСз-1, Т. 16, № 12137.

30. ЯРКИМ ПРИМЕРОМ ЭТОГО ЯВЛЯЕТСЯ УКАЗ СЕНАТА ОТ 14 СЕНТЯБРЯ 1778 Г., КОТОРЫЙ СОСТОЯЛСЯ В СВЯЗИ С ТЕМ, ЧТО ЮСТИЦ-КОЛЛЕГИЯ ПОЗВОЛИЛА СЕБЕ ПРИНЯТЬ ЖАЛОБУ НА ЛИФЛЯНДСКОГО ГЕНЕРАЛ-ГУБЕРНАТОРА БРАУНА. ОБЕР-КОНСИСТОРИИ, ПОДАВШЕЙ ЭТУ ЖАЛОБУ, БЫЛО ЖЕСТКО НАПОМНЕНО, ЧТО ПОСТУПОК ЕЁ «ОКАЗАН В ПРОТИВНОСТЬ ВОЗЛОЖЕННОЙ ПО СИЛЕ ГУБЕРНАТОРСКОГО 176421 АПРЕЛЯ НАСТАВЛЕНИЯ, НА ГЕНЕРАЛГУБЕРНАТОРА ОТ ЕЕ ИМПЕРАТОРСКОГО ВЕЛИЧЕСТВА ДОВЕРЕННОСТИ И ТОЧНО В ОБИДУ И ПРЕДОСУЖДЕНИЕ ЗВАНИЯ И ВЛАСТИ ГОСПОДИНА ГЕНЕРАЛ-ГУБЕРНАТОРА». В РЕЗУЛЬТАТЕ ЕЙ БЫЛО ПРЕДПИСАНО ПРОСИТЬ У БРАУНА ПРОЩЕНИЯ. А ДАЛЕЕ СЕНАТ, ПРОЦИТИРОВАВ П. 1 «НАСТАВЛЕНИЙ» 1764 Г., УКАЗЫВАЛ, ЧТОБЫ ЖАЛОБЫ НА ЛИФЛЯНДСКОГО ГЕНЕРАЛГУБЕРНАТОРА «ПО СИЛЕ ТОГО ЖЕ НАСТАВЛЕНИЯ 3-ГО П. ДОЛЖНЫ БЫТЬ ОТНОСИМЫ В СЕНАТ, А ОТНЮДЬ НИ В КАКОЕ ДРУГОЕ МЕСТО», В ПСЗ-1, Т. 20, № 14800.

31. АНДРЕЕВСКИЙ, О НАМЕСТНИКАХ, С. 133; ГРАДОВСКИЙ, ИСТОРИЧЕСКИЙ ОЧЕРК, С. 307-309; УОРТМАН, ВЛАСТИТЕЛИ И СУДИИ, С. 61; ОМЕЛЬЧЕНКО, МОНАРХИЯ ПРОСВЕЩЕННОГО АБСОЛЮТИЗМА В РОССИИ, С. 242-247.

32. АКУЛЬШИН, ПРОСВЕЩЕННАЯ БЮРОКРАТИЯ, С. 356.

33. УОРТМАН, ВЛАСТИТЕЛИ И СУДИИ, С. 54-55; Е.В. АНИСИМОВ, ГОСУДАРСТВЕННЫЕ ПРЕОБРАЗОВАНИЯ И САМОДЕРЖАВИЕ ПЕТРА ВЕЛИКОГО В 1-Й ЧЕТВЕРТИ ХVIII ВЕКА, СПБ., 1997, С. 274; В.А. ТОМСИНОВ, ИСТОРИЯ РУССКОЙ ПОЛИТИЧЕСКОЙ И ПРАВОВОЙ МЫСЛИ. Х-ХVІІІ ВЕКА, М., 2003, С. 217; О.А. ОМЕЛЬЧЕНКО, ВЛАСТЬ И ЗАКОН В РОССИИ ХVIIІ В.: ИССЛЕДОВАНИЯ И ОЧЕРКИ, М., 2004, С. 64,180.

34. О ЮРИДИЧЕСКОЙ СИЛЕ «НАКАЗА» 1767 Г. В НАУЧНОЙ ЛИТЕРАТУРЕ СУЩЕСТВУЮТ РАЗНЫЕ МНЕНИЯ. ОДНИ СЧИТАЮТ, ЧТО ОН ИМЕЛ ТОЛЬКО «ВНЕШНЕЕ» УПОТРЕБЛЕНИЕ, Т. Е. ПИСАЛСЯ В ПРОПАГАНДИСТСКИХ ЦЕЛЯХ ДЛЯ СОЗДАНИЯ В ЕВРОПЕ ПРЕДСТАВЛЕНИЯ О РОССИЙСКОЙ ИМПЕРИИ КАК ОБРАЗЦЕ «ПРОСВЕЩЕННОЙ МОНАРХИИ». ДРУГИЕ ПОЛАГАЮТ, ЧТО «НАКАЗ» СЧИТАЛСЯ ПОЛНОЦЕННЫМ ЮРИДИЧЕСКИМ АКТОМ И К НЕМУ МОГЛИ ПРИБЕГАТЬ В СВОЕЙ ПРАКТИКЕ СУДЫ. МЫ ПРИДЕРЖИВАЕМСЯ ВТОРОЙ ТОЧКИ ЗРЕНИЯ. БОЛЕЕ ПОДРОБНУЮ АРГУМЕНТАЦИЮ ЭТОЙ ТОЧКИ ЗРЕНИЯ СМОТРИ: Г.С. ФЕЛЬДШТЕЙН, ГЛАВНЫЕ ТЕЧЕНИЯ В ИСТОРИИ НАУКИ УГОЛОВНОГО ПРАВА, ЯРОСЛАВЛЬ, 1909 (ГЛ. 2 И 3); ОМЕЛЬЧЕНКО, ВЛАСТЬ И ЗАКОН, С. 86-87, 189, 217-218.

35. БЕЗУСЛОВНО, ЧТО ЭТА БЫЛА НЕ ОРИГИНАЛЬНАЯ МЫСЛЬ ЕКАТЕРИНЫ ІІ. ОСНОВНЫЕ ДОВОДЫ, УБЕДИВШИЕ ЕЁ В НЕОБХОДИМОСТИ ДАННОГО УТВЕРЖДЕНИЯ, БЫЛИ ЗАИМСТВОВАНЫ ЕЮ ИЗ ЗНАМЕНИТОГО ТРУДА Ш. МОНТЕСКЬЕ «О ДУХЕ ЗАКОНОВ», 
КОТОРЫЙ ИМПЕРАТРИЦА ОДНО ВРЕМЯ СЧИТАЛА СВОИМ «МОЛИТВЕННИКОМ». В СВОЮ ОЧЕРЕДЬ, ЭТО УТВЕРЖДЕНИЕ МОНТЕСКЬЕ ПРОИЗВЕЛ ОТ СФОРМУЛИРОВАННОЙ ИМ ЖЕ ТЕОРИИ РАЗДЕЛЕНИЯ ВЛАСТЕЙ, СТАВШЕЙ РУКОВОДСТВОМ К ДЕЙСТВИЮ ДЛЯ ВСЕХ ПРОСВЕЩЕННЫХ УМОВ И ПРАВИТЕЛЕЙ ЕВРОПЫ И АМЕРИКИ СО 2-Й ПОЛОВИНЫ XVIII В. НАКАЗ ЕЁ ИМПЕРАТОРСКОГО ВЕЛИЧЕСТВА ЕКАТЕРИНЫ ВТОРОЙ, ДАННЫЙ КОМИССИИ О СОЧИНЕНИИ ПРОЕКТА НОВОГО УЛОЖЕНИЯ, СПЬ., 1770, С. 56, 90; Ш.Л. МОНТЕСКЬЕ, О ДУХЕ ЗАКОНОВ, М., 1999, С. 75-77; АННЕРС, ИСТОРИЯ ЕВРОПЕЙСКОГО ПРАВА, С. 231-232.

36. ЗДЕСЬ ДЛЯ НАС ВАЖНО ЗАМЕЧАНИЕ Г.О. БАБКОВОЙ О ТОМ, ЧТО «ЕКАТЕРИНА II ОТЛИЧАЛАСЬ ОТ МОНТЕСКЬЕ ТЕМ, ЧТО НЕ СЧИТАЛА ОТКАЗ МОНАРХА ОТ ОТПРАВЛЕНИЯ СУДЕБНОЙ ВЛАСТИ В КАЧЕСТВЕ КРАЕУГОЛЬНОГО КАМНЯ» СВОБОД И БЕЗОПАСНОСТИ ГРАЖДАН (Г.О. БАБКОВА, ПОЛИТИКА ЕКАТЕРИНЫ ІІ В ОБЛАСТИ УГОЛОВНОГО ПРАВА, ДИСС. ... К.И.Н., М., 2006, С. 108).

37. МОНТЕСКЬЕ, О ДУХЕ ЗАКОНОВ, С. 105.

38. ЦИТ. ПО: ИНСТИТУТ ГЕНЕРАЛ-ГУБЕРНАТОРСТВА... Т. 2, С. 114.

39. МАТЕРИАЛЫ, СОБРАННЫЕ ДЛЯ ВЫСОЧАЙШЕ УЧРЕЖДЕННОЙ КОМИССИИ О ПРЕОБРАЗОВАНИИ ГУБЕРНСКИХ И УЕЗДНЫХ УЧРЕЖДЕНИЙ. ОТДЕЛ АДМИНИСТРАТИВНЫЙ, Ч. 1, МАТЕРИАЛЫ ИСТОРИЧЕСКИЕ И ЗАКОНОДАТЕЛЬНЫЕ, ОТД-Е 1, ПАР. 2, СПБ., 1870, C 113-114.

40. ИНСТИТУТ ГЕНЕРАЛ-ГУБЕРНАТОРСТВА... Т. 1, С. 43; МИГУНОВА, АДМИНИСТРАТИВНОСУДЕБНАЯ И ПРАВОВАЯ РЕФОРМЫ, С. 51; ВОРОПАНОВ, РЕГИОНАЛЬНЫЙ ФАКТОР, С. 245, 259, 343 , 512.

41. М. ФУКО, НАДЗИРАТЬ И НАКАЗЫВАТЬ: РОЖДЕНИЕ ТЮРЬМЫ, М., 1999, С. 53-54.

42. УОРТМАН, ВЛАСТИТЕЛИ И СУДИИ, С. 55-61, 66.

43. Н.В. ПЕЧЕРСКАЯ, «МЕТАМОРФОЗЫ СПРАВЕДЛИВОСТИ: ИСТОРИКО-ЭТИМОЛОГИЧЕСКИЙ АНАЛИЗ ПОНЯТИЯ СПРАВЕДЛИВОСТИ В РУССКОЙ КУЛЬТУРЕ», ПОЛИС, 2001, № 2, С. 132; N. Pecherskaya, «Spravedlivost' [justice]: the origins and transformation of the concept in Russian culture», Jahrbücher für Geschichte Osteuropas, 53 (4), 2005, p. 546; ПЕЧЕРСКАЯ, «СПРАВЕДЛИВОСТЬ: МЕЖДУ ПРАВДОЙ И ИСТИНОЙ (ИСТОРИЯ ФОРМИРОВАНИЯ КОНЦЕПТА В РУССКОЙ КУЛЬТУРЕ)», В «ПРАВДА». ДИСКУРСЫ СПРАВЕДЛИВОСТИ В РУССКОЙ ИНТЕЛЛЕКТУАЛЬНОЙ ИСТОРИИ», ВЫП. 24, М., 2010, С. 12.

44. Pecherskaya, «Spravedlivost'...», p. 550; ПЕЧЕРСКАЯ, «СПРАВЕДЛИВОСТЬ...», С. 24.

45. КРИМИНАЛЬНЫЕ ЗАКОНЫ, В КОТОРЫЕ ТОГДА ВХОДИЛИ И ПРОЦЕССУАЛЬНЫЕ НОРМЫ, БЫЛИ ОТНЕСЕНЫ ИМПЕРАТРИЦЕЙ К РАЗРЯДУ «ОСНОВНЫХ», Т.Е. ТАКИХ, КОТОРЫЕ УСТАНАВЛИВАЛИСЬ ТОЛЬКО ИМПЕРАТОРОМ И КОТОРЫМ ДОЛЖНЫ БЫЛИ ПОДЧИНЯТЬСЯ ВСЕ «ГРАЖДАНЕ», НЕ ИСКЛЮЧАЯ И САМОГО МОНАРХА.

46. ТАКАЯ ХАРАКТЕРИСТИКА ДАЁТСЯ БОЛЬШИНСТВОМ ИССЛЕДОВАТЕЛЕЙ, СМ., НАПР.: ФЕЛЬДШТЕЙН, ГЛАВНЫЕ ТЕЧЕНИЯ, С. 105-118; ОМЕЛЬЧЕНКО, ВЛАСТЬ И ЗАКОН, С. 189-193: АМПЛЕЕВА, ИСТОРИЯ СУДОУСТРОЙСТВА, КН. 2, С. 118-120.

47. СМОТРИ ОБ ЭТОМ ПОДРОБНЕЕ: БАБКОВА, ПОЛИТИКА ЕКАТЕРИНЫ II, С. 140-255.

48. ПЕЧЕРСКАЯ, «МЕТАМОРФОЗЫ...», С. 133-134; Pecherskaya, «Spravedlivost'...», p. 546, 549; ПЕЧЕРСКАЯ, «СПРАВЕДЛИВОСТЬ...», С. 15,22.

49. ТОМСИНОВ, ИСТОРИЯ РУССКОЙ ПОЛИТИЧЕСКОЙ, С. 216.

50. Pecherskaya, «Spravedlivost'...», p. 548; ПЕЧЕРСКАЯ, «СПРАВЕДЛИВОСТЬ...», С. 16-17. 
51. ПЕЧЕРСКАЯ, «МЕТАМОРФОЗЫ...», С. 140; Pecherskaya, «Spravedlivost'...», p. 558, 560; ПЕЧЕРСКАЯ, «СПРАВЕДЛИВОСТЬ...», С. 37.

52. В.М. БОКОВА, «ТЕМА ЗАКОННОСТИ В РУССКОЙ ПЕЧАТИ НАЧАЛА ХІХ В.», ВЕСТНИК МОСКОВСКОГО УНИВЕРСИТЕТА, СЕРИЯ 8, ИСТОРИЯ, 1989, № 6, С. 39; Е.Г. ЛУКЬЯНОВА, «ТРАКТОВКА ЗАКОНА В РОССИЙСКОЙ ЮРИСПРУДЕНЦИИ НАЧАЛА ХІХ - НАЧАЛА ХХІ ВВ. (СРАВНИТЕЛЬНЫЙ АНАЛИЗ)», ГОСУДАРСТВО И ПРАВО, 2010, № 10, С. 76-82.

53. ИМЕЮТСЯ В ВИДУ: РОССИЙСКИЙ ГОСУДАРСТВЕННЫЙ ИСТОРИЧЕСКИЙ АРХИВ (ДАЛЕЕ РГИА), ГОСУДАРСТВЕННЫЙ АРХИВ АРХАНГЕЛЬСКОЙ ОБЛАСТИ (ДАЛЕЕ ГА АО) И НАЦИОНАЛЬНЫЙ АРХИВ РЕСПУБЛИКИ КАРЕЛИЯ (ДАЛЕЕ НА РК).

54. ГУБЕРНСКИЙ ПРОКУРОР, ЕСЛИ НАХОДИЛ УГОЛОВНЫЙ ПРИГОВОР «ПРОТИВНЫМ ЗАКОНАМ» ИЛИ «СОМНИТЕЛЬНЫМ», ОБЯЗАН БЫЛ СНАЧАЛА ПРЕДСТАВИТЬ СВОИ ЗАМЕЧАНИЯ УГОЛОВНОЙ ПАЛАТЕ, И ЕСЛИ ОНА НЕ СОГЛАШАЛАСЬ С ЕГО МНЕНИЕМ, ТО ДОНОСИТЬ СВОЕМУ НАЧАЛЬСТВУ И ГЕНЕРАЛ-ГУБЕРНАТОРУ. НО В ОТЛИЧИЕ ОТ ЭТИХ ПЕРСОН, ОН НЕ МОГ ОСТАНОВИТЬ ИСПОЛНЕНИЕ ПРИГОВОРА, ПСЗ-1, Т. 22, № 15979 (СТ. 4); № 16456; т. 27, № 20533; т. 30, № 23729; т. 33, № 26653; ПС3-2, т. 3, № 2426.

55. К СОЖАЛЕНИЮ, НАМ НЕ УДАЛОСЬ ПРОСЛЕДИТЬ, ЧЕМ ЗАКОНЧИЛОСЬ ЭТО ДЕЛО, ТАК КАК МЫ НЕ НАШЛИ ЕГО НИ В ОПИСЯХ ОЛОНЕЦКОЙ УГОЛОВНОЙ ПАЛАТЫ, НИ ФОНДА СЕНАТА В РГИА.

56. ГА АО, Ф. 1367, ОП. 1, Д. 84, № 1053, 1323, 1563; Д. 133, № 27.

57. В ОСНОВНОМ ЭТО БЫЛИ ОБРАЩЕНИЯ К ГУБЕРНСКОМУ ПРАВЛЕНИЮ ПО ПОВОДУ МЕДЛЕННО РЕШАЕМЫХ ДЕЛ ПРИСУТСТВЕННЫМИ МЕСТАМИ, В Т. Ч. И СУДЕБНЫХ, ГА АО, Ф. 1367, ОП. 1, Д. 76, 90, 215, 462, 656.

58. СМОТРИ СПЕЦИФИКУ ПРОИЗВОДСТВА ПО ТАКОМУ РОДУ ДЕЛ В МНЕНИИ ГОСУДАРСТВЕННОГО СОВЕТА ОТ 28 ДЕКАБРЯ 1823 Г. (СНОСКА 21).

59. ГА АО, Ф.1367, ОП. 1, Д. 36, № 251, 252, 290, 291; Д. 191, № 1, 2, 3, 676-678; Ф. 68 (АРХАНГЕЛЬСКАЯ ПАЛАТА УГОЛОВНОГО И ГРАЖДАНСКОГО СУДА), ОП. 14, Д. 44, Л. 31; НА РК, Ф. 655, ОП. 1, Д. 23, Л. 101.

60. СМ., НАПР.: ГА АО, Ф. 1367, ОП. 1, Д. 16, 17, 55 (ВЕДОМОСТИ ЗА 1820 Г.); Д. 153, 164 (ЗА 1823 г.); д. 220, 245 (ЗА 1824); Д. 302 (ЗА 1825 г.); Д. 406 (ЗА 1826 г.); д. 469 (ЗА 1827); Д. 584, 605 (ЗА 1828 г.); Д. 679, 680 (ЗА 1829 г.).

61. СМ., НАПР.: ГА АО, Ф. 1367, ОП. 1 , Д. 84 (ЖУРНАЛ ИСХОДЯЩИХ БУМАГ ЗА 1821 Г.) № 1439, 1782, 1869, 1870, 1898, 2299; Д. 191 (ЖУРНАЛ ЗА 1823 г.) № 184, 492, 716, 967, 1143; Д. 329 (ЖУРНАЛ ИсХОДящИХ БУМАГ ЗА 1825 г.) № 377, 433, 572, 724; д. 371; Ф. 68, ОП. 14, Д. 44, УКАЗНАЯ КНИГА АРХАНГЕЛЬСКОЙ УГОЛОВНОЙ ПАЛАТЫ ЗА 1821 Г., Л. 41-42, 99-100,102,132.

62. ГА АО, Ф. 1367, ОП. 1, Д. 262, № 759, 784.

63. ГА АО, Ф. 68 , ОП. 14 , Д. 84 , Л. 18.

64. ГА АО, Ф. 1, КАНЦЕЛЯРИЯ АРХАНГЕЛЬСКОГО ГУБЕРНАТОРА, ОП. 9, Д. 257, Л. 5-10, 37-45.

65. В КАНЦЕЛЯРИИ ГЕНЕРАЛ-ГУБЕРНАТОРОВ СОХРАНИЛИСЬ СПЕЦИАЛЬНЫЕ ПОДШИВКИ ВСЕХ ПОСТУПИВШИХ К НИМ ЗА ГОД ЖАЛОБ И ПРОШЕНИЙ - СМ., НАПР.: ГА АО, Ф. 1367, ОП. 1 , Д. 33, 78, 216, 279, 280, 315, 352, 378, 463, 464.

66. ГА АО, Ф. 1367, ОП. 1, Д. 329А, № 389; Д. 329Г, № 2276, 2451; Д. 329Д, № 2580. 
67. ОДНАКО С.И. МИНИЦКИЙ ПО НЕЗАВИСЯЩИМ ОТ НЕГО ПРИЧИНАМ ТАК И НЕ СМОГ ПЕРЕНЕСТИ ЭТО ДЕЛО В СЕНАТ (ГА АО, Ф. 1367, ОП. 1, Д. 84, № 2122, 2123; Д. 329, № 185; ОП. 2, Д. 1825; НА РК, Ф. 655 (ОЛОНЕЦКАЯ ПАЛАТА УГОЛОВНОГО СУДА), ОП. 1, Д. 877).

68. ГА АО, Ф. 1367, ОП. 1, Д. 84. № 1323.

69. ГА АО, Ф.1367, ОП. 1, Д. 133. № 27; Д. 652, Л. 1; РГИА, Ф. 1345, 5-Й ДЕПАРТАМЕНТ СЕНАТА (УГОЛОВНЫЙ), оП. 103. Д. 166, Л. 21-23.

70. ПСз-1, Т. 28, № 21605; т. 39, № 29725.

71. ГА АО, Ф. 1367, ОП. 1, Д. 370, Л. 25-31; Ф. 1, ОП. 9, Д. 257, Л. 50.

72. РГИА, Ф. 1345 , ОП. 103, Д. 310.

73. РГИА, Ф. 1345, ОП. 102, Д. 308.

74. РГИА, Ф. 1345, ОП. 103, Д. 308.

75. РГИА, Ф. 1345 , ОП. 100 , Д. 100.

76. ОН ПРИГОВОРИЛ СЕНЧУКОВА ЛИШЬ К СНЯТИЮ ЗНАКОВ ОТЛИЧИЯ И 40 УДАРАМ ПЛЕТЬМИ С ОСТАВЛЕНИЕМ НА ПРЕЖНЕМ МЕСТЕ ЖИТЕЛЬСТВА.

77. ПОД «ПРОЦЕССОМ» ИМЕЛОСЬ В ВИДУ «КРАТКОЕ ИЗОБРАЖЕНИЕ ПРОЦЕСОВ ИЛИ СУДЕБНЫХ ТЯЖЕБ». ГЕНЕРАЛ-ГУБЕРНАТОР ССЫЛАЛСЯ НА П. 9 И 10 ГЛ.5, КОТОРЫЕ ГЛАСИЛИ, ЧТО ЕСЛИ В ДЕЛЕ НЕТ «ЯВНЫХ ДОКАЗАТЕЛЬСТВ», ТО СУДЬЯ «В СМЕРТНЫХ ДЕЛАХ» ДОЛЖЕН ОПАСАТЬСЯ ПРИГОВАРИВАТЬ К ТЯЖКОМУ НАКАЗАНИЮ, «ПОНЕЖЕ ЛУЧШЕ ЕСТЬ 10 ВИНОВНЫХ ОСВОБОДИТЬ, НЕЖЕЛИ ОДНОГО НЕВИННОГО К СМЕРТИ ПРИГОВОРИТЬ» И ЛУЧШЕ «ОНОЕ ДЕЛО ПРЕДАТЬ ВОЛИ БОЖИЕЙ..., ПОКА ВПРЕДЬ САМО ОБъЯВИТСЯ».

78. ГА АО, Ф. 1367, ОП. 1, Д. 366.

\section{RÉSUMÉS}

In the 1775 Statute of Provincial Administration, Catherine II vested governors general with the right to confirm criminal sentences. It is commonly held that this right further aggravated the deficiencies of the investigation procedures used at the time. The author's purpose is to refute this opinion. To do this, she analyzes the ideas put forward by Catherine to justify that right in the Russian penal procedure, then traces its evolution in the legislation between the end of the eighteenth and the first third of the nineteenth centuries, and shows how A.F. Klokachev and S.I. Minitskii, governors general of Arkhangel'sk, Vologda and olonets made use of this right.

The author reaches the following conclusions: (1) at a time when criminal law and proceedings were marked by cruel punishments and the theory of formal evidence prevailed, it was necessary to maintain the governors general's right to confirm heavy sentences. As immediate subordinates to the tsars, governors general had a duty to promote the ideas of the Enlightenment embraced by Catherine II and her grandson Alexander I locally; (2) governors general of northern provinces very seldom exercised the right granted to them. The author infers from the cases studied in the article that lawmakers could still abide, vis-à-vis persons of "low standing," by the prescription established in Article 82 of the Statute of Provincial 
Administration: "The governor general is not a judge, but [...] the advocate of the oppressed," and must "show goodwill, love and compassion towards the people through his actions."

Dans ses règlements de 1775 pour le gouvernement des provinces, Catherine II avait attribué aux gouverneurs généraux le droit de confirmer les sentences prononcées dans les affaires criminelles. Il est traditionnellement admis que ce droit aurait encore aggravé les défauts de la procédure d'enquête pénale, de type inquisitoire, alors en vigueur dans l'Empire russe. L'auteur remet en question cette opinion. Dans ce but, elle analyse d'abord les idées mises en avant par Catherine II pour justifier le droit en question dans la procédure pénale russe. Puis l'auteur suit l'évolution de ce droit dans la législation de la fin $\mathrm{du}_{\mathrm{XVIII}}^{\mathrm{e}}$ siècle et du premier tiers du XIX siècle. Enfin, elle montre comment ce droit fut mis effectivement en application par les gouverneurs généraux de l'ensemble septentrional formé par les trois provinces d'Arhangel'sk, Vologda et Olonec, A.F. Klokačev et S.I. Minickij. L'auteur en tire deux conclusions. En premier lieu, à une époque où la procédure pénale et le droit pénal de l'Empire russe étaient marqués par des châtiments cruels et où dominait la théorie des preuves formelles, il était nécessaire de réserver aux gouverneurs généraux le droit de confirmer les peines criminelles lourdes. Il était du devoir des gouverneurs généraux, qui étaient les plus proches compagnons des empereurs, de répandre sur le terrain les idées des Lumières européennes, auxquelles adhéraient Catherine II et son petit-fils Alexandre $\mathrm{I}^{\mathrm{er}}$. En second lieu, l'auteur conclut que, dans la pratique, les gouverneurs généraux des provinces septentrionales faisaient un usage extrêmement rare du droit qui leur était accordé. Sur la base des cas examinés dans l'article, il lui apparaît qu'à l'égard des personnes de condition inférieure fut effectivement mise en application l'intention initialement exprimée dans l'article 82 des règlements de 1775 qui stipulait que « le représentant du souverain n'est pas un juge, mais... l'intercesseur des opprimés", qui doit «faire preuve dans ses actes de bienveillance, d'amour et de compassion pour le peuple ».

\section{AUTEUR}

\section{ВИКТОРИЯ ЕФИМОВА}

ПЕТРОЗАВОДСКОГО ГОСУДАРСТВЕННОГО УНИВЕРСИТЕТА (ПЕТРГУ) 